Portland State University

PDXScholar

$1-1-1984$

\title{
The contribution of social support to the successful functioning of men with epilepsy
}

Diane L. Pancoast

Portland State University

Follow this and additional works at: https://pdxscholar.library.pdx.edu/open_access_etds Let us know how access to this document benefits you.

Recommended Citation

Pancoast, Diane L., "The contribution of social support to the successful functioning of men with epilepsy" (1984). Dissertations and Theses. Paper 374.

https://doi.org/10.15760/etd.374

This Dissertation is brought to you for free and open access. It has been accepted for inclusion in Dissertations and Theses by an authorized administrator of PDXScholar. Please contact us if we can make this document more accessible: pdxscholar@pdx.edu. 
THE CONTRIBUTION OF SOCIAL SUPPORT

TO THE SUCCESSFUL FUNCTIONING

OF MEN WITH EPIIEPSY

by

DIANE L. PANCOAST

A dissertation submitted in partial fulfillment

of the requirements for the degree of

\author{
DOCTOR OF PHILOSOPHY \\ in
}

URBAN STUDIES

Portland State University

1984 


\section{TO THE OFFICE OF GRADUATE STUDIES AND RESEARCH:}

The members of the Committee approve the dissertation of

Diane L. Pancoast presented May 10, 1984.

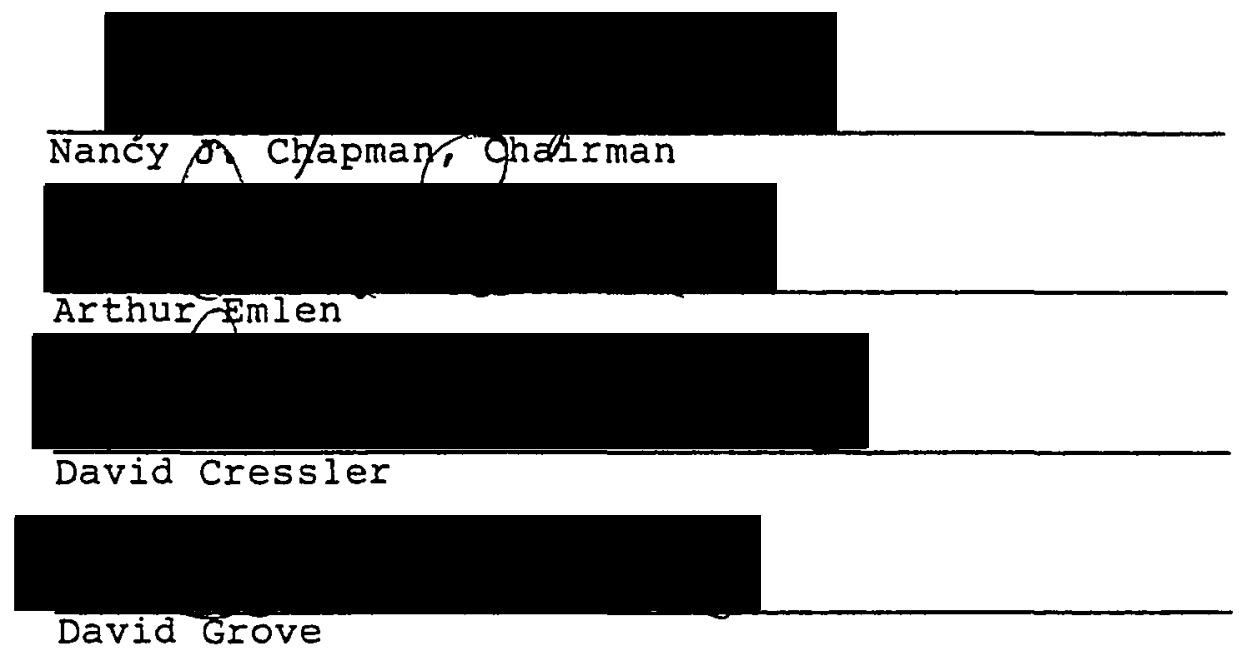

APPROVED :

Kenneth J. Dueker, Acting Dean, School of Urban and Public Affairs

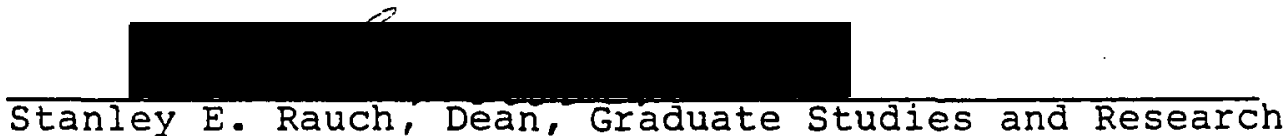


AN ABSTRACT OF THE DISSERTATION OF Diane I. Pancoast for the Doctor of Philosophy in Urban Studies presented May 10, 1984 .

Title: The Contribution of Social support to the successful Functioning of Men with Epilepsy.

APPROVED BY MEMBERS OF THE DISSERTATION COMMITTEE:

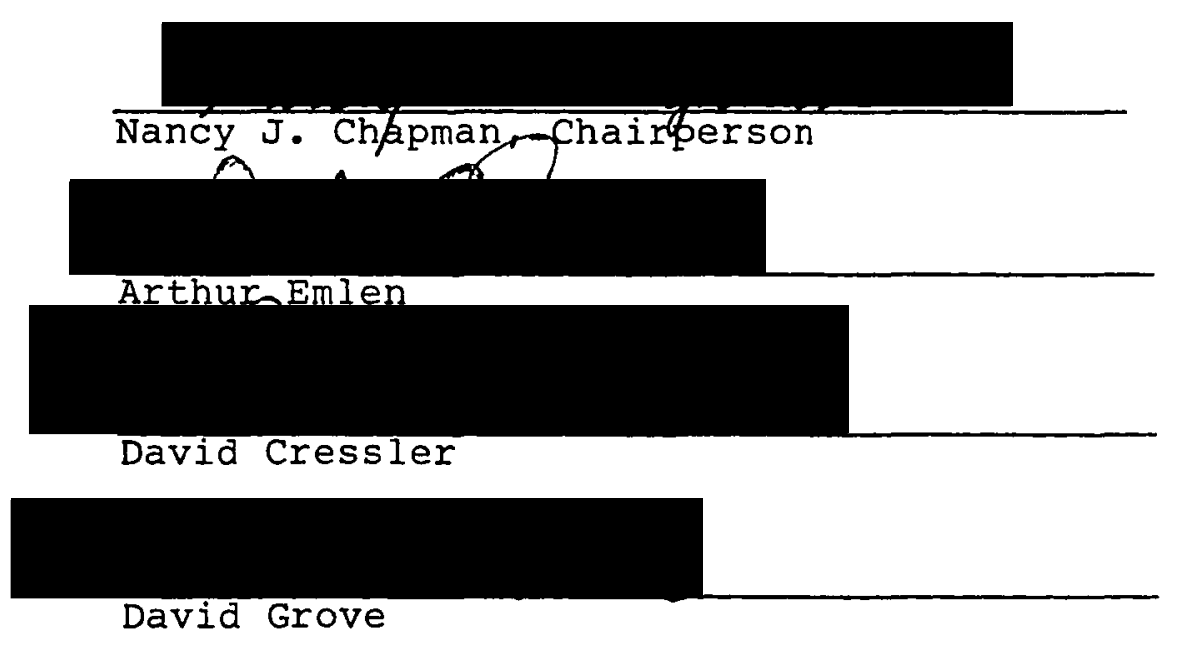

People with epilepsy who would formerly have been institutionalized can now live relatively normal lives if their seizures can be controlled with medication. Nevertheless, many find it difficult to cope with this 
chronic disability, as evidenced by higher rates of unemployment and general dissatisfaction with their lives. Research on the coping process has found that support From significant others can be a mediating influence, helping an individual cope with the continuing impact of the disability and promoting positive outcomes.

One hundred men with epilepsy were interviewed for the current study. They were asked about the history of their illness, attitudes toward it, their employment history and their personal support network.

This study examined the role of social support in the coping process in greater detail than has been done in most other studies of social support. Included as sources of support were: household members, close friends and relatives, more distant relationships and general forms of social participation such as church membership. Four potentially supportive aspects of these relationships were assessed: structural features of the pattern of relationships; characteristics of the individual ties; exchanges of helping resources and subjective assessments of the supportiveness of ties.

The social support networks of the men who were 
satisfied with their lives were similar to those of other successfully functioning groups. Their networks were large, diverse, active and generally helpful. Church membership was also a strong predictor of satisfaction. Indicators of social support were not as predictive of employment success although close knit ties between friends and kin and general social participation were associated with successful employment. Efforts of professional service providers, friends and family members to provide help specifically directed toward helping the person deal with epilepsy were negatively associated with successful employment outcomes when the individual perceived himself as unable to control his symptoms and limited by his condition.

The implications of these findings for research are that a fine-grained approach to the study of the effects of support, in terms of sources, types and effects yields a richer, and in some cases, less optimistic picture of the role of informal support in helping a person cope with a chronic disability. Personality factors must also be taken into consideration since they are often more important than the level of disability in predicting outcomes.

The implications for policy are that support from 
family and friends is limited, strains these relationships and may reinforce patterns of dependence on the part of the recipient that are counterproductive to successful employment and independent living. Help from professionals may produce many of the same results. Programs that are attempting to help such people become successfully employed might do better to focus on changing the self-perceptions of clients in the direction of greater autonomy and focus their social activities towards a more "normal" pattern of general sociability and equal exchange rather than dependence on a few, close ties. 
TABLE OF CONTENTS

PAGE

IIST OF TABLES . . . . . . . . . . . . . . . . viii

LIST OF FIGURES • • • • • • • • • • • • • • • • • $\mathrm{x}$

CHAPTER

I INTRODUCTION •. . . . . . . . . . . . 1

Statement of the Research Problem . . . 1

The Nature of Epilepsy and the Require-

ments for Support... . . . . . . . 3

A Model of Stress, Support and out-

comes ................. 4

Elements of the Model

Hypotheses

Major Hypothesis

Hypothesized Relationships

Significance of the Research Problem . . 13

II SOCIAL SUPPORT, SOCIAL NETWORKS AND HEAITH • 17

Social Support . . . . . . . . . 18

The Effects of Urbanization on

Social Life and Individual

Functioning

The Relationship Between Social

Support and Health

The Political Context

Identifying the Supportive Aspects

of Interpersonal Relationships

Social Networks and Social Support . . 30 
PAGE

Major Network Variables . . . . . . 34

Structural Variables

Characteristics of the Iinkages

The Content of Exchanges

Perceptions of Support

Supportive Networks and Long-term

Stress ................ . 51

Conclusions . . . . . . . . . 53

III COPING WITH EPILEPSY, A CHRONIC DISEASE • . 58

Epilepsy . . . . . . . . . . . 60

What is Epilepsy?

Living with Epilepsy

Public Attitudes

Self-care

Psychological Aspects

The Contribution of Interpersonal Support

to Coping with Epilepsy . . . . . . . 75

IV METHODOLOGY • • . . . . . . . . . . 77

Sampling Procedures . . . . . . . 78

Sample Selection

Characteristics of the study Group

Representativeness of the sample

Data Collection Procedures . . . . . 83

Types of Data Collected . . . . . . 85

Epilepsy and Employment

Self Concept

Life Satisfaction

Social Participation

Social Network

Construction of Variables . . . . . . 88

Aggregating the Network Data

Scale Construction 
Data Analysis . . . . . . . . . . 95

Descriptive Analysis

Hypothesis Testing Qualitative Analysis

Presentation of Findings

$\mathrm{V}$ INDIVIDUAI CHARACTERISTICS AND COPING • • • . 98

Individual Characteristics of the

Sample . . . . . . . . . . . . 98

Demographics

Attitudes and Self Concept

Representativeness

The Impact of Epilepsy on Functioning . . 106

Other Predictors of Successful

Functioning . . . . . . . . . . 109

Education

Personality

Age

Summary • • . • . • . . . . . . 110

VI SOCIAL NETWORKS . . . . . . . . . . . . 112

Describing the Networks . . . . . . . 114

Zones

Relationships Among Contextual

Characteristics

Content of Relationships . . . . . 123

Epilepsy Related

General Support

Relationships Among Content

Variables

Relationships Between Structural

and Linkage Variables and

Content Variables 
PAGE

Personal Characteristics and Network

Variables . . . . . . . . . . 130

\section{Age}

Socioeconomic Status

Personality

Epilepsy

Networks and Outcomes . . . . . . . 135

Conclusion . . . . . . . . . . . 137

VII FAMILIES AND SOCIAL PARTICIPATION • • • • . 139

The Families of Men with Epilepsy . . . 139

Household Types

Patterns of Family support

Social Participation . . . . . . . 144

VIII TESTING THE MODEI . . . . . . . . . . 150

Are the Elements of the Model Related to

Each Other? . . . . . . . . . . 151

Are the Support Variables Related to the Other Elements of the Model? . . . . 155

Relationships Among the Support

Variables

Support and Personal Resources

Support and Severity

Support and Perceived Limitations

Support and outcomes

Results of the Multiple Regression

Analysis ............. . 161

Predicting Employment

Predicting Life Satisfaction

Interaction Effects . . . . . . . . 172

Interaction Effects of Severity and

Support on Perceived Limitations 
vii

PAGE

Interaction Effects of Severity and

Support on Employment and Life

Satisfaction

Conclusion . . . . . . . . . . 176

IX IMPLICATIONS FOR RESEARCH AND POLICY . • • 178

Implications for Research . . . . . 179

The General Model of Coping

Social Support and Personal

Characteristics

Social support and Outcomes

Implications for Policy . . . . . . 195

The Roles of the Formal and

Informal sectors

Intervention Strategies

Conclusion .......... 203

REFERENCES . . . . . . . . . . . . . . . . 204

APPENDIX

A Data Collection Instruments . . . . . . . 214

B Scale Construction . . . . . . . . . . 239

C Additional Tables . . . . . . . . . . . 246 


\section{LIST OF TABLES}

TABLE

PAGE

I Personal Characteristics and Outcomes . . . 107

II Contextual Network Variables . . . . . . 122

III Network Content Variables . . . . . . . 127

IV Network Variables . . . . . . . . . . 129

V Personal Characteristics, Network Variables and Outcomes . . . . . . . . . . 131

VI Family Support, Personal Characteristics and Outcomes . . . . . . . . . . . 143

VII Family Support and Network Characteristics . 145

VIII Social Participation, Personal Characteristics and Outcomes . . . . . . . 147

IX Social Participation and Network Characteristics . . . . . . . . . . . . 148

X Correlations of Elements of Model . . . . . 152

XI Summary of the Relationships of the Support Variables . . . . . . . . . . 156

XII Predictors of Employment and Satisfaction • • 163 XIII Support Variables as Predictors of Outcomes . 166 XIV Partial Correlations of Interaction Terms . . 174 
PAGE

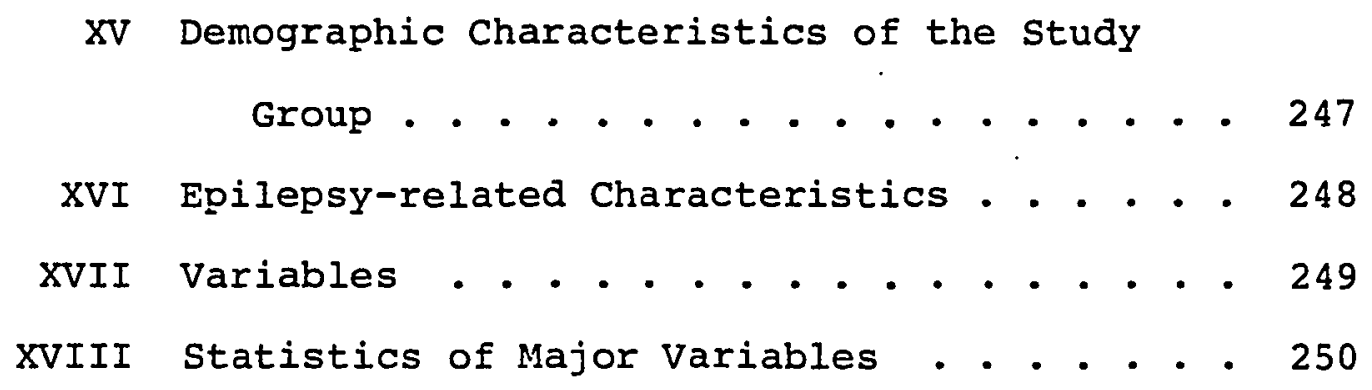




\section{LIST OF FIGURES}

$\begin{array}{ll}\text { FIGURE } & \text { PAGE }\end{array}$

1. General Model of the Coping Process . . . 5

2. Applied Model of the Coping Process . . . 10

3. Comparison of Iife Satisfaction Scores . 103

4. Frequency Distribution of Network Size . . 116

5. Revised Model of the Coping Process . . . . 153 


\section{CHAPTER I}

\section{INTRODUCTION}

STATEMENT OF THE RESEARCH PROBLEM

Complex urbanized societies demand a high level of performance even from disabled individuals. Yet a number of factors contribute to the ability of the disabled to live more independent lives and function at a higher level now than was possible in earlier, agrarian times. Technological improvements in the detection and treatment of all sorts of physical problems have gone hand in hand with other technological improvements in transportation and communication media which have made it easier for persons with physical limitations to participate more fully in society. The highly specialized organization of a modern city provides an array of services for a wide variety of physical and mental problems. Governmentally funded income programs provide basic support to those who are certified to be too disabled to work.

General public attitudes towards the disabled have improved in the past fifty years. Concepts such as "mainstreaming" indicate the willingness of society to make institutional adjustments to accommodate the special requirements of the disabled for full participation. But, 
on the whole, the general public may be somewhat overly optimistic at this point about the progress in medical treatment and rehabilitation and may underestimate the burdens still borne by the handicapped. Certain groups, such as the chronically mentally ill and ex-prisoners, are still not accepted readily in many communities and the costs of providing adequate services to enable the disabled to live independent lives are still great and provide a barrier for many disabled persons.

In fact, a disabled person needs more than professional services and general acceptance by the public in order to manage his or her life successfully. Supportive interpersonal relationships can enable the individual to maintain the treatment regimen that may be required to keep the physical or mental problem under control, deal with crises as well as continuing problems for which no professional services are available and provide general approval and encouragement. There is a growing suspicion among professionals who are concerned with disabled persons that the presence or absence of such social supports may be a crucial determinant of whether or not the individual is able to make appropriate use of professional services and function successfully. 
THE NATURE OF EPILEPSY AND THE REQUIREMENTS FOR SUPPORT

Epilepsy provides an example of a chronic condition with some associated disability. The extent to which epilepsy actually interferes with daily living varies greatly from one individual to another. Some social stigma is still associated with epilepsy although there has been dramatic improvement in public attitudes, largely because many people now believe that seizures can be completely controlled with medication.

Persons whose epileptic symptoms are fairly well controlled by anti-convulsive medications and do not have other related problems such as mental retardation, are generally able to function fairly well. Their handicap is invisible. However the condition still has an effect on their relationships with others. For example, they may need to follow regular routines, take their medications faithfully, get plenty of rest and eat regularly. They may also have to avoid situations where a seizure would be a risk to themselves or others such as driving a car or engaging in a risky sport or occupation. If they continue to have seizures, they may have to explain to those around them - family, friends, neighbors, coworkers - what to do when a seizure happens. Therefore although most people with epilepsy are not handicapped to the extent that 
persons who are living in the community with quadraplegia or schizophrenia are, living with their disability as normally as possible may require them to develop a supportive personal network if they are to function optimally.

\section{A MODEL OF STRESS, SUPPORT AND OUTCOMES}

Although the usefulness of support may seem obvious, assessing its relative importance in a process which is complex and involves many interactive factors is not easy. Modeling such a process is a useful device for identifying important elements and and describing the relationships among them. Although this study will chiefly be interested in the contribution of support to a person's ability to function successfully in spite of a disability, a general model of the coping process helps to indicate which other factors are likely to affect support as well as where support is likely to have an impact.

A number of researchers have developed models of the support process (House, 1981; Gore, 1981). This research will test a model developed by Gottlieb (1983). In this model (see Figure 1), external stressors create internal stress responses within the individual. The individual must cope with this stress or succumb to it, thereby affecting such sequellae as longevity, psychological 


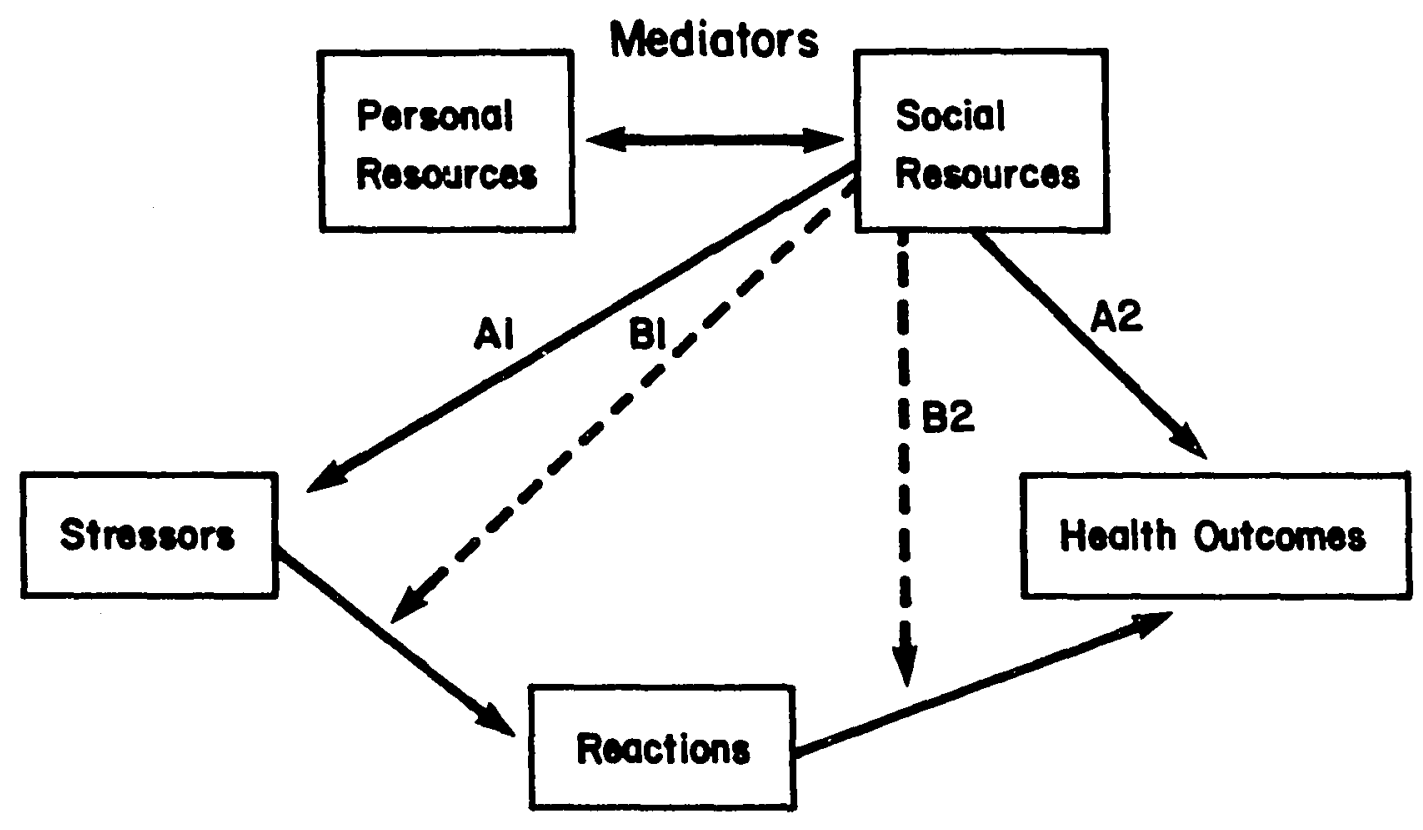

\section{General Model}

Figure 1. General Model of the Coping Process 
health and general well-being. A number of factors, including social support, can reduce the threat posed by the stressor, increase the coping abilities of the individual and/or affect the outcome directly. The effects of these factors may be felt regardless of the level of stressor (A1 or A2) or may only come into play at certain levels of stressor or response (B1 and B2).

\section{Elements of the model}

- Stressors. Gottlieb lists three types of stressor: acute life events, chronic hardships and daily "hassles." In this application, a chronic condition, epilepsy, will constitute the stressor.

- Reactions. Gottlieb (1983) defines reactions as "Subjective experiences of strain or distress" (p.37). It seems reasonable that the individual's evaluation of the seriousness of the threat posed by the stressor will affect the amount of energy he mobilizes to cope with it. It would be useful to have a direct measure of the actual coping response but none is available for this sample. The early work of selye (1976) and others measured physiological responses such as changes in level of adrenalin. This sort of measure is inappropriate in a study of a chronic stressor since one would not 
expect to detect such changes in body chemistry when the stressor is a continuing one. Lazarus and his colleagues (1981) have identified appraisal processes and coping strategies of a cognitive nature but instruments to measure them were not available at the time this study was conducted. Instead there are measures of various attitudes the person has about the impact of epilepsy on his or her life.

- Personal Resources. Factors other than the impact of epilepsy and the effectiveness of a personal support network will affect the way an individual copes with stress. For this model, elements are included which have been demonstrated in many studies to influence life outcomes: gender, age, education and self concept.

- Social resources. Measures of support in the literature on social support vary widely. No single measure or scale has yet been developed which adequately measures the construct. Gottlieb (1983, p.61) states that "...social support is properly conceived of as a multidimensional construct and should be measured accordingly." He suggests that the major dimensions of support are: the structural properties of the social system in which the individual is embedded, the characteristics of the 
individual's links to others, helping resources actually extended in an interaction, and the individual's subjective perception of being sustained by a personal community. The first two aspects of relationships can be termed contextual while the second two deal with the content of relationships. In order to measure these dimensions in as much detail as possible, network analysis was used in which specific data about each of these four dimensions were gathered about members of the network. Support received from members of the household was analyzed separately.

- Outcomes. Freud said that the two criteria for successful performance of adult roles were "leiben und arbeiten," being able to love and to work. The outcome measures used in this model are life satisfaction and employment. While life satisfaction does not exactly capture what freud meant by the ability to love, it allows for the inclusion of a more qualitative, subjective measure of success.

\section{Hypotheses}

Stressors are generally considered to elicit coping responses. The coping responses of the individual may be inadequate or the individual may be able to muster internal or external resources sufficient to deal 
successfully with the stressors and avoid negative outcomes. Social support can mediate the impact of stressors by directly affecting the stressor, the reaction to the stressor or the outcomes. Referring to Figure 2, an application of the general model to the specific stressor of epilepsy, support would not be expected to affect the type of epilepsy but it might reduce the frequency of seizures by reducing stress, which can bring on seizures. On the other hand, support could be positively related to severity if greater severity called forth more support from members of the network (B1 in the model). Support could have an effect on the reaction to the stressor by reducing the level of perceived threat (B2 in the model). Here again, the effect of support could be in the opposite direction if perceiving oneself as more limited by epilepsy was a motivation for seeking more support from others. Support could also directly affect the outcome measures by helping the person with epilepsy find and maintain stable employment or by giving him a greater sense of satisfaction with life, (B3 in the model). In reality these various effects of support could all obtain within a single relationship between a person with epilepsy and a member of his or her network, at a single point in time or over the course of the relationship. The effects of one 


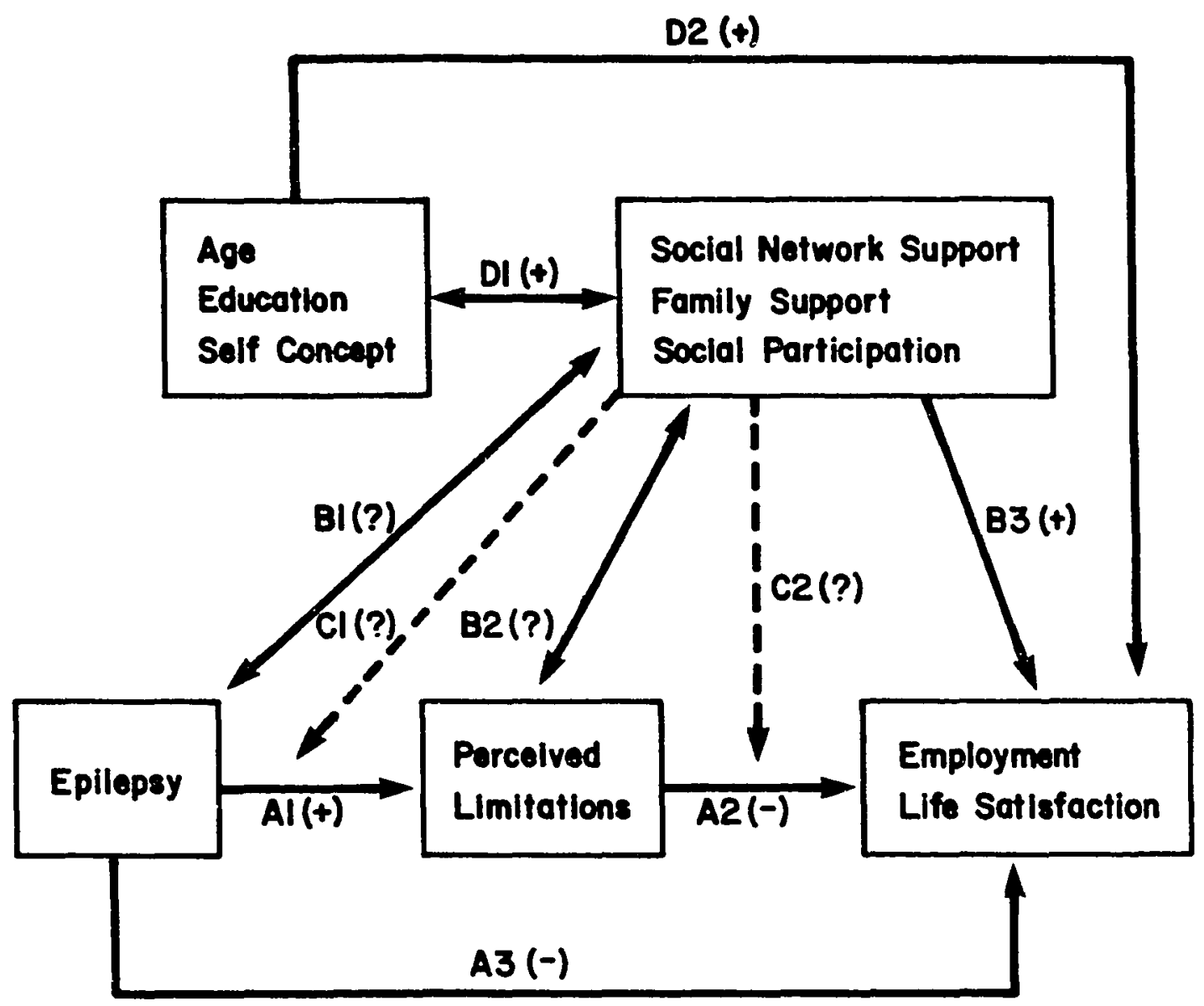

\section{Applied Model}

Figure 2. Applied Model of the Coping Process 
relationship could be in one direction while the effects of another were in the opposite direction. It is also possible that support comes into play only at certain levels of stressor or stress, whether low, moderate or high (C1 and $C_{2}$ in the model). These effects are termed interaction effects. A cross-sectional study of this type which uses aggregate data about the relationships the subjects have with significant others can not hope to disentangle these complex causal chains. Instead, it must focus on trends and look for common characteristics in the study group.

The other personal resources and characteristics that might affect outcomes must be controlled for so that the negative effects of epilepsy can be seen and the potential mediating impact of effective social support can be examined. Therefore, in this application of Gottlieb's model the relationships between personal resources and support and resources and outcomes will also be examined. In some cases, relationships in the model will be explored rather than predicted, either because the current state of theory does not suggest a plausible hypothesis or because there are competing hypotheses about the relationship. The model leads us to the following hypotheses which are illustrated in Figure 2. 


\section{Major Hypothesis}

- Support will be positively correlated with successful employment and life satisfaction when personal resources, the severity of symptoms and the reaction to the stressor are controlled for.

\section{Hypothesized Relationships}

- A1: Severity will be positively correlated with reaction to the stressor (perceived limitations).

- A2: The reaction to the stressor will be negatively correlated with outcomes.

- A3: Severity will be negatively correlated with outcomes.

- B1: The relationship between seizure severity and support will be explored.

- B2: The relationship between reaction to stressor and support will be explored.

- B3: Support will be positively correlated with employment and life satisfaction.

- C1: The interaction effect of the level of stressor and the amount of support on the reaction to the stressor will be explored.

- C2: The interaction effect of the level of reaction to the stressor and the amount of support on the outcomes will be explored 
- D1: Personal resources will be positively correlated with support.

- D2: Personal resources will be positively correlated with outcomes.

In Figure 2, the presence of a line indicates that a significant relationship is hypothesized to exist between the variables or sets of variables while the absence of a line indicates that no relationship is hypothesized to exist between the elements in question. The arrows indicate the direction of the hypothesized relationship derived either from theory or from temporal order. The values in parentheses indicate whether the predicted relationship is hypothesized to be positive or negative.

\section{SIGNIFICANCE OF THE RESEARCH PROBLEM}

The increasing success of medicine in helping people survive serious illnesses such as cancer and heart disease is creating a large number of disabled individuals who must find a way of adjusting to their disability. If social supports are an important determinant of successful rehabilitation, it would be useful to understand just what aspects of the individual's social environment are crucial. This will permit a more sensitive assessment of an individual's prognosis as well as suggesting some interventions which might improve the quality of support 
available to the person. Interventions at this level might be more feasible and economical than attempts to reduce the barriers which still remain for disabled persons. It may be easier, for example, to mobilize a personal network to help a person deal with occasional seizures than to achieve complete seizure control. A personal network may be more important for helping an individual find and maintain a job than professional job placement services or efforts to change employer attitudes.

On the other hand, it is equally important to understand the limitations of personal support networks. Especially in a time when government is eager to find ways to achieve cost savings in service delivery and the prevailing conservative political ethos supports the devolution of responsibility to the local and family level, the actual carrying capacity of these personal support networks must be carefully assessed. A new program in Wisconsin proposes to offer rehabilitative services only to those disabled persons who can muster a group of individuals who are willing to provide extensive support and care services on a volunteer basis (Griess, 1983, personal communication). This program seems to be based on the genuine preference of some disabled persons for a personalized support system and the success of a few 
severely handicapped persons in creating and maintaining such support systems. However it remains to be seen whether their experiences can be generalized. Without greater knowledge of the availability of such supporters and their potential as unpaid service deliverers, it may be unrealistic and even cruel to put the burden of recruiting such a network on already heavily burdened persons.

In order to develop effective policies in this area we need, first of all, to know how much of a difference supportive relationships make and under what circumstances. Early research on the effects of social support is promising but hardly adequate to suggest either policy directions or specific interventions. Few studies control for personal attributes such as education, socio-economic status or personality in order to separate the effects of support from other sorts of personal resources. "Social support" has been measured in many different ways, usually in terms of only a few measures in each study, making it impossible to compare different aspects of support to see which is most effective. For example, little is known about the different effects of support from family members, members of a personal network and other, more general forms of social participation such as church membership. 
This study will take a fine-grained look at social support, examining whether personal resources are highly correlated with social support and hence may be the "real" predictor of successful coping, and looking at various aspects of support to see which, if any of them, seem to be most effective and at what level of stressor. 
CHAPTER II

SOCIAL SUPPORT, SOCIAL NETWORKS AND HEALTH

Research on the effects of social support on individual health and well-being has grown out of two separate traditions which are only now coming together. One tradition is sociological, viewing social support as the bridge between large scale social organizations and individuals. Described variously as primary groups, mediating structures and, most recently, as social networks, sociologists have been interested in examining how these entities have adapted to large scale social change and, in turn, how these changes have affected the individuals enmeshed in them.

The other tradition starts with the individual, viewing external events as potential stressors which can have a physiological impact resulting in disease and death. Investigators are interested in how the individual copes with stress and view social support as one of the factors that can mediate the impact of stressors. This line of inquiry has been pursued mostly by psychologists, epidemiologists and medical researchers.

These two lines of inquiry have converged in the past decade with social network analysis as the unifying approach. This review will discuss these two lines of 
research and then summarize what social network analysis has been able to contribute to date.

SOCIAL SUPPORT

The Effects of Urbanization on Social Life and Individual Functioning

The development of theory and research on social support is one of the central manifestations of the interest of sociology in the impact of the changes of the last two hundred years, often summarized as industrialization and urbanization, on society and the individual. Indeed, the founders of the discipline: Simmel, Durkheim and Weber, were preoccupied with the identification of the stressors inherent in these changes and with the impact of new forms of organization -impersonal, bureaucratic, rationalistic -- on the traditional forms of social organization and sources of support: community and family. Durkheim hypothesized that modernization would weaken these traditional ties without substituting new forms of social integration and the resulting social isolation and anomie would be manifested in higher rates of suicide. He was able to show that suicide rates in modern societies are highest among the most isolated individuals (Durkheim, 1951). Other sociologists followed in this tradition, relating other 
indicators of individual pathology, such as mental illness, to urbanization (Farris \& Dunham, 1939). As industrialization rates have slowed and urbanization has stopped or even reversed in highly developed countries, it appears that the higher rates of individual pathology and evidence of greater social disorganization associated with urbanization may have been due to the stressful impact of change rather than to urban life, per se (Srole, 1972). This is not to say that modern life does not impose different stressors on individuals or that the tremendous changes in social organization chronicled by the sociologists have not altered the ways in which individuals deal with these stressors. But these changes have not turned man into the alienated, anomic, dysfunctional creature predicted by the gloomiest of the early sociologists. Nor have bureaucratic forms of social organization turned us into a society of "organization men." There is evidence that the older forms of social organization and support: family, neighborhood, ethnicity and religion are still very important (Berger \& Neuhaus, 1977). In addition, new social settings such as the workplace, recreational and leisure contexts provide different sorts of supportive contacts. The complexity, diversity and mobility of a modern urban lifestyle enable the individual to maintain greater separation among the 
different roles he or she performs and the contacts associated with them than was possible in an earlier society. This can be a source of personal satisfaction and support as much as a cause of anomie. Also, more impersonal forms of support such as the media, formal helping agencies and professionals are more available in the modern urban context.

The Relationship Between Social Support and Health

The general issue of the contribution of social support to the health and well-being of individuals directly and as a buffer of the noxious effects of life stressors has received a great deal of attention in recent years from psychologists and epidemiologists. Selye (1976) was the first to attempt to demonstrate a connection between "outer" events and the inner man by identifying a patterned set of bodily responses to stressors. He showed that these stress reactions could cause disease states. A whole body of research has developed which seeks to identify important stressors. It is based on the use of a measure of stressors that is an index of such stressful life events as the loss of a job or a loved one, a move or an illness. The first research detected significant correlations between this index and negative health outcomes (Holmes \& Rahe, 1967). Since the correlations were fairly small, other researchers began to 
look for factors which could be having a moderating effect on the stressors or increasing the ability of the individual to cope with them. In addition to various personal characteristics, social support has been found to have a moderating influence. For instance, in a large scale epidemiological study, Berkman and syme (1979) showed that persons who were well supported had lower mortality rates.

other research has proceeded by examining support as it buffers the effects of a particular stressor, such as a serious illness or the loss of employment. After conducting a large literature review, DiMatteo and Hays concluded that, "Taken as a whole, the research suggests that social support may, in fact, be associated with recovery and coping with serious physical illness and injury." (p. 121, 1981). Some studies have shown that support can diminish the level of the stressor, for example DeAraujo's finding that patients with high levels of emotional support needed lower doses of prednisone to control their asthma, a chronic illness that can be considered to be a stressor (DeAraujo, Van Arsdel, Holmes \& Dudley, 1973). Others have shown that support promotes positive reactions to the stressor (Gore, 1978) or promotes beneficial outcomes regardless of the amount of stress the individual experiences (Berkman \& Syme, 1979). 
More recent attention has centered on whether social support has a direct effect on stressors or outcomes or whether it interacts with the level of stressor and the individual's coping responses to promote beneficial outcomes. Of course, these alternatives need not be mutually exclusive: the effects of support could be felt in any or all of these ways in a particular instance. The issue is interesting from a methodological perspective, however, because the buffering effects could remain undetected, leading to a conclusion that support was not significant, unless interactions were specificaliy tested for. Nuckolls, Casel \& Kaplan (1972), for example, found that the possession of high levels of "psychosocial assets" led to fewer complications in pregnancy only when the level of stressors was also high. Buffering effects can also be missed if the individual's reaction to the stressors is not included in the model and only stressors and outcomes are measured. Barrera (1981) found that teenage mothers who had large, supportive networks were not as likely to be depressed as those with small, conflicted ones even though they were as likely to experience negative life events.

Most of the research on the effects of social support has been cross-sectional. Studies of stressful life events usually ask the subjects to report how many of 
these events have happened to them within the past year or six months but the subject's reports may be colored by their present situation. Gore (1978) was able to follow a group of men for two years after they had lost their job to measure the effects of stress and support. However, the initial measures of physiological status and life situation were made after the men had learned that the factory which employed them was going to be closed, although they were still working there at the time. The evidence of the Berkman and syme study (1979) that support significantly reduced mortality rates in a ten-year epidemiological study in which health behaviors as well as demographic variables were carefully controlled for is probably the most convincing and dramatic evidence to date of the effectiveness of social support. Several other longitudinal studies have failed to find such effects for social support however (Schaefer, Coyne \& Lazarus, 1981); Williams, Ware \& Donald, 1981; Warheit, 1979). Until more longitudinal studies are performed the causal role of social support in promoting beneficial outcomes will not be known.

\section{The Political Context}

The interest in social support has not remained free of political and ideological connotations. It has been associated with movements in human services for more 
emphasis on prevention and citizen control of services (Froland, Pancoast, Chapman \& Kimboko, 1981) and, more radically, with basic critiques of professionalism and an "overschooled" society.

The questions of what constitutes support and how it can be mobilized have taken on greater policy relevance as the limits of growth of the welfare state appear to have been reached in most developed countries and the expense of additional formal provisions becomes prohibitive. publicly provided care is most costly for those groups in the population that have been increasing: the elderly and those with chronic mental or physical disabilities. There is hope that social support from informal sources can continue to bear the major burden of care for these groups and perhaps even be extended. Twisting this argument around, some foes of any governmental welfare services argue that if informal support is so effective, the government ought to abandon the field. It is thus more imperative than ever that the research in this area be clear about what support is and what it can and cannot do.

Identifying The Supportive Aspects of Interpersonal Relationships

What is support? Research on social support has often been accused of being atheoretical, interested 
largely in discovering empirical relationships between various indicators of support and favorable wutcomes such as longevity, successful coping with crises and emotional well-being. Because the research has not been guided by a central theoretical perspective, differing definitions of what constitutes social support have been used. Marital status, contacts with others, number of friends, the presence of a confidant and psychological perceptions of being supported have all been taken as evidence of social support. Some researchers have emphasized the provision of emotional support, either by attempting to measure the amount of advice, sympathy and caring the person receives from others or by measuring the extent to which the person feels supported by others or has greater self-esteem because of feeling part of a caring group or because of being able to make favorable social comparisons. Other researchers have looked for evidence of more objective forms of supportive behavior such as frequency of contact or the provision of instrumental forms of assistance. More and more studies are attempting to operationalize support broadly and include both emotional and instrumental support and objective measures of association and exchange as well as the individual's perceptions of being supported. Probably the "classic" definition of the types of 
support provided by a support system is Caplan's (1974):

... (a) the significant others help the individual mobilize his psychological resources and master his emotional burdens; (b) they share his tasks; and (c) they provide him with extra supplies of money, materials, tools, skills, and cognitive guidance to improve his handling of his situation. (p.20)

Several others have developed more detailed descriptions which can be readily operationalized for research purposes (Gottlieb, 1978; Barrera, 1981) but all of the more comprehensive measures of support include these basic areas of emotional, instrumental and cognitive support. The principal difficulty with all definitions of support is that, in the absence of a theoretical framework, what is "supportive" tends tc be defined post hoc in terms of association with favorable outcomes. Several researchers have recently experimented with formulations that would overcome this circularity by introducing such concepts as "latent" support (Eckenrode \& Gore, 1981) and "negative" support (Shumaker \& Brownell, 1983, September). However, these concepts introduce problems of their own, one of which is that they serve to move the concept further away from what an average person would intuitively conceive of as support.

It should be noted that, although much of the interest in support from a policy perspective is in those forms provided within naturally occurring relationships, 
the definitions of support provided above do not confine themselves only to this source of support. Gottlieb's classification of helping behaviors was developed from interviews with women about the sorts of help they received from informal sources. However, most of the reviews of research on support, including Gottlieb's, make no distinction between support provided by professionals or self-help groups and that provided by family, friends and neighbors (Gottlieb, 1983; DiMatteo \& Hays, 1981). There have been attempts to contrast these two forms of support (Lenrow, 1976) but not within the support literature.

Constraints. It is frequently noted in the literature on social support that various factors that can be considered as personal resources or as indicators of the individual's structural position in the contemporary division of labor such as sex, education, occupation and stage in the life-course can affect the amount of support available and the way in which it can be utilized (Fischer, 1982). Since personal relationships depend on mutual exchange or norms of obligation for their continuance, a person with few resources to exchange or who has few obligatory relationships, such as with kin, will not be able to sustain potentially supportive relationships. In addition, the limits of a poor 
education, lack of participation in the workforce, physical infirmities or social stigma make it difficult for the individual to make new contacts and thereby widen the base of support or replace lost resources.

It is not surprising, therefore, that many studies have found a positive correlation between the possession of such resources and the availability of social support. It is also well-established that these resources contribute directly to physical and mental health. Because of these relationships, a well-conducted study of social support must control for these factors when assessing the independent contribution of support to successful outcomes. Many of the studies which have been conducted so far have not done so. In concluding a comprehensive review of the research on social support and serious illness, DiMatteo and Hays note, "the effect of these sociodemographic factors [e.g. social class, education and ethnicity] on the relationship between social support and illness outcome has largely been ignored" (p. 135, 1981).

Another influence on the availability and importance of social support is the personality of the individual. Some people have a personal coping style that is based on not relying on others for help or support. In a finding that is not often cited in the support literature, Pearlin 
and schooler (1978) discovered unexpectedly that self-reliance was a more effective coping strategy than seeking help. Others have negative personality traits such as hostility or excessive dependence which make others reluctant to help them. The individual's general level of optimism and feeling that he can control his life will also influence how he views and makes use of the support offered by others. Sandler and Lakey (1982) found that support was effective for college students who had an internal locus of control but not for those who felt that they were unable to control what happened to them. Again, few studies have introduced personality variables. Finally, the physical condition of the individual will affect the amount of support needed. While an individual who is ill may need more support, the seriousness of the illness, the amount of pain and other effects it has on the functioning of the individual, its chronicity and resistance to treatment and the extensiveness of the nursing care required will affect the amount of support that will be offered and its effectiveness. Research on the elderly has found that family members may be willing or feel obligated to provide extensive support in the event of a severe or chronic illness, but friends and neighbors are less likely to play a major role (Rosow, 1967). If a person has few kin, he is 
likely to be lacking support should he fall seriously ill. This is borne out by the many studies which have shown that most of the elderly who are in nursing homes are not more seriously ill than many other elderly persons who are not in nursing homes but they do not have kin available to care for them (Roberts, 1983).

DiMatteo and Hayes (1981) also point to some research which indicates that some social relationships, which might be intended to be supportive can have negative effects. For example, Lewis (1966) found that heart attack victims from over-protective families were less likely to return to work. Relationships can also contain sources of stress. Garrity (1973) found that men whose families were worried about them worked less after heart attacks. Barrera (1981) found that conflict within the network was a significant source of stress for teenage mothers.

SOCIAL NETWORKS AND SOCIAL SUPPORT

Social network analysis offers a possible source of greater descriptive precision for the support concept although it does not contribute much in the way of a theoretical base. A number of studies have recently used this approach (Hirsch, 1980; Tolsdorf, 1976; Sokolovsky, Cohen, Berger \& Geiger, 1978; Wilcox, 1981; Hall \& 
Wellman, 1982). Social network analysis proceeds from an examination of the specific set of relationships an individual has with others and the relationships these people have with each other. These relationships need not be confined to supportive ones, but the supportive elements of the relationships can be examined as part of the analysis.

It has been argued that the specificity and rich detail provided by a network approach permits a much better understanding of what effective support is and how it is mobilized as well as an appreciation of the constraints and negative elements that relationships with others also entail (Wellman, 1981; Gottlieb,1981; Froland, et.al., 1981). The network approach would also seem to have the potential for providing information that is more useful at the practice level than most of the more general findings in the support system literature. Social network research is still fairly new but it has already begun to yield information which gives specificity to the construct of support. It also has provided a number of cautions to glib assumptions and hasty interventions. It shows us that people's social worlds are highly complex and constantly changing, and that much of this complexity and change is not within the awareness of the individual and difficult for an outsider to understand. A network 
perspective avoids the reification implicit in the term "support system." As Wellman (1981) says, "support system" conveys the impression of "...a single system composed only of supportive social relations..." when;

We all know intuitively that ties are not always supportive; that support is transmitted in variable, often ambiguous ways; that people often participate in several social networks in different spheres of their lives. (p. 173)

However, social solidarities and primary groups are also important social entities and network analysis, in its disdain for functionalism, can be accused of ignoring them. Families, members of church congregations and even neighbors have certain social roles and act, in part, out of social and cultural norms and expectations which can be important determinants of their actions (Gouldner, 1960). These groups can be incorporated in a network analysis by noting the role relationships of network members and treating the role sets separately for some analyses. Many network analyses do not do this, however, treating all ties equivalently.

Another drawback of the network approach is that it entails the collection, processing and analysis of large amounts of data. Since a study of social support is interested in the network primarily as it affects the focal individual, this data must be aggregated at the individual level. For example, composition may be 
expressed as numbers or percentages of kin or friends. In this process of aggregation a good deal of the richness of the data is lost and a number of decisions have to be made about the appropriate statistic to use. Is an average more descriptive than a total? Are percentages better than absolute numbers? Finally the use of multiple regression or some other form of multivariate analysis usually precludes the inclusion of as many network variables as might be desirable because the samples are generally not very large.

In spite of these drawbacks a number of studies have been conducted which enable us to set the parameters of normal networks with some confidence and other studies have shown relationships between network variables and health outcomes. The evidence that has emerged so far is that there are some consistent relationships between network variables and health outcomes but they are quite complex, making it impossible at this point to select a key network variable or to create an index. We will review these findings as they relate to the major network variables of interest in a study of social support. Because this review is intended to be suggestive rather than conclusive, it will not be based on a detailed analysis of the methodology of each study. Therefore the following cautions should be kept in mind: 
- As is explained below, the methods used to describe the networks varied.

- The outcomes were different, although all of them related generally to health, well-being, positive mental attitudes, or satisfaction with life.

- Each study selected some subset of the possible range of network variables to relate to outcomes and only significant findings will be discussed here when it might be equally valuable to know that a specific network variable had no significant relationship to outcomes. Also, since many of the studies tested a number of network variables, some unspecifiable number of the significant associations could be due to chance.

- Some studies controlled for other variables known to affect these outcomes while others did not.

- Almost all of the studies were conducted at one point in time so the implied causal direction of the relationships between variables may be spurious.

MAJOR NETWORK VARIABLES

Findings from the literature on social support will be discussed as they relate to the four dimensions of support enumerated by Gottlieb (1983). The four dimensions are: structural characteristics, linkage characteristics, 
exchange content and subjective evaluation of the supportiveness of the tie.

\section{Structural Variables}

It is the emphasis on the structure of peoples' relationships with each other -- how they are tied together, what sorts of ties they have outside of the network under study, which members are central in the network and which are peripheral -- that really distinguishes network analysis from other approaches to the study of social support. In fact, the original definition of a social network defines it in structural terms as "...a set of points which are joined by lines: the points of the image are people or sometimes groups and the lines indicate which people interact with each other" (Barnes, 1954, p.43). The structural aspect received further emphasis in Mitchell's definition of a network as "...a specific set of linkages among a defined set of persons, with the ...property that the characteristics of these linkages as a whole may be used to interpret the social behavior of the persons involved" (1969, p.2). Structural variables are popular with network researchers because they readily lend themselves to precise definition and they are comparable across populations and across studies (Hammer, 1981). However, these properties of structural measures must be viewed 
cautiously since almost all network analysis begins by selecting the members of the network on the basis of some relationship they have with each other. Some network studies have been done which simply recorded interactions (Milgram,1967; Killworth \& Bernard, 1979), but all studies of support which use network analysis have selected a subset of the personal network based on a definition of relevant relationships and the perceptions of the focal individual about his or her relationships with others. Therefore, before examining the specific variables used in any study it is crucial to know what the eliciting question was. Some studies have tried to use broader, more general questions in order to include a wider network such as: "Name the people you know well." or "Tell me the names of the people you feel closest to." Wellman (1981) found that when he used the latter elicting question for a large, random sample in Toronto, the majority of the ties did not provide support of any kind and that, while the great majority did have some help available from their networks, most (86 per cent) of his respondents did not get help from the majority of their intimates, indicating that his elicting question did generate a wider network. Others have focused directly on the provision of various forms of support by using eliciting questions like "Who would you ask for help if a) you needed money; b) you 
needed advice; c) you needed a place to stay?" (McCallister \& Fischer, 1978). Using this approach, respondents are also often asked for the names of others who are important to them but were not mentioned in response to the exchange questions. Therefore networks generated in this way may also include members who do not offer any support but it is not surprising that the percentage of members who do offer support in these sorts of studies is higher than Wellman's. In Fischer's (1982) sample, only three percent received little or no companionship, six per cent received little nor no practical assistance, and 15 per cent received no counseling.

Network zones. The number of persons named as members of a personal network depends, of course, on the sort of question that is used to elicit the names. In order to keep this in mind, it is useful to use Boissevain's categorization of network zones (1974). He identified five zones:

- nuclear family or members of the household.

- intimate zone: close friends, neighbors, coworkers and relatives who are of high significance to the person and with whom there is a high degree of structured and expected exchange of affective and instrumental resources. 
- effective zone: strategically important persons with whom relations are maintained in order to utilize resources, persons with whom one has less regular contact or persons whom one sees frequently but does not value as highly.

- nominal zone: casual acquaintances.

- extended zone: people not known personally but known of who could easily become friends or acquaintances.

Many network studies fail to make these distinctions, either in their eliciting questions or in reporting their data. Nuclear family members, for example, may be included in the intimate zone. Boissevain's categorization includes the notion of support as a criterion of intimate zone membership although it does not preclude the possibility of these relationships also being stressful. His definition of the effective zone is probably the least useful in his categorization as far as support research is concerned because it includes both individuals who may be very important sources of support and people who are incidental acquaintances or with whom one is forced to spend time because of propinquity.

Network size. Three authors who reviewed a large number of network studies of normal populations concluded that intimate zones typically contain between six and ten 
members (Hammer, Makiesky-Barrow \& Gutwirth, 1978). Effective zones may add another 10 - 20 members to the active personal network (Pattison \& Pattison, 1981). In all, it is estimated that most persons have some sort of contact with $1000-1500$ people (Boissevain, 1974; Pool \& Kochen, 1978). Studies of social support are primarily interested in the intimate zone, with a secondary interest in the effective zone. The two methods of generating networks described above probably can be expected to reveal all of the members of the intimate zone. However, the extent to which they tap the salient members of the effective zone may vary and is apt to be influenced by other aspects of the way the questionnaire is administered or other factors. There is some variation in the number of names generated in different studies. Pattison and Pattison (1981) report that, in the course of many studies, normal persons "consistently and reliably" name about 25 persons who are important to them. However his group has never published the data on which this conclusion is based. When McFarlane and his associates asked a large, general sample how many people they could discuss important problems with, the mean number reported was nine (McFarlane, Neale, Norman, Roy \& Streiner, 1981). When asked who they could turn to in a major crisis, they reported a mean of five individuals. Fischer's most 
common network size for a large, random sample was between fifteen and nineteen names. Wellman (1981) found, in reinterviews of a small subsample of his larger study, that the range of persons with whom the respondents were "in touch" was between 16 and 35. However, another sample which was given the same eliciting question only named an average of 12 persons (Hall \& Wellman, 1982).

There are no consistent findings on sex differences with regard to network size. The size of networks has been found to be inversely related to age and positively related to education and socioeconomic status. Controlling for these variables, Phillips (1981) found that size had the strongest relationship with happiness for men in their large, random sample of any of the network variables they tested. A larger network is generally considered to offer more resources.

A large network may also be indicative of better interpersonal skills. A number of studies of groups with varying levels of psychiatric impairment have found consistently that network size varies inversely with level of impairment (Tolsdorf, 1976; Froland, Brodsky, Olson, \& Stewart, 1979; Mueller, 1980), the greater the impairment, the smaller the network.

Density. Members of a personal network may be connected to each other in a variety of ways or they may 
not know each other at all. Just as in the case of the eliciting question for generating the network itself, "connections" must be specified in order to be described. They can be specified in the same terms as the eliciting question, e.g. "How many of these people are in touch with each other?" or according to some different criteria for the existence of a relationship. The data on these connections can be gathered from the focal individual or from the members themselves. Most studies have relied on data gathered from the focal individual. If members of the household are included in the network, density can be expected to be higher than if they are excluded, since household members are likely to know others in the network.

There are several ways to measure the extent of actual interconnections. The most commonly used one has been density, the ratio of actual ties to possible ones. Density is commonly found to range between .20 and .30 . Hammer(1981) has noted that, although density might be expected to decrease rapidly with size, it does not appear to do so and shows a limited range across studies. She feels that this is so because of the presence in most networks of clusters of relationships with few ties between them. The number of clusters and the patterns formed by them, therefore, may be more revealing than the 
simple density ratio, especially in the middle ranges. Wellman (1979) states that the network of the typical resident of East York, an urban neighborhood he studied in Toronto, consisted of three clusters of about five persons each and a few single ties.

While many have predicted that dense networks would offer more support because of the close communication among members and shared norms, (Walker, MacBride \& Vachon, 1977; Hammer, 1981) density has not been found to be highly related to the amount of support provided or to beneficial outcomes (Wellman, 1979). This may be so because density is too general a measure. Hirsch (1981) studied women who were recently widowed and found evidence that density between clusters was predictive of successful adjustment whereas overall density was not. Those women who had few connections between their kin cluster and their friend clusters made a more successful adjustment. It may also be true that dense clusters offer a different type of support than single ties. If the general agreement on the size of networks in studies so far is an indication that people can only maintain a small number of close ties, the members of a network who form a dense cluster will have a higher proportion of their relationships with other members of the network than those who are not part of such a cluster since most of their 
significant relationships will be within the cluster. It follows that the focal person can be linked to more people who are not part of his network through someone who is not part of a cluster since this person is likely to have significant relationships with persons who are not known to the focal individual. This is the way that networks ramify and form chains of connection. These second-order linkages may be important sources of new information, attitudes and connections to other resources. The question of what type of support is provided by dense clusters must be separated from the role relationships of the members of the clusters. Kin clusters are likely to be dense and a network dominated by kin is likely to have a high density so it is important to separate the implications of having mostly kin to turn to from density, per se. The detailed studies necessary to investigate the differences systematically have not yet been done.

\section{Characteristics of the Linkages}

Composition. Individuals draw their networks from various segments of their lives. Generally, the sources of relationship can be categorized as: kinship, friendship, locality (neighborhood), and workplace. Some people may also include professionals or volunteers from whom they get help. An individual member of the network 
can occupy more than one status: both workmate and friend, for example. It has been argued that two concomitants of modernity are the growth in size and importance of the friendship sector of networks and the smaller number of network members who occupy multiple statuses, indicating greater specialization in relationships.

Kin still hold an important place in most people's networks. The median percent of kin in the networks in Hall and Wellman's (1982) sample was 40 per cent, roughly the same proportion as in Fischer's data. Having a network dominated by kin has been associated with negative outcomes, however. Arling (1976) found that a high percentage of kin was related to low morale for widows and Phillips and Fischer (1981) found it to be associated with unhappiness for the men in their sample. On the other hand, kin, particularly parents for young adults or adult children for the elderly, can be important sources of major assistance.

As Fischer (1982) has discussed in his choice-constraint model, having a diverse network with members drawn from a variety of sources is somewhat dependent on the opportunities presented to or cultivated by the individual. One of the ways that personal resources and an individual's structural position in society affect networks is in terms of the opportunities 
provided to make diverse connections. Education, particularly higher education, is one of the best opportunities for persons in our society to make diverse contacts. Employment is another and some types of employment offer much greater opportunities than others. Multiplexity. The second hypothesized change in networks due to modernity, the extent to which relationships are more specialized, is generally expressed in the network literature as multiplexity. Multiplexity has been defined operationally in two different ways in the network literature (Minor, 1983). In some studies it is defined as the number of role relationships in a given tie. That is, a member of the network can be both a friend and a neighbor. The second way that multiplexity has been defined is in terms of the number of exchanges that occur in the tie. A network member can be a source of advice as well as of a loan. In order to keep the two concepts separate, we shall refer to the latter as multistrandedness.

It is important to realize that these two ways of operationalizing multiplexity are conceptually distinct. Fischer (1982, p.143), for example, failed to make this distinction when he applied his findings, based on multistrandedness to Boissevain's discussion of urban-rural differences in multiplexity. Both multiplex 
and multi-stranded ties are predicted to be stronger, more supportive and less likely to be broken (Hammer, 1981). Most studies of personal networks have adopted the strategy of classifying relationships in terms of the most important role relationship in a given tie. This means that there is little explicit data on how much multiplexity there is in normal networks in terms of multiple roles and even less on what its effects may be. Most people do have a friendship sector, however, which is not drawn from the more obligatory contexts of kinship, locality or workplace. Within these contexts, McFarlane et.al.(1981) found that men found close, confiding relationships among workmates while women were more likely to draw such relationships from their kin and neighbors, even if the women worked. Laumann (1973) did not find that multiplex ties were any longer lasting or more intimate than uniplex ties.

In terms of the second definition of multiplexity, multi-strandedness, Hall and Wellman (1982) found that most ties provided only one or two dimensions of aid lout of a possible fifteen). Fischer's (1982) findings were similar.

Frequency of contact. High frequency of contact has been associated with high levels of support (Wellman, 1979) and positive outcomes (Gove \& Geerken, 1977). These 
findings in the network literature are consonant with earlier work detailing the negative effects of social isolation. Physical contact and verbal exchange have been found to be essential for the successful nurturing of infants and to prevent senility and other forms of mental deterioration among the elderly.

Duration. The data available on the duration of relationships suffers from the tendency of much network analysis to treat all ties equivalently. Ties to kin can be presumed to continue indefinitely, while ties to neighbors and workmates may be broken due to changes in housing or jobs. Friendships would seem to be the ties for which duration would be most voluntary. In spite of the turnover in networks, most people seem to have at least some friendships of fairly long duration. Hall and Wellman (1982), for example, found that the median duration of non-kin ties was eight years. Mutuality or balance. In spite of the frequent assertion in the network literature that ties are based on reciprocity, what actual data exists seems to indicate that imbalance in relationships is the rule. Wellman (1981), for example did not find equal exchanges of specific types of support either in the short or long run. Frequently there was not even an overall balance in exchanges. Hurd, Llamas and Pattison (n.d.) state that 
this may be due to reporting errors, since they have found that people tend to report giving more than they receive. Tolsdorf (1976) found that imbalanced exchanges, more receiving than giving, distinguished his sample of psychotics from a normal control group.

Tolsdorf's psychotic patients also had networks dominated by kin. Kin may have persisted in their relationships with these persons in spite of the lack of reciprocity because other norms prevailed. The psychotic person may then be trapped in a vicious circle where pathological relationships with family serve to further deteriorate social skills and make it less possible to engage in reciprocal relationships. Another form of vicious circle is described by stack (1974) where the mutual exchanges among the low income black women she studied made day to day existence possible but they also ensured that the women would not be able to accumulate enough "capital" to finance any long-term changes in their situation.

The Content of Exchanges

Through his relationships with network members, the individual may receive material assistance, emotional support or cognitive guidance. A number of the studies of social support have focused on the latter two, but there are many indications that material assistance is also 
highly valued. Hall and Wellman (1982) folind that instrumental support was more common than emotional support although they were correlated. Schaefer, et al. (1981) found that, after controlling for all forms of support they measured, tangible assistance was the only form of support that was correlated with less depression and positive morale. In their study, network size was positively related to depression.

One indicator of emotional support that has been found to be particularly significant is the presence of a confidant. Having one such relationship has been found to be a significant buffer of stress, even if the total network is small. Men seem to rely heavily on their wives to fill this function if they are married, while women tend to have other confidantes, even if they are married. The presence of a supportive wife has been found in a number of studies to be an important buffer of stress (Medalie \& Goldburt, 1976; Gore, 1978; House, 1981)

The early finding of Sussman (1959) that people tend to turn to different sectors of their network for different types of support has been verified in numbers of studies. Fischer (1982), for example, found that people got companionship from friends, practical help from neighbors and relatives and counseling from immediate relatives and friends. 


\section{Perceptions of Support}

Measures of the individual's feelings of being supported are problematic from a research standpoint because they are likely to be confounded with measures of some stressors, with personality variables such as self esteem, and with outcome measures such as life satisfaction or depression. They are also likely to be affected by what the respondent feels should be the case. Nevertheless it is important to attempt to assess these perceptions because there is evidence that they are not always directly related to more objective measures of support. For example, Liang, Dvorkin, Kahana and Mazian (1980) found that feelings of loneliness and isolation were better predictors of morale for their elderly sample than measures of the actual number of friends they had or their participation in organizations.

Theoretically, perceptions of support are important because they may be part of the individual's reaction to a stressor. Feeling supported may contribute to the individual's sense of coherence (Antonovsky, 1979), milieu reliability (Gottlieb, 1983) or sense of control. Whether or not these sources of support are actually utilized, the individual may experience a reduction of anxiety from the knowledge that they are available. 


\section{SUPPORTIVE NETWORKS AND LONG TERM STRESS}

Most of the social support studies have dealt with the role of socially supportive relationships in helping an individual cope with single or multiple specific, short-term stressors such as an acute illness or an environmental stressor such as job loss or a natural disaster. The stress model, as it was originally formulated, dealt with the individual's ability to cope with a change from a steady state. While it has long been acknowledged in the stress literature that continuing sources of stress may have an even greater impact on individual functioning, studies of the role of social support in helping an individual cope with long term, chronic stress or disability are much less common. Research on this issue is difficult because, by the time an individual is determined to have a chronic disability, the effects of the illness or handicap have already had time to alter the person's self perceptions and relationships with others. Research on the support networks of mentally ill persons, for example, is generally open to the criticism that the distinctive patterns of relationships may be the consequence of mental illness rather than part of the cause. Without having evidence of the long term effects of 
support on coping with chronic stressors, the cross-sectional studies which have been done show some consistent findings concerning the relationship that chronic stressors have with support. Liem and Liem (1978) review a number of studies of unemployment and observe that if unemployment becomes chronic, the relationships with others that helped to moderate its initial effects deteriorate. Iin et al (1979) hypothesize that stress may result in support mobilization for high status persons but may cause support deterioration for low status persons. In adition to the fact that low status persons lack resources for reciprocal exchange, their low status may be a result of chronic stressors which have taken their toll of their support network and decreased its capacity and willingness to respond to the current crisis.

In a study of men who were dealing with a first heart attack, Croog, Lipson and Levine (1972) found that kin and friends were both involved in providing assistance. If the men experienced a second heart attack, however, friends tended to fall by the wayside and relatives provided most of the support and direct assistance. MacElveen-Hahn and Smith-DiJulio (1978) conducted a study of the support networks of a sample of persons (mostly married men) with end-stage renal disease who had been receiving kidney dialysis for at least six 
months. They found that their networks were somewhat smaller than those reported for normal populations and contained a higher proportion of kin. They also had more frequent contact with relatives than with friends. These patterns were true for spouses or household partners as well, perhaps indicating the impact of a chronic illness on other members of the household.

\section{CONCLUSIONS}

In discussing in some detail the relationships of various aspects of personal networks to individual health and well-being, we may have lost sight of the forest as we wandered among the trees. Research into personal relationships has burgeoned in the past few years because the findings of the earliest work were so promising. Various measures of support did seem to affect health outcomes, either directly or when stressors were high. As the research has proliferated, however, without a strong theoretical base and within various disciplines and traditions of research each of which differs in its framework and approach, the promise of the early findings has been somewhat dimmed by the plethora of conflicting findings, leading to what Gore (1981, p.202) has termed "increasing frustrations with prospects for investigating the stress-buffering effects of social supports." 
The stress model has become increasing complex in order to incorporate more intervening variables. There are difficulties in the measurement of stressors and in the selection and measurement of appropriate outcome measures but the greatest difficulties lie in specifying and measuring the intervening variables. Since attention must be paid to the possibilities of interaction and threshold effects, the addition of one intervening variable adds considerable complexity to the model and to the analysis of data. This is the case for such constructs as "coping response" or "reaction to stressor", and "personal resources" but we are chiefly interested in the social support construct. This review of the research on social support points to some of the important areas of inconsistency or ambiguity which must be resolved if the research is to move ahead with greater coherence. First, greater attention must be paid to the eliciting questions used to define network membership if the findings of network studies are to be comparable. We have seen that different questions have implications for structural variables such as size and density as well as the type of support being measured. Adoption of a classification scheme of zones such as the one developed by Boissevain would help to clarify network membership. From the perspective of research on social support there 
are two improvements that could be made in Boissevain's system. First, it would be helpful if the classification system were based on criteria other than the supportiveness of the tie. Secondly, it should not include casual acquaintances and important but infrequently seen or emotionally distant figures in the same zone.

Secondly, we have seen that the advantages that measures of network structure and the characteristics of the linkages have in terms of precise definition, quantifiability and conceptual independence from the supportive aspects of the relationships are accompanied by difficulties of interpretation because they may have either positive or negative implications with respect to outcomes depending on other factors, many of which are not clearly understood at this time. A large network may offer more resources than a small one but it may also demand more from the individual. A dense network may offer more of some kinds of help and less of others. Multiplex ties may be stronger and hence more reliable sources of support but they may also be indicative of a network that offers little diversity. Thirdly, there is evidence that different kinds of networks are supportive for different kinds of people. Men, for example, seem to use different sources of support 
than women. Life opportunities affect the kind of network an individual can have in terms of such variables as diversity and multiplexity. Such personal characteristics as sex, age, and education must be taken into consideration when examining the effects of variations in network variables.

All of these considerations introduce complexities into the modeling of the support process and the design of research. Generally, more complex research designs require larger samples. But they also require more complex research instruments such as lengthy, open-ended questionnaires and interviews and more extensive analysis, all of which becomes increasingly difficult with a large sample. Research in this field has reached the stage where greater standardization of variables and methodologies would be useful. Careful replications of previous studies would also help to distinguish the significant relationships between various network measures and outcomes from those due to chance, always a problem when a large number of variables are used.

We have also seen that additional difficulties in gathering and interpreting data are imposed in the study of a chronic stressor. Chronic stressors are thought to lead to a deterioration in support so that greater severity may be associated with less support being 
available. It is also more difficult to study a chronic stressor longitudinally.

While the temptation is to proceed to the construction of more elaborate models and to theoretical debates about issues such as direct or interactive effects, this review has shown that there is still much work to be done in the careful measurement, description and comparison of the various aspects of social support. 


\section{CHAPTER III}

\section{COPING WITH EPILEPSY, A CHRONIC DISEASE}

One of the most striking effects of the advances in medical care in this century has been the prolongation of the lives of persons with chronic diseases. Kidney failure, heart disease, diabetes, and a host of other maladies which formerly claimed their victims in childhood or with the first acute episode are being managed with various forms of medical treatment which permit a much better prognosis. It is estimated that 50 per cent of the civilian population of the United States has at least one chronic disease (Levin \& Idler, 1981). In addition to prolonging life, better medical treatment has resulted in improving the ability of persons with a chronic disease to live a normal life. Persons who were formerly institutionalized, such as schizophrenics and epileptics, can now control many of the symptoms of their disorder with medication.

Increasing concern is being evidenced about the monetary costs of expensive forms of treatment to individuals, their families and society. More recently, it has also been recognized that the maintenance of larger numbers of persons with chronic conditions has other costs, to the person with the condition and to the family, 
friends and others who care about him or her. As Levin and Idler note "...families are heavily and increasingly involved with chronic disease management" (1981, p.81). Medical treatment and other formal services can only go so far in guaranteeing a person with a chronic condition a relatively normal life. Good self care and supfort from others are also necessary. A number of rehabilitation studies have shown that positive family attitudes and active family support are associated with successful rehabilitation and employment (Lindenberg, 1977). On the other hand, overprotectiveness or excessive burden on family members have been associated with poor rehabilitation outcomes (Garrity, 1973; Lewis, 1966). There is some concern that changes in the family structure, in particular the entry of women into the work force to an unprecedented extent, is lessening the ability of the family to provide appropriate support. Fewer studies have investigated whether the relationships with those outside the immediate family circle such as friends, relatives, neighbors or workmates or more general forms of social participation are also important to successful adaptation to a chronic condition. A further question is whether such relationships can compensate for a lack of support from family members. Epilepsy presents a case in point of a disease which 
was formerly stigmatizing and incapacitating whose victims are now offered the promise of a nearly normal life through improvements in medical treatment. successfully coping with the condition, however, requires more than formal services. We will first examine the nature of the disease and the impact it has on an individual and then discuss the requirements for successful adaptation. Finally we will speculate on how support from family, personal network and the community could contribute to successful coping.

\section{EPILEPSY}

What is Epilepsy?

Epilepsy is from the Greek word, epilepsia, which means to be seized or taken hold of. The Greeks used it to describe the same sort of symptoms as we do today. The Hippocratic collection of 400 B.C. includes a monograph written by a physician for laymen on the "sacred disease" which attacked the superstition and magic that surrounded epilepsy. Such famous historical figures as Alexander the Great, Julius Caesar, Socrates and Luther are said to have had epilepsy. In spite of its long history as a medical entity, however, epilepsy remains a rather elusive and very complex phenomenon. One contemporary neurologist says, 


\begin{abstract}
To grasp the problems posed by epilepsy requires a Renaissance viewpoint extending from membrane to social organization, a viewpoint encompassing problems ranging from neuronal function to those of derangements of perception and adaptation as a result of disease at the highest levels of the nervous system, and to problems of ethology and cultural anthropology (Daly, 1978, p.158).
\end{abstract}

Our focus will be on the psychosocial aspects of epilepsy in a non-institutionalized population so we do not need to delve deeply into neurological aspects or medical management. It is sufficient to understand how epilepsy is conceptualized currently, what the major diagnostic categories are and to review current medical practice in the control of the symptoms.

Etiology, incidence and classification. Epilepsy is generally described as a disorder of the central nervous system in which brain cells (neurons) create electrical discharges that cause seizures - temporary loss of control of certain bodily functions. There is some debate as to whether epilepsy should be considered a disease or merely a set of symptoms. There are numerous causes of epilepsy and many cases are idiopathic, that is, their cause cannot be explained. Of the identifiable causes, two of the major ones are brain injury due to accidents, infections or toxic substances and conditions such as birth trauma which result in lack of oxygen to the brain. Epilepsy can escape diagnosis or be concealed. 
Seizures during high fevers are not uncommon in young children but are not considered epileptic unless they recur. The actual incidence of epilepsy, then, is difficult to determine but a widely accepted estimate is that approximately 2 million people have it (What Everyone Should know about Epilepsy, 1978). The prevalence rate most widely quoted is $5 / 1000$. The number of new cases due to injury was increasing relative to those of idiopathic or unknown origin but has dropped again recently with the adoption of the $55 \mathrm{~m} . \mathrm{p} . \mathrm{h} . \mathrm{speed}$ limit and the subsequent reduction in the number of head injuries. Seizures most often occur for the first time early in life. Over sixty per cent of all cases develop before adolescence. Men are slightly more likely to have epilepsy than women. The classification of seizure types is another confusing aspect of epilepsy. Confusion resulting from the complicated nature of the symptoms and the lack of a clear understanding of causation is compounded by well-intentioned efforts to alleviate some of the stigma attached to the condition by adopting new terminology. Some would even substitute the term "seizure disorder" for epilepsy. The most recent attempt to classify seizure-producing brain disorders was developed in 1969 by the International League Against Epilepsy and is based on new understanding about the part of the brain affected by 
various types of seizures and, to some extent, on the victim's overt manifestations. The two major divisions in this classification scheme are partial and general, depending on whether the whole brain is involved or only a part. This classification system has proven to be useful in prescribing medications but has not been widely adopted by the public. Therefore this study has used an earlier classification which breaks seizures down into five types (the newer terminology is also given):

- Grand mal or tonic-clonic - major motor convulsions with loss of consciousness.

- Petit mal or absence - loss of consciousness for very short periods (5-20 seconds), age at onset under 12 years.

- Psychomotor or complex partial - more prolonged loss of consciousness than petit mal (1-2 minutes) with automatic behavior (e.g. walking or running aimlessly, picking at clothing, lip smacking) but not convulsions, preceded by an aura.

- Focal or simple partial - consciousness may or may not be impaired, manifestations may be motor or sensory, depending on which part of the cortex is affected.

- Other- seizures which were very rare or could not 
readily be classified.

Grand mal seizures are the most widely known, most commonly diagnosed and are equated with epilepsy in the public mind. Approximately 50 per cent of all cases of epilepsy involve grand mal seizures. Petit mal seizures are frequently outgrown and may go undetected in childhood. Psychomotor seizures are more varied in their manifestations and not as common but they have generated considerable debate as to whether they are associated with a particular personality type and, more specifically, whether such persons are more prone to violent behavior. There is no conclusive evidence for either hypothesis (Hermann, 1977).

While all of these seizure types are based on similar neurological dysfunction, the behavioral manifestations vary widely. The common neurological basis may justify their inclusion under the single term "epilepsy" but it is easy to see from this brief review that a diagnosis of epilepsy tells one little about the actual impact of the disorder on a specific individual. It is necessary to know what type of seizures are currently being experienced (types may occur serially or in combination) and how frequently. The age at which seizures first occurred also has a large bearing on prognosis as well as determining how much of the 
individual's life was affected by the disability.

Medical treatment. There is no cure for epilepsy. Actually, the idea of a single cure for such a complex phenomenon is unrealistic. Effective treatment for epilepsy consists of preventing seizures. The first drug which could prevent seizures, phenobarbitol, was developed in the middle of the 19 th century. Since then a number of other drugs have been developed and approximately 15 are currently in use. Although seizures can, in some cases, also be prevented through maintaining a nonstressful, healthful lifestyle, or through surgical removal of damaged parts of the brain in cases which are not amenable to medication, drug therapy is the overwhelming treatment of choice for all forms of epilepsy.

Since the exact way in which the various drugs work is not known, the usual procedure is to prescribe a moderate dose of the drug which has proven to be most effective for similar cases and then adjust the dosage for the particular patient on a trial and error basis until the maximum amount of seizure control with the minimum amount of side effects is achieved. Usually the drugs must then be taken indefinitely and on a daily basis. It is estimated that as many as 80 per cent of all persons with epilepsy could be successfully maintained in this way, at least 50 per cent of them seizure-free. Since 
many people do not adhere strictly to their regimen and since the drugs are not completely effective, the actual percentage of persons who stay seizure-free once their epilepsy has been diagnosed and an effective treatment found is variously estimated as between 30 per cent and 50 per cent (Rodin, Rennick, Dennerll \& Lin, 1972).

According to the National Commission for the Control of Epilepsy and its Consequences, approximately 3 to 4 per cent of all persons with epilepsy are in institutions but they may have been institutionalized for reasons other than their epilepsy (Commission Report, Vol. I, p.17). This figure is similar to the percentage of persons hospitalized for other chronic conditions (American Hospital Association, 1971). An additional estimated 768,600 Americans receive regular outpatient medical treatment for epilepsy (Commission Report, p.17). Epilepsy itself is a cause of mortality only when the seizures cannot be stopped (status epilepticus) and the person experiences respiratory failure or when the person has a fatal accident during a seizure. Individuals whose seizures are well controlled have a normal life expectancy.

Living with Epilepsy

Before detailing the impact of having epilepsy on an individual's daily functioning, considered to be mostly 
negative, it might be useful to get the perspective of two people who had epilepsy on what seizures meant to them. Dostoyevsky, an epileptic himself, put these words into the mouth of one of his characters:

You all, healthy people, he said, can't imagine the happiness which we epileptics feel during the second before our fit. Mahomen, in his Koran, said he had seen paradise and had gone into it. All these stupid clever men are quite sure that he was a liar and a charlatan. But no, he did not lie, he really had been in Paradise during an attack of epilepsy; he was a victim of this disease like I was. I don't know if this felicity lasts for seconds, hours or months, but believe me, for all the joys that life may bring. I would not exchange this one. (In Ervin, 1975, p.205)

Aside from the occasional injuries that persons with epilepsy sustain during seizures, the negative consequences of having epilepsy are almost entirely due to the reactions of others. A young woman who experienced a seizure while participating in a self-help workshop with other epileptics said:

Wouldn't it be terrific if one day everyone would have the attitude that an epileptic seizure is nothing more than a pause that is necessary to achieve a natural rhythm? The seizure I had on Saturday was the first ever in my life where I felt that way. I did not awaken with the fear that normally accompanies the confusion... Everyone was so calm, almost to the point of being blase. Subconsciously I tuned into that. All I know was that it was easy and almost necessary to my well-being in relation to the day's experience and continuation. (Serpico, 1981, p.3) 
It would seem from the self-reports of epileptics that the seizures themselves are not really a major handicap to normal functioning unless they occur frequently. It has even been noted recently that some people with epilepsy who could be completely seizure-free with medication seem to "need" to have occasional seizures in order to avoid other symptoms. For some epileptics the side effects of medication may be more troublesome, physically, than occasional seizures. However it may still be desirable to be free of seizures to avoid the problems that having them causes for others. In a sense, epilepsy is a social disease and those who are concerned with making life better for persons with epilepsy have been as concerned with breaking down social barriers as with finding causes or better forms of treatment.

\section{Public Attitudes}

A series of Gallup Polls from 1949 to 1974 showed great strides in public acceptance and understanding of epilepsy (Caveness, Merritt \& Gallup, 1974). The public has come to understand that epilepsy is not contagious or inherited and that most epileptics can control their seizures with medication. In 1974, 62 per cent knew someone with epilepsy, perhaps an indication that epileptics are now more willing to disclose their condition, and 61 per cent had witnessed a seizure. This 
figure may actually decline as more people with epilepsy are able to be seizure-free. Other surveys do not give quite as optimistic a picture and there is evidence that behavior lags behind attitudes. Individuals with epilepsy still report educational and employment discrimination, public ignorance and social ostracism (see Commission Report, 1977). Unemployment among persons with epilepsy consistently runs about twice the national average (Commission Report, 1977, p.85). In general, however, attitudes in the United States now would seem to be quite enlightened.

Legislative changes also reflect greater public acceptance and understanding. In the past, laws regulated the marriages of persons with epilepsy, in some cases requiring sterilization, denied them an opportunity to immigrate to this country or to operate a motor vehicle. Although some of these discriminatory laws were still on the books as late as the mid-Seventies, most of them have been eliminated. In most states, a person with epilepsy can now have a driver's license if he or she has been receiving medical treatment and has been certified by a physician to have been free of seizures for some period, usually two years. 


\section{$\underline{\text { Self-care }}$}

An epileptic cannot take care of himself when he is having a seizure. It is precisely because one is out of control during a seizure that the seizure is frightening, at least to those observing it, and that led to ideas that the person was possessed by a benign or evil spirit. With little or no warning, the person having the seizure must be able to depend on others to see that he avoids harm. Ironically, in these days of expensive medical care, persons with epilepsy are equally worried that others will call an ambulance or summon other expensive forms of assistance when it is not necessary. It is therefore in the interest of the person with epilepsy that the general public and, even more importantly, those who are most likely to be around when a seizure occurs -- family members, teachers, employers and workmates -- know what to do. Speaking strictly in terms of managing the condition, it is best for the person with epilepsy to disclose the condition to those around him. Therefore an important part of self-care for the person with epilepsy is judging when and how to disclose the condition. Family members and close friends may also need to perform this educative function.

The other major aspect of self-care is avoiding having seizures. The major way this is accomplished is 
through the maintenance of an appropriate amount of anti-convulsant drug in the blood stream at all times. Sophisticated techniques have been developed to measure blood levels and wide use of them has revealed that many people do not take their medications as prescribed. As with many other chronic conditions, nonadherence to a medical regimen is a major problem.

It may not be entirely accurate to equate failure to take medications with poor self-care, however. In some instances, the individual and his family may judge that running the risk of an occasional seizure is preferable to the side effects of the medication. Moreover, the individual may not make such a decision consciously but ambivalence may be reflected in occasionally forgetting the medication. In its concern with eliminating seizures, the medical profession may not have paid enough attention to the negative side effects of the medication. It is interesting that this issue is nowhere dealt with in the four volumes of the Commission Report although the side effects of the medication may be the only reminder of his condition for the person whose epilepsy is controlled. The chief side effect of the medications is usually drowsiness and the family may have to accept the person's need for more rest and compensate for difficulties he or she may have performing activities which require 
alertness.

The person with epilepsy can also improve his chances of remaining seizure-free through maintaining good health practices, and avoiding stress and alcohol. Here too, the cooperation of others is helpful for adults and essential for children who have epilepsy.

Therefore, just as many of the difficulties of daily living posed for the person with epilepsy are social in origin, the solutions also lie in relationships with others. Good self-care is greatly facilitated by having helpful family members and friends.

\section{Psychological Aspects}

Discussion and research on the psychological impacts of epilepsy have centered on two issues: whether epilepsy affects intelligence and whether or not there is an epileptic personality. In addition, it can be assumed that the experience of living with a disabling and somewhat stigmatizing condition will affect an individual's self esteem and attitudes about others. Intelligence and epilepsy. The current consensus seems to be that being prone to seizures does not, per se, affect intelligence. There may be some deterioration in intelligence with prolonged, frequent and severe seizures but lower intelligence among persons with epilepsy is usually associated with other forms of brain damage. The 
Commission Report noted:

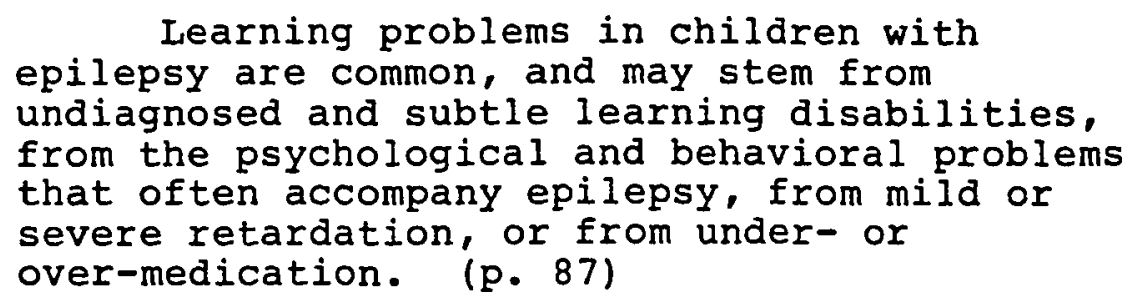

Thus while intellectual problems may not be directly caused by epilepsy, it is predictable that some proportion of any sample of individuals with epilepsy will have learning deficits. However, the proportion is not as high as was once thought when studies were based on institutionalized or hospitalized groups.

Personality. It has already been mentioned that a good deal of research has investigated the "epileptic personality." As in the study of intelligence, the earliest work was based on institutionalized groups and was conducted before medication was very effective in controlling seizures. Assessments of personality disturbance were also clinical judgements and usually based on only one rater's opinion (Hermann, 1977). More recent studies which have used samples with less severe symptoms and more reliable personality assessment techniques such as the MMPI, have failed to differentiate epileptics from normal comparisons (Klove and Doehring, 1962; Matthews and Klove, 1968). There do seem to be a disproportionate number of 
epileptics in prisons and mental hospitals, whether because their disturbances are "innate" or a result of the life experiences associated with having epilepsy. The Commission Report says: "...the incidence of apparent mental illness may be greater among those with epilepsy, particularly among those whose seizures originate in the temporal lobes of the brain, the areas that control thought and emotion" (p. 78). One expert estimates that between one-sixth and one quarter of people with epilepsy have psychological problems and 10 per cent may have been admitted to mental hospitals.

Attitudes and self esteem. Without being associated with psychopathlogy, it is still possible that epilepsy could affect self esteem in the way that any sort of disability does, and that it could also affect one's sense of control and attitudes towards others. The commission Report repeatedly refers to psychological and behavioral problems that sometimes accompany epilepsy including overdependence, aggressiveness, insecurity, and defensiveness. These psychological problems are also mentioned in the rehabilitation literature (Scott, 1978; Smith, 1978). However, these may be problems of the clinical population and not characteristic of epileptics who have made a successful adjustment. 
The Contributions of Interpersonal Support to Coping with Epilepsy

DiMatteo and Hays (1981) have suggested that there are three types of recovery or health-related outcomes: physical recovery (e.g. reduced seizure frequency); social role recovery (e.g. employment); and socioemotional recovery (e.g. life satisfaction). In the case of a person who has had epilepsy from birth or childhood, "recovery" can be thought of as the attainment and maintenance of these statuses. It is in terms of these outcomes that we can measure successful coping for a person with epilepsy. This study will use measures of successful employment and life satisfaction. Reduced seizure frequency would be a less sensitive measure of the current impact of support for this group, since most of them had achieved the best possible level of control of their symptoms and had been able to maintain themselves at this level for some time before the study was conducted. This review has noted a number of ways in which support from others could assist a person with epilepsy to function normally and attain these outcomes. In order to summarize them, we can return to the definition of support given earlier. Family members, network members and social acquaintances and organizations can provide verbal and/or nonverbal information, advice and feedback. They can 
offer tangible aid or action that will help the person deal with seizures or self care or assist them in some other aspect of daily living such as finding a job or interceding with an employer after a seizure. They can provide the person with the sense that he is cared for and loved, esteemed and valued. We have seen that these forms of support have been shown to contribute to beneficial health outcomes for people suffering from a variety of acute and chronic conditions. It remains to be seen whether a person who receives these forms of support has more successful outcomes in the specific instance of epilepsy. 
CHAPTER IV

METHODOLOGY

This study was undertaken as part of the Epilepsy, Disclosure, and Job Placement Project, funded by the National Institute of Neurological and Communicative Disorder and Stroke, Public Health Service, Department of Health and Human Services, through the Comprehensive Epilepsy Program of Good Samaritan Hospital and Medical Center, Portland, Oregon, and conducted by the Regional Research Institute for Human Services, Portland state University, Portland, Oregon. The Project had three parts:

- research on the effects of disclosure patterns, severity of symptoms and stigma on employment,

- investigation of legal discrimination against people with epilepsy,

- an experimental rehabilitative program for persons with epilepsy who had severe employment problems.

The project continued for five years, from 1975 to 1980. The data that will be reported on here were gathered as part of the investigation of the employment problems of men with epilepsy. 


\section{SAMPLING PROCEDURES}

\section{Sample Selection}

The sample was initially recruited through the distribution state-wide of a small screening questionnaire through doctor's offices, the oregon Comprehensive Epilepsy Program, the Epilepsy Association of Oregon and other agencies serving persons with epilepsy. Persons with epilepsy were invited to complete the questionnaire and mail it back. A second questionnaire was then mailed to those who had indicated in the screening questionnaire that they would be willing to provide more information and who met the criteria for inclusion (i.e. were over 15 years of age and had held at least one job since the onset of seizures). After extensive follow-up, 445 people completed and returned this questionnaire in 1976.

In April and May of 1978, the persons who completed the questionnaire were recontacted to see if they would be willing to be interviewed. Two-hundred and thirty men and women agreed to an interview and were interviewed over the summer.

Characteristics of the Study Group

The group of one hundred men who are the basis of this study was drawn from the larger initial group of 445 men and women who had volunteered to participate in the 
study two years earlier. It was decided to concentrate on the males in this group because it was anticipated that the men and women would have quite different employment histories and that employment was a more straightforward indicator of successful functioning for men than it would be for women. There were not sufficient resources to accomplish the extensive data analysis required to analyze the women separately. of the original 226 men, 119 could be found and were willing to be interviewed. Therefore this sample is probably biased towards the more stable members of the first group. Evidence for this is provided by a comparison of the employment rates for the groups. The per cent of unemployed men over 25 who responded to the initial screening questionnaire was 40 per cent. The rate for those who answered the longer mailed questionnaire was 34 per cent. The rate for the men who completed the interview was 27 per cent. It was also decided to eliminate men who were less than twenty-five years of age because they had not had enough experience with employment to have developed a characteristic pattern. Therefore, the final study group is composed of 100 men.

A second limitation was that, while this was a study of a group with a chronic illness, it was not conducted in a medical setting. This may have resulted in a sample 
that included more people who were experiencing little or no difficulty associated with their epileptic condition than are generally found in studies done on clinical populations. It also meant that the data on the nature, treatment and degree of impairment caused by the epileptic condition were based entirely on self report. Since epilepsy is sometimes accompanied by other forms of neurological impairment which may affect functioning, it would have been useful to have measures of neurological capacity and other diagnostic information. Information on medications was also self-reported. Since medications can have an effect on functioning, largely through side effects, it would also have been useful to have information on medications from medical records. However, this study also offered several advantages for a careful assessment of the impact of support on the functioning of men with epilepsy. It included more men who were seizure free than most clinical studies would. It included men who were able to conceal their condition from employers. This meant that the sample included a representation of those who would provide examples of successful strategies for coping with epilepsy. Secondly, the study was fairly large in scale. This meant that the sample was larger than that which is available in many clinical studies, interviews could be conducted rather 
than relying on self-administered questionnaires and there would be sufficient time allotted in the interview for fairly detailed exploration of the individual's network. The interviewers could probe for completeness of responses. Since some subjects were functioning at a minimal level, the assistance of the interviewer was particularly important to assure complete and accurate responses.

A major drawback of the study for the purposes of testing the coping model is that the data was essentially gathered at one point in time. This is problematic in two respects. The stress which is being measured here, resulting from epilepsy, is a chronic condition rather than an acute situation for most of the sample. Therefore, patterns of adaptation may be fairly long standing. The age of onset of the disability can be taken into consideration but this is an inadequate index for measuring the development of patterns of adaptation over many years. Secondly, the outcomes, which in the model should be consequences of the impact of the stressor, actually co-exist in time with the experience of having epilepsy. The existence of the relationships among variables posited by the model can be tested and an ordering can be imposed by means of hierarchical regression and tested but truly causal inferences cannot 
be drawn. These limitations, however, are common in the social sciences and this investigation is strengthened by proposing a model of relationships rather than simply "fishing" for significant relationships.

\section{Representativeness of the Sample}

It is difficult to ascertain the representativeness of a sample of an unknown population. Epilepsy can be a hidden disorder and the recruitment of this sample depended on the initiative and voluntary cooperation of the participants. It is likely that participation in the study was more appealing to those who were not keeping their condition hidden or for whom epilepsy presented real problems in daily living. On the other hand, efforts were made to encourage the participation of less heavily burdened persons by assuring confidentiality and attempting to recruit participants in non-medical settings.

Once the data were gathered, they were compared with other large studies of persons with epilepsy and with what data were available on a national basis. These comparisons are discussed in more detail in the next chapter, but, in general, this sample seems to be representative of an outpatient epileptic population. The age distribution of the men in this sample who had driver's licenses was very similar to that of the men with 
epilepsy on file with the oregon Department of Motor Vehicles (Emlen and Ryan, 1979).

\section{DATA COLLECTION PROCEDURES}

The first task was to develop an interview schedule. Two open-ended interviews were conducted with men with epilepsy and content analyzed for important dimensions of social support and social participation. The literature on social support was also consulted for guidance on appropriate items. Because of the overall purpose of the study, particular attention was paid to aspects of support which might help the individual in coping with epilepsy and finding and maintaining employment. Some questions were included in a mailed out questionnaire to save interviewing time. Others were included in the interview schedule. Both data collection instruments and the informed consent form are in Appendix A. After the interview schedule was developed, it was pretested on two additional subjects.

The next phase was data collection. Eleven interviewers, all of whom had some graduate training and previous interviewing experience, were hired to conduct the interviews. Four hours were spent training them in the use of the instruments. All of the interviews were completed within a month's time, from mid June to mid 
July, 1978. The interviewers were interviewed by their supervisor after they had completed several schedules in order to check for misunderstandings, interpretations, etc. In the interview, responses to the self-completed network items in the mailed questionnaire were checked for completeness. Every interview was checked by a project staff person for completeness and missing items were filled in by recontacting the subjects. This careful followup resulted in a data set with few missing values. There are no more than five missing values on any of the variables included in this study.

The interviews were coded by two staff members. Items which required some judgement by the coder, such as the assignment of socio-economic status, were coded by a group consisting of the two staff members and their supervisor. The coding was done on machine readable forms to eliminate errors when the data was transferred from the coding sheets to the computer. Interviews were selected at random to be recoded by the supervisor to check for accuracy of coding.

After completing the coding of the interviews, the data were put onto the computer. Initial data checks were done by tallying frequencies of responses on the questionnaire items and examining them for values which were not part of the coding scheme. The errors found were 
corrected. Logical checks were done by running cross-tabulations to discover mutually inconsistent items. The raw data were then examined for actual responses, and mistakes corrected accordingly.

\section{TYPES OF DATA COLLECTED}

\section{Epilepsy and Employment}

Information about the subject's epilepsy and employment history was collected in the first and second mailed questionnaires. Attitudes about epilepsy were also measured at this time. In the interview employment experience was brought up to date. More detailed information was also obtained about the history, type and frequency of seizures, the impact of having seizures on the job and the medical management of the condition.

\section{Self Concept}

Attitudes toward self were measured with the Tennessee Self Concept Scale (Fitts, 1965). This scale was chosen because it was an easily self-administered questionnaire with a sixth-grade reading level and fairly non-threatening content. It was not felt to be appropriate to use a more direct measure of psychopathology such as the MMPI in a study of employment and discrimination. The Tennessee self Concept scale has been widely used and normed on large populations although 
it is not generally considered to be a reliable diagnostic tool for individual cases (Wylie, 1974).

\section{Life Satisfaction}

Items on general life satisfaction developed by Campbell, Converse and Rogers (1976) were also included in the instrument. These items had also been used previously on large, randomly selected samples of the general population, permitting comparisons of the scores of this group with the more general random samples.

\section{Social Participation}

A number of general questions about the social activities of the subjects were included in the questionnaire. They covered such areas as the extent to which they participated in organized activities, how often they went out socially and how satisfied they were with the amount of contact they had with family and friends.

\section{Social Network}

Data about the three zones of the network (household, intimate and effective) were collected by means of matrices with the names of individuals listed on the left side and responses to a number of questions about each person ranged across the page. In order to avoid the circularity of assessing the capacity of the network to provide support by asking only for the names of 
individuals who were considered to be supportive, a more neutral definition of network membership similar to the one used by Wellman (1979) was used. For the effective zone, subjects were asked to list "the people you know well who are not living in your home." Twelve lines were provided for names but the respondents were encouraged to use more or fewer than the spaces allowed. They were then asked to give information about the age, occupation, role relationships, frequency of contact and knowledge of the person's epilepsy. Since the questionnaire was self-administered, it was obvious that five questions would have to be answered for each person named which may have had an inhibiting effect on the number of persons named. Fischer (1982) found that reluctant interviewees named fewer network members than cooperative ones. For the intimate zone subjects were asked by the interviewer to select up to five names from this list who are "most important to you." All the men who had named five or more people originally selected five people for the second list. Men who had named fewer than five people on the first questionnaire included all of their nominees on the second list. These names were listed on a new matrix and additional questions were asked about them. These questions dealt specifically with the amount and kind of support received and feelings about the 
relationship. A third set of questions was asked about members of the household. The interviewer also obtained information about the density of the whole network in response to the question "How many people on this list know each other?" The areas covered for each zone are summarized in Appendix C, Table XVII.

\section{CONSTRUCTION OF VARIABLES}

In order to reduce the complexity of the large data set, data about individual members of the network were aggregated to the subject level and added to the subject file. Composite variables measuring various network attributes were also created.

\section{Aggregating the Network Data}

Data on the members of the interviewee's networks was entered as raw data in a file. Network variables were created using the SPSS subroutine AGGREGATE. Data on each characteristic of the network was aggregated by zone as a sum, a mean, an absolute value or percentage depending on which measure was most appropriately descriptive. The variables created through this process were added to the

subjects' files. This procedure is somewhat difficult using the SPSS procedure because the output of the aggregate procedure is written in binary format which must be converted in order to be included in a standard SPSS 
data file. This makes it difficult to move easily from the network to the focal individual level of data in the SPSS data handing system.

Aggregation of the network data is necessary in order to relate the data about the network to the characteristics of the individual who is the focal person in the network. In choosing the appropriate statistic to use to measure a particular network variable, however, some of the richness of the data is lost. There are few guides in the network literature at this time to aid in the selection of the most appropriately descriptive statistic. For this study, both percentages and actual counts were often made for the same variable (e.g. number and per cent of friends in the network). Totals and averages were also compared with each other for some variables (e.g. number of contacts).

Density is an aggregate measure of the ratio of the actual number of ties between members of the network compared to the possible number of ties. Density of the network was computed according to the formula:

$$
\begin{aligned}
\text { density }=\frac{2(\mathrm{Na})}{n(n-1)} & \\
\mathrm{Na}= & \begin{array}{l}
\text { number of actual } \\
\text { relationships }
\end{array} \\
\mathrm{n}= & \begin{array}{l}
\text { number of persons } \\
\text { in the network }
\end{array}
\end{aligned}
$$


The number of interconnections between friends and relatives was computed according to the formula:

$$
\begin{aligned}
\text { fr/fam } d=\frac{\mathrm{Na}}{\mathrm{Nf}} \times \mathrm{Nfa} & \\
\mathrm{Na} & =\begin{array}{l}
\text { number of actual } \\
\text { relationships between }
\end{array} \\
& \text { friends and relatives } \\
\mathrm{Nf} & =\text { number of friends } \\
\mathrm{Nfa} & =\text { number of relatives }
\end{aligned}
$$

The formula for density is the one mostly commonly used in network analysis. The formula for friend/family density was developed by Hirsch (1980). Ties between the interviewees and their network members were not included in the count of actual ties.

Scale Construction

Several of the areas of interest in this study were too complex to be measured by a single variable. Scales were constructed to measure these concepts. The composition of these scales will be described in general terms in this section. More specific information is contained in Appendix B. Reliability analyses, using the SPSS Reliability sub-program, were conducted of each scale to determine whether or not there was enough internal consistency among the variables of which they were composed to justify their inclusion in a composite measure. The standardized coefficient of inter-item 
consistency (Cronbach's alpha) is reported for each scale.

Stressor. First, a measure, SEVERITY, was created in which seizure types were arranged from most to least severe (grand mal to minor and focal). They were then combined with frequency in the order which maximized the correlation between severity and the outcome measures. In order to attempt to take into account the psychological impact of epilepsy as well as physical symptoms a composite measure was developed which incorporated both type and frequency as well as other evidence of the importance of the epileptic condition to the subject. The reliability (Cronbach's alpha) of this scale, EPSCORE, was .62 for this sample.

Reaction to stressor. A five-item attitude scale, ANXIETY, constructed for another study (Ryan, Kempner \& Emlen, 1980), which measured the extent to which the person perceived epilepsy as a limitation was used as a subjective measure of the reaction to the stressor. The reliability of the scale was 0.55 for this sample. Personal characteristics. Two scales from the Tennessee Self Concept Scale were used to measure different aspects of personality. Although the scale provides scores on various aspects of self concept, the reliability and validity of these subscales has been 
questioned (Wylie, 1974). For this analysis only two overall measures were used: positive self concept which is the overall measure of self concept using all 90 items and deviant self concept which is a scale that has been shown to discriminate normal subjects from those with diagnosed psychopathology. The Tennessee self Concept scale is not a diagnostic test, however, and the deviant self concept scores should be regarded cautiously. It has been found that twenty per cent of normals will be misidentified as deviant (Wylie, 1974).

A measure of socio-economic status was created using an occupational classification system originally developed by the National Opinion Research Center (Hatt \& North, 1947; Hodge, Siegel \& Rossi, 1964) and used by the United States Census. A score is assigned to each occupation based on general ratings of occupational prestige and esteem.

Social participation. An index of social participation was constructed from a number of items which measured generally how frequently the interviewee interacted with others in a social context. The items are quite similar to those used in a number of other studies. The reliability of the index was .57 .

Network support. Separate measures of specific types of help (i.e. job-related, material assistance and 
emotional support) were creating by aggregating the responses for all network members to each item. They were also added together to form a combined measure of how many persons provided these forms of support and how much they provided. The reliability of the general assistance score was . 64 .

A measure of help specifically directed toward helping the person deal with epilepsy was also created by adding together the number of things members of the network did to help the focal person cope with epilepsy such as reminding him to take medication, helping him avoid stress and taking him to the doctor. Again this is a combined measure of how many persons provided this form of assistance and how much was provided.

The subjective component of support from the network was assessed by the percentage of people in the network who, in the subject's opinion, had made it easier for him to cope with epilepsy. Two other measures were created in the same fashion, measuring the percentage of relationships in the network which had been negatively affected by the fact that the subject had epilepsy and how satisfied the subject was with the relationships. These two measures reveal one of the difficulties inherent in the aggregation process. A man who had only one person in his network and who assessed the impact of epilepsy on 
this relationship as negative would receive a score of 100 per cent on this variable while a man with five relationships, two of which were affected negatively would receive a score of 20 per cent. Thus, these measures are better conceived of as measures of the overall impact of epilepsy on the network (in the man's estimation) than as measures of the amount of strain or subjective support.

Family support. No questions about general assistance were asked about family members. Since the primary focus of this study was on the personal networks rather than the families of men with epilepsy and interview time was Iimited, questions about family relationships were limited to allow more time for exploration of the network.

The measures of epilepsy-related assistance, subjective support, and the effect of epilepsy on the relationships were created in the same way as those for the network and the same cautions apply.

Employment. Since we had employment data at two periods of time for each man, we were able to create a more complex measure than simply whether or not the man was employed at the time of the interview. A measure of employment was developed which took into account patterns of employment and satisfaction with the current job as well as whether the individual was employed at the time of 
the survey. The reliability of the employment measure was .67 for this sample.

Life satisfaction. While employment is an important indicator of successful functioning in adult roles, it is not the sole criterion. Therefore a general measure of life satisfaction was also included as an outcome measure. It was composed of the response to a general question "How satisfied are you with your life as a whole these days?" and the responses to a nine-item semantic differential scale developed by Campbell, Converse and Rodgers (1973) to cover specific areas of well-being. Two items were discarded because they lowered the reliability of the scale. The reliability coefficient of the final scale was .90 .

\section{DATA ANALYSIS}

\section{Descriptive Analysis}

One of the objectives of this research was to take a fine-grained look at the elements of support as they related to each other and to the other variables of interest. This was done through the use of frequencies, cross tabulations and zero-order correlations.

\section{Hypothesis Testing}

Major hypotheses of the model were tested with multiple regression. Multiple regressions were used to 
test for the effects of support, controlling for other variables and to test for interaction effects. The procedure followed was that recommended by House (1981). First, scattergrams of the relationships among the variables were examined for linearity. Then a series of multiple regressions were performed using the stressor, personal characteristics, coping response and support measures as independent variables and employment and life satisfaction as dependent variables. Plots of the residuals were examined for non-linear relationships. Interaction terms, representing the interaction of the stressor and the support measure were also included as independent variables. The beta weights of the independent variables were examined for statistical significance.

\section{Qualitative Analysis}

Wilcox (1981) has noted, "Network data are particularly susceptible to inappropriate interpretation in the absence of [qualitative data]. Quantitative network data must be grounded in qualitative data"(p.276). In order to better interpret the complex findings, certain cases were reviewed in greater depth and used as examples to flesh out the findings. 
Presentation of Findings

The following chapters present the results of the analyses which were performed on this data. Chapter $V$ discusses the characteristics of the study group, comparing them to other data on men with epilepsy and to normal populations. Chapter VI presents the descriptive data on the social networks of this sample, both in terms of the various network measures and in terms of the interrelationships among the network variables. These findings are compared with those of other network studies. Chapter VII deals with similar data about the families of the men in the sample and their general level of participation in community life. In Chapter VIII, the contribution of support to outcomes when severity and personal characteristics are controlled for is assessed, elements of the model are tested using path analysis and profiles of certain cases are presented to flesh out the findings. 
CHAPTER V

INDIVIDUAL CHARACTERISTICS AND COPING

A number of factors affect whether an individual will find a chronic condition such as epilepsy a minor obstacle or a major barrier to successful independent living. This chapter will examine the individual characteristics of the study group to determine the representativeness of the group, both in terms of the general population and in comparison with other studies of men with epilepsy and will examine the interrelationships between these individual characteristics. Finally the question of the impact of epilepsy will be addressed.

INDIVIDUAL CHARACTERISTICS OF THE SAMPLE

\section{Demographics}

Individual characteristics of the study group are presented in Tables XV and XVI in Appendix C. Highlights are discussed below.

Age. No men were included in the group who were less than twenty-five years of age. Since a prime focus of the study was on employability, it was desirable to exclude those individuals who were still preparing for careers through some form of education or who were just entering the job market. It was assumed that, by the age of 
twenty-five, most of the men would have had the opportunity to find employment. Several men over 65 were included because 65 was considered an arbitrary age for retirement and the principle measure of employment. included a measure of employment history. Two thirds of the sample were less than forty and the median age was 35.5

Education. In general the study group was fairly well educated with only 15 per cent having less than a high school education. Sixty-one percent had at least a college degree. As a group, they showed upward mobility in spite of their handicap since 35 per cent of their fathers had less than a high school education.

Residence. The sample was drawn from western Oregon with the preponderance coming from the metropolitan Portland area. Thus it can be considered, for the most part, to represent an urban population with the access to medical, rehabilitative and employment opportunities that that implies.

Driver's license. As was mentioned in Chapter II, it is difficult for people with epilepsy to get driver's licenses because they must be certified by a physician to have been seizure-free for two years. Some people cannot afford the medical monitoring that is required to obtain the certification. Almost one third of this sample did 
not have a driver's license. This would seem to be a high figure compared with a general population of males in that age group.

Employment. Twenty-seven of the men were unemployed at the time of the survey. The unemployment rate for this group was $21 / 2$ times that of the general population of the state at the time of the survey (Emlen and Ryan, 1979). While the unemployed in this sample include men who have dropped out of the labor force (i.e. are not actively looking for work) and the state figures do not, this rate is comparable to that reported in a number of other studies of men with epilepsy (Goodglass et al., 1963; Rodin et al., 1972; Schwartz 1977). A number of the men who were not employed were receiving disability benefits. Over forty percent of the men had been employed at least ninety per cent of the time since they entered the labor force or over the period of their last four jobs. Those who were employed occupied a wide range of professional, skilled and semi-skilled positions. One-fifth were unskilled workers. Their earnings for the study period (1977 to 1978) reflected this range of occupations, ranging from zero to $\$ 50,000$ per year.

Marital status. One study of male and female epileptic outpatients reported that 46 per cent had never married compared to 16 per cent of the general population 
(Edward,1974). Two-thirds of this sample, however, were married, almost half having dependent children as well. Children under five were excluded from the analysis of support received from household members. Nine men in the group were still living with their parents. Epilepsy. This group reported the full range of epileptic seizure types (grand mal, petit mal, psychomotor, minor and focal) and frequencies (from multiple daily seizures to a few in a lifetime). The distribution of seizure types and frequencies falls within the ranges of the studies summarized in the Commission Report (1977, p.22). About one-third of the sample was currently experiencing less than one seizure per year. Almost all of the men were currently taking anti-convulsive medications and many had been doing so for many years. However, two-thirds of the men acknowledged that they forgot to take their medication at least once a week. The majority of the sample had developed epilepsy before the age of twenty. Twenty percent of the men were using rehabilitative or employment services at the time of the survey and about half of them had used them in the past.

Attitudes and Self Concept

Life satisfaction. In response to the question "How satisfied are you with your life in general these days?" 
the responses of this group were comparable to those of a national, randomly selected sample in distribution but were more negative (Campbell et al., 1973). Thus thirty-four percent of this group said they were highly satisfied compared to sixty-two percent of the national sample and eight percent said they were highly dissatisfied compared to three percent of the national group. Figure 3 shows the distributions of the two sets of scores.

Tennessee Self Concept Scale. There was a similar response pattern to the Tennessee Self Concept Questionnaire. The Number of Deviant Signs Scale, the best single index of psychopathology, was more than one standard deviation above the norm. The Total Positive score, reflecting the overall level of positive self-esteem was slightly lower than the norm. Although the subscale scores are not considered very reliable, in this case they do reflect what might be expected in this group with a physical handicap. While the group was comparable to normal groups in terms of their feelings of self worth and social adequacy li.e. as a family member and friend) they were lower in their evaluations of their perceptions of their physical and behavioral self image. Attitudes toward epilepsy. Several aspects of the men's attitudes toward epilepsy were also measured. They 


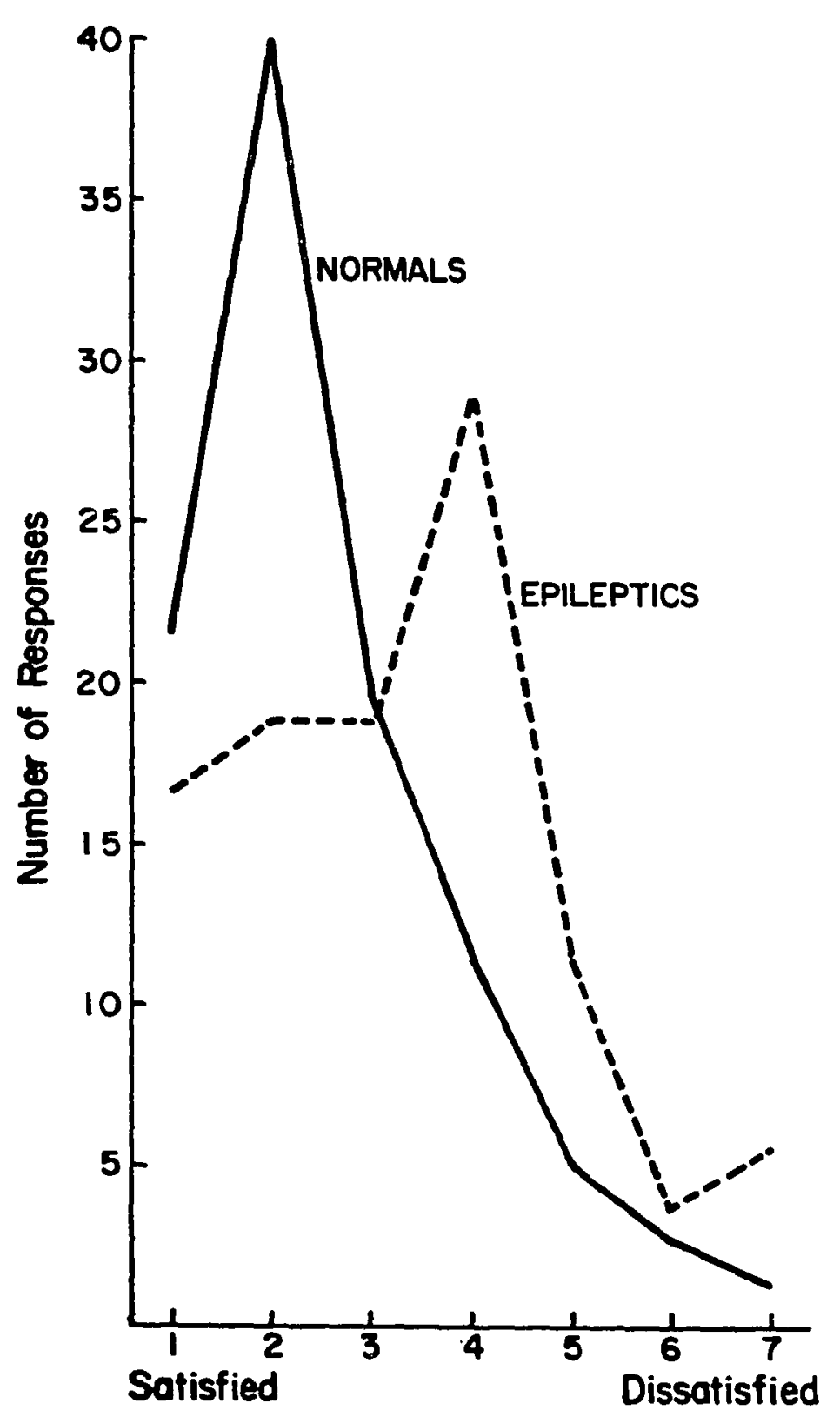

Figure 3. Comparison of Life Satisfaction Scores 
were asked how important epilepsy had been in their lives. Responses were polarized with thirty-three percent feeling that it was unimportant and thirty-eight percent feeling that it was quite important. Interestingly, their feelings about the importance of epilepsy were not correlated with the severity of their symptomatology although they were more likely to be using epilepsy-related services if they felt that epilepsy was important in their lives ( $r=.22, p=.01)$.

Th.: adequacy of medical treatment did not seem to be a problem for this group. Eighty-eight percent were satisfied with the medical treatment they had received for their epilepsy. However, approximately half felt that they had experienced discrimination in employment due to epilepsy. Thirty-three per cent said they had been fired from at least one job because of epilepsy.

\section{Representativeness}

The sampling methods employed in this study ensured that the sample contained more subjects who could be considered "normal" than a sample drawn from a clinical population would have. Nonetheless comparisons of this sample with other normal populations show that they were deviant in several respects. The unemployment rate for this group was higher than for all males in the state. One third of these men did not have drivers' licenses. As 
a group, the men had lower self concepts and lower life satisfaction scores than normal comparison groups.

These indicators may be taken as evidence of the "price" paid for having epilepsy, even in a group whose symptoms vary from only a few seizures in a lifetime to daily seizures, whose employment history ranges from continuous employment in high status occupations to chronic unemployment and whose family status ranges from typical nuclear families to dependency on parents well into adulthood or social isolation. Thus, while examples can be found among the men in this sample of individuals who are living and functioning quite successfully, it is fair to say that, for the group as a whole, epilepsy casts a shadow over their participation in the worlds of work and family life.

It does appear however, from comparisons of this group with other studies of men with epilepsy, that this group is representative of this special population. The age distribution of this sample was similar to that of the population of men with epilepsy having driver's licenses in the state (Emlen \& Ryan, 1979). As has been already noted, the distribution of seizure types and the employment rates were also similar to those of other studies. 
THE IMPACT OF EPILEPSY ON FUNCTIONING.

The next most obvious question to ask is how much of this variation in levels of functioning, self concept and attitudes towards epilepsy and life in general is due to variation in the severity of the epileptic symptoms? In order to gain an accurate appreciation of the impact of epilepsy, it is necessary to separate its effects from those of other factors which could also influence outcomes. This is difficult to do in a study of a chronic disease, especially when the data is collected at one point in time. Epilepsy may have exerted an influence during childhood and adolescence, both in terms of diminished opportunities for education and socialization and in terms of family dynamics (i.e. overprotectiveness) and personality development. One way to examine the early effects of epilepsy in an adult sample is to see whether the age of onset affected self concept, the level of education attained, the likelihood of being married, socioeconomic status or the outcome measures of employment and life satisfaction. Table I shows the correlations between age of onset and these variables. Age of onset seems to have made little difference for this sample. There was no correlation between age of onset and education, severity of current symptomatology, attitudes 
TABLE I

PERSONAL CHARACTERISTICS AND OUTCOMES

AGEON SEVERITY EPSCORE ANXIFTY STIGMA AGE YPSSCN TOTPOS DEVSIGN SES SATSCORE

IGEON: Age of Onset

SEVERITY

EPSCORE: General

Impact of Epilepsy

ANXIETY: Perceived

Limitations

ST IGMA

AGE

YRSSCH: Education

TOTPOS: Positive

Self-Concept

DEVSIGN : Deviant

Self-concept

SES: Socio-economic

Status

SATSCORE: Life

Satisfaction

EMPSCORE: Employment

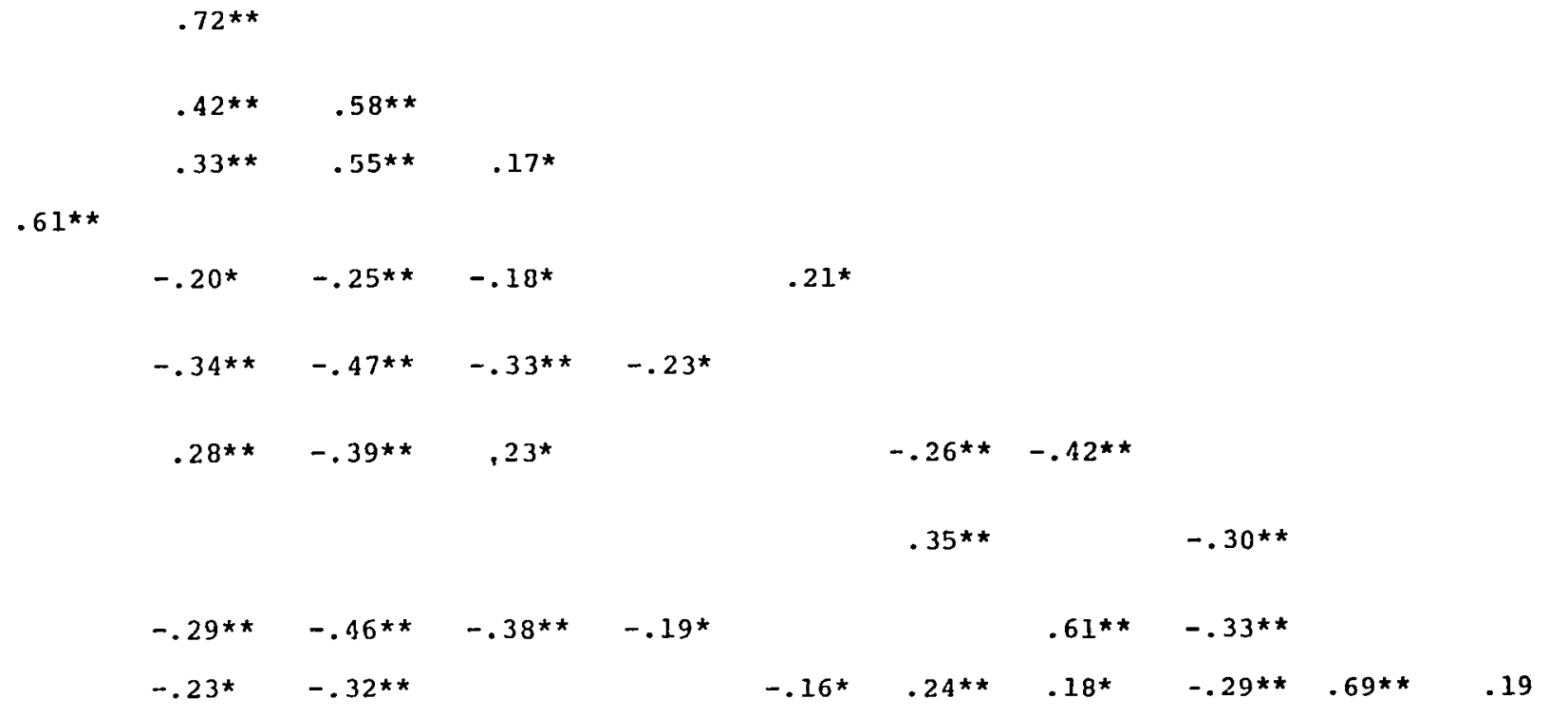

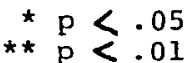

Range of $\mathrm{N}=95-100$ 
about epilepsy, or socioeconomic status. Age of onset is a crude measure in this case since it does not take into account the severity of the symptomatology. Nevertheless, the absence of significant correlations may be taken as an indication that the current level of severity adequately reflects the impact of epilepsy on functioning. Table I also shows the correlations between the two measures of epilepsy -- severity of symptoms and general impact -- and the outcome measures. The severity of current symptomatology was significantly correlated with both employment and life satisfaction. The more inclusive measure of the impact of epilepsy was somewhat more strongly correlated with employment and much more strongly correlated with life satisfaction, probably because this measure included subjective components. It can be seen, then, that epilepsy does indeed have a strong relationship with outcomes. These relationships were maximized by combining seizure types and frequencies in the order that maximized the correlation between severity and employment and by including subjective as well as objective measures in the general impact score. However, they explain only eight per cent of the variance in employment and twenty percent of the variance in life satisfaction, leaving much to be explained by other factors. 
OTHER PREDICTORS OF SUCCESSFUL FUNCTIONING

\section{Education}

As with any other sample, educational level should be predictive of employment success. For this group the correlation between highest level of education attained and successful employment was significant (Table I), but not very high. Education was not correlated with life satisfaction.

Personality

Positive self-esteem was highly correlated with life satisfaction but only weakly with employment. Number of deviant signs, the indicator of pathology on the Tennessee Self Concept Scale, was more strongly correlated with employment than was positive self concept, but less related to life satisfaction. Thus, it would seem that negative personality traits may interfere with holding a job but a positive self image is not especially helpful. It is not surprising that positive self image and life satisfaction are highly correlated since both can be considered to be measures of attitudes of general well-being. 
Age

Age was negatively related to employment, but not strongly. In another analysis performed on the same sample, Emlen and Ryan (1979) give evidence that this is indicative of premature retreat from the labor market due to the accumulated effects of epilepsy, poor education and poor employment history. Age was not related to life satisfaction.

SUMMARY

Thus we see that lack of education, age and signs of personality disturbance all affect employment success in the expected direction. Only a positive self concept is related to life satisfaction and the strength of this correlation may be based, in part, on a confounding of the two measures. Our general hypothesis that personal resources would be related to outcomes was supported in part, but the relationships, with the exception of the personality measures, were not strong, particularly in comparison with the effects of epilepsy. Table I also shows the relationships between measures of epilepsy and these other personal factors. Age is not related to the severity of the symptoms. However there are significant relationships between education and self concept on the one hand and epilepsy on the other. This would seem to 
indicate that, even though age of onset was not related to education or self concept, measures of current symptomatology are indicative of cumulative impact or, perhaps, of associated neurological damage. Therefore, it is possible that epilepsy has indirect effects on employment and life satisfaction through its effects on these other variables.

Next, we will look at the measures of social support, first to see how these men compare to other groups in their patterns of personal support and then to see how social support related to the measures of epilepsy and to the outcomes. 
CHAPTER VI

\section{SOCIAL NETWORKS}

The study of social networks is new enough that the empirical description of their structure and content still has about it the excitement of the discovery of new territory. Therefore careful measurement and comparison of social networks remains a useful exercise. While evidence is beginning to accumulate, for example, of consistency in the number of people that most people consider important to them, it is still too early to be able to state confidently the size and composition of "average networks," much less how they may be expected to vary according to personal and situational factors (Hammer, 1981).

Beyond that, the interrelationships among network variables are still being discovered and verified through comparison. Researchers are looking for empirical answers to such questions as: Are dense networks usually kin networks? Are friends of long standing more likely to know one another than new friends? Do different kinds of relationships serve different functions, for example, are strong, intimate ties better providers of emotional support and weak ties more effective when new contacts or information is required? 
To take the inquiry one step further, there is an important set of questions about how network characteristics relate to other important aspects of functioning. What is the relationship between socioeconomic status and social networks? How are personality variables related to characteristics of the social network? Do special circumstances such as urban or rural residence, or a handicapping condition affect an individual's social network?

Finally, one gets to the question of how different types of social networks affect various outcomes such as physical or mental health, employment success or ife satisfaction. We have seen in Chapter II that a number of studies have shown interesting and significant relationships between various aspects of social support, measured in terms of network characteristics, and such outcomes but no coherent, integrated picture of how these various indicators are related to each other has yet emerged.

This chapter will examine each of these areas of inquiry. The social networks of this group of men with epilepsy will be compared with those reported in the literature of other special populations and of large, randomly selected samples. It will not be possible to address all of the questions posed above because some data 
is lacking. The main intent of this study was to test a model of the contribution of support to functioning rather than to exhaustively describe the networks of the sample. Nonetheless, a number of relationships among network variables and between network characteristics and other individual characteristics can be explored.

\section{DESCRIBING THE NETWORKS}

\section{Zones}

Three of the men who were asked to list the names of people who knew them best were unable to list anyone, so for the purposes of this study, they can not be corsidered to have a network at all. Only one of these men is a true social isolate, however, because the other two are married. When the remaining 97 men were then asked to select the people from this list who were most important to them (up to five names), thirty of the men selected all of the names from their first list. These five most important people will be referred to as the intimate zone of the network. The other people from the first list who were not selected for the second list will be referred to as the effective zone. Thus of the 100 men, 97 have networks (753 names), 97 have intimate zones (437 names) and 67 have effective zones ( 316 names). Data on the networks will be presented for the network as a whole and 
for the various zones.

Size. For the 97 men who could name others who knew them well, the range of network size was from one to fifteen members. The mean was 7.5 but, more interestingly, the distribution was bimodal (see Figure 4) so it is more accurate to say that the sample divided into those who had small (6 or less) networks and those who had larger ones ( 7 to 15 members). Of course different eliciting questions produce different sorts of networks, but we saw in Chapter II that there seems to be an emerging consensus in the iiterature that most people report having from 6 to 10 important relationships with others and up to 20 more relationships with what could be considered effective zone members. As was discussed in Chapter IV, the networks of this sample may have been artificially limited by the way the data were collected. The initial instrument was a self-completed one on which twelve lines were provided for names. Respondents were encouraged to disregard the number of lines, but their presence may have had some effect, although several men did provide more than twelve names. The number of members of the intimate zone was arbitrarily limited to five. In spite of these methodological limitations, it is striking that about half of this group appears to be impoverished in terms of significant relationships. Not 


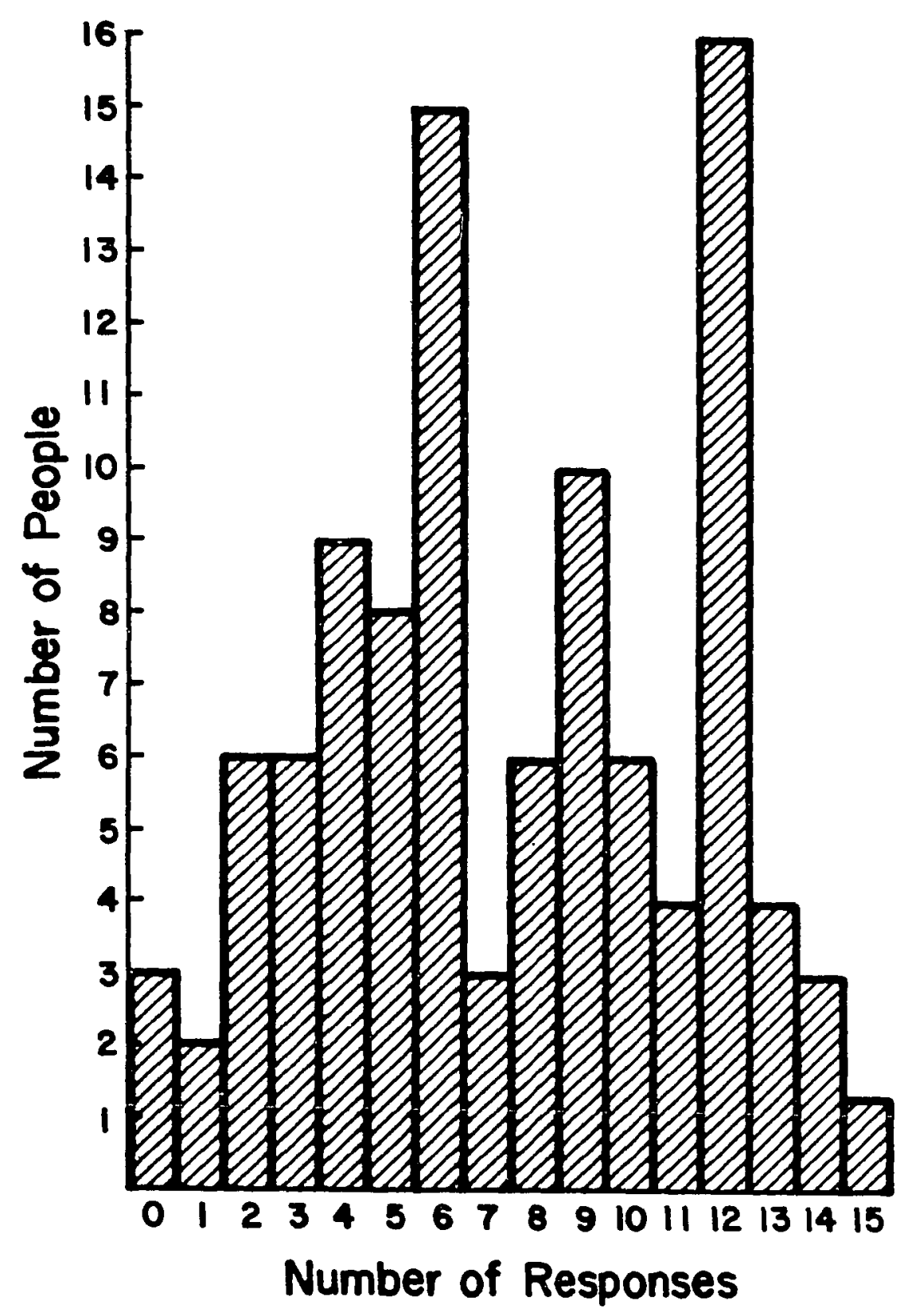

Figure 4. Frequency Distribution of Nețork Size 
only do those with larger networks have more potential sources of assistance, but their networks contain a greater variety of relationships, some of which are strong, intimate ties and others which are important but less centrally so. Again there is evidence in the literature that people who have both types of relationships are better off than those who must depend on a very small number of intimate relationships to meet their various needs (Tolsdorf, 1976: Sokolovsky et.al., 1978; Pattison, Llamas, \& Hurd, 1979). Effective zone relationships and ties that are not part of a dense cluster may offer support that is different in kind as well as in amount.

Composition. The men were asked whether the basis of their relationship with each person on their list was kinship, friendship, neighborliness, working together or going to that person for services, either professional or non professional. Friendship was the basis of the largest percentage of the relationships ( 47 per cent) and kinship was next (26 per cent). Neighbors and co-workers accounted for another 10 per cent and service providers were the smallest category, (about 5 per cent). The kinship sector appears to be smaller for this group than for those reported by Hall and Wellman (1982) and Fischer (1982). Both of their samples, however, contained women 
and women have been found to name more kin than men. The other categories were similar in size to those reported in the other studies.

Heterogeneity. Members of the networks could vary on a number of characteristics which might be significant determinants of the type of network which resulted and the rewards and costs associated with it. However, as a practical matter, the potential benefits of getting as much information as possible about each member of the network had to be weighed against the costs of fatigue to interviewer and interviewee, since each question would have to be asked about every member of the network. There were also limitations in the amount of data that could be processed and analyzed. Two aspects of heterogeneity were examined in this study: age and source of relationship. Data were also gathered about the sex and occupation of each network member but not coded or analyzed.

The age of network members ranged from 16 to 91 . The average age of the members of the network was compared to the average age of the subject in both the intimate and effective zones. In both cases the difference was quite large as was the variance (intimate zone: mean difference=11 years, s.d.=12 years; effective zone: mean difference $=20$ years, s.d.=18 years) . Not surprisingly, there was a strong correlation between the age of the 
subject and the average age of the network ( $r=.36, p$ $=.001)$. However, the correlation was stronger for the intimate zone (.61) than for the effective zone (.12) indicating greater homogeneity in the intimate zone. Variation in the source of the relationship was examined in terms of the number of different role relationships included in the network. Potentially, the subjects could have had five different role sources in their network (friend, kin, neighbor, co-worker, service provider) but the maximum number of different relationships actually found in the group was four and only four percent of the men had networks with this much diversity. Most typically, the networks had two different types of role relationship, usually kin and friends.

Multiplexity. As was mentioned in Chapter II, multiplexity has been used in the literature to refer either to the number of different role relationships in a single tie (i.e. co-worker and friend) or to the number of different kinds of exchanges that occur in a single tie (i.e. lending money and giving advice). A uniplex tie has only one type of role relationship or exchange while a multiplex tie has at least two. For this group, the former definition of multiplexity was used. Approximately 80 per cent of all relationships were uniplex. The most frequently combined relationships were 
co-worker-and-friend, followed by neighbor-and-friend and relative-and-friend. The combination of relative-and-friend was more common in the intimate zone than in the effective zone, while the combination neighbor and friend was more common in the effective zone.

Duration. Other researchers have found considerable turnover, even among these most important relationships. We have no data on actual turnover but the men were asked how long they had known members of the intimate zone of their network. Only three relationships (less than one percent) were of less than a year's duration. Twenty-nine per cent of the relationships had existed for five years or less. On the whole the networks seem to be quite stable. When the kin ties are removed, only thirty per cent of the friendships are less than six years old. Only four men had no friendships of more than a year's duration, while 80 per cent had at least one friendship that had lasted for five years or more. Frequency of contact. The men were asked how often they had been in contact with each member of their network in the previous month - in person or by telephone or letter. All of the men who had networks had been in contact with at least one member in the previous month and the mean number of contacts per network member was five. Those with both an intimate zone and an effective zone had 
significantly more contacts with members of their intimate zone ( 36 contacts in the previous month) than with their effective zone ( 26 contacts, $p=.002)$.

Density. The extent of interrelationships among network members was examined in two ways: overall density and proportion of actual relationships between $k i n$ and friends in the network.

Four men had networks of zero density and 14 had networks where the density was 100 per cent. The others were very evenly spread between these two extremes. The mean density was 49 per cent. This is higher than that reported in many studies, which is especially interesting since the kin sector was relatively small in this group and members of the household were not included in the network. Those whose networks were larger (7-15) exhibited the same range and even spread but the mean density was somewhat lower (44 per cent).

Relationships Among Contextual Characteristics

Table II shows the correlations among structural and linkage network variables. Many of them are in the expected direction although most of the correlations are not very large. There are more likely to be relationships between kin and friends when the friendships are of long standing and when the focal individual has a lot of contact with network members. Density is positively 
TABLE II

COMTEXTUAL NETWORK VARIABLES

\begin{tabular}{|c|c|c|c|c|c|c|c|c|c|}
\hline Size & 8 Friends & $8 \mathrm{Kin}$ & $\begin{array}{l}8 \text { Service } \\
\text { Providers }\end{array}$ & Diversity & Multiplexity & Duration & $\begin{array}{l}\text { Total No. } \\
\text { of Contacts }\end{array}$ & Density & $\begin{array}{l}\text { Friend/ } \\
\text { Family } \\
\text { Density }\end{array}$ \\
\hline
\end{tabular}

Size

8 Friends

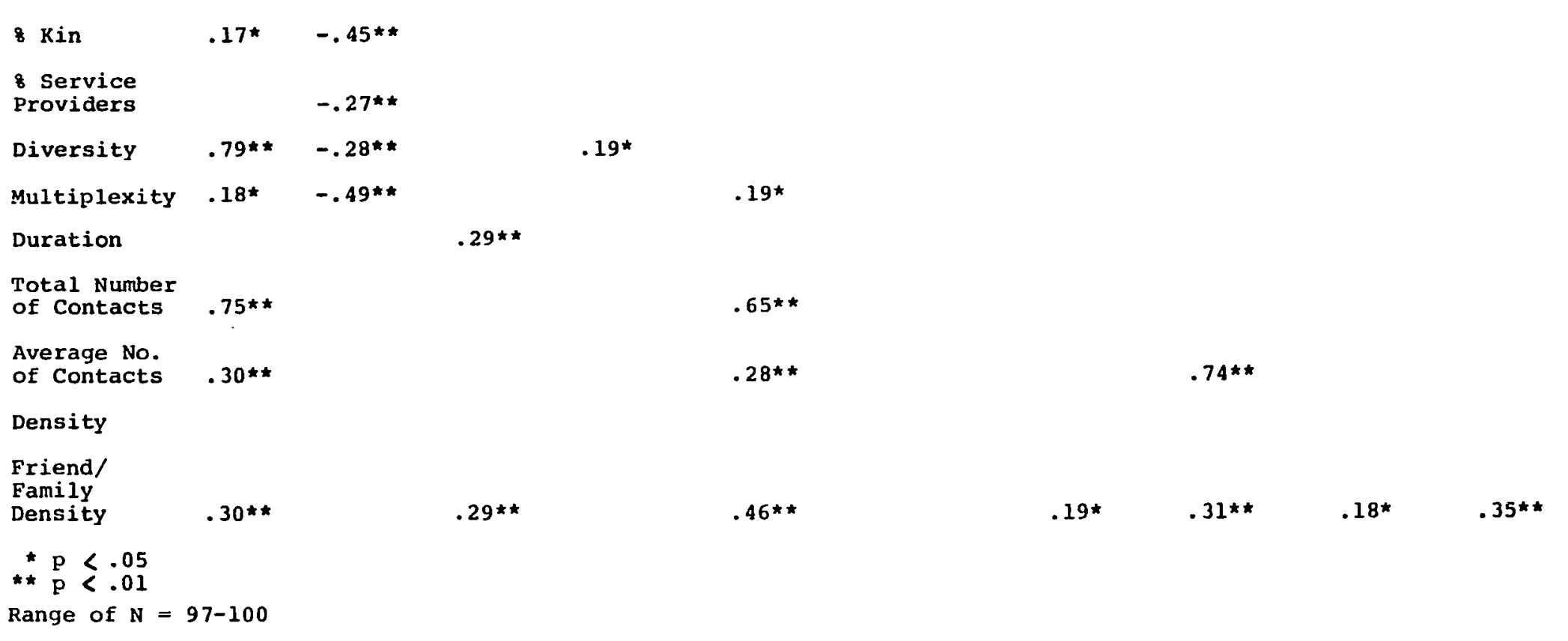


related to duration of friendships although the relationship is not significant. Networks with a high proportion of kin are more dense but not to a significant degree. Larger networks are more complex in that they have a greater number of different role relationships and a higher percentage of multiplex relationships. Network size and number of contacts are highly correlated (.75).

$$
\text { CONTENT OF RELATIONSHIPS }
$$

The men were asked a number of questions about the nature and quality of their relationships with network members, both generally and as they related to their epileptic condition. DiMatteo and Hays (1982) have argued that both the objective and subjective aspects of support are important. That is, it is important to know both what kinds of positive interactions and forms of emotional and material assistance are provided and also whether or not the person feels that his relationships with others are supportive. The two aspects may not be highly correlated.

\section{Epilepsy related}

The only question related to epilepsy asked of the network as a whole was whether each member of the network knew that the man had epilepsy. Eighty-five percent of all network members knew about the epileptic condition. 
This openness about disclosure corroborates the attitudes of this group which have been described elsewhere (Ryan et a1., 1980). However, few members of the network were likely to have been directly confronted with the epileptic condition. Sixty-three per cent of the intimate zone had never witnessed a seizure, twenty-eight per cent had seen an occasional seizure while only nine per cent had often been present during a seizure. The men said epilepsy had had no effect on eighty-seven per cent of the relationships in their networks and 54 percent of the relationships had had no effect on their ability to cope with epilepsy. A very small percentage, less than two per cent of the network members, had made it harder for the individual to cope with epilepsy.

Nonetheless, there a remains a substantial number of relationships which are acknowledged by the men in this group to be important to them in coping with epilepsy. The men were asked about objective forms of support as well as their subjective feelings of being supported. Epilepsy support scale. All indications of assistance in coping with epilepsy were combined into a single measure, epilepsy-related help. Twenty-four men received very little help, forty-one men received some help, eleven a moderate amount, only three received a lot of help. 
Subjective support. Eighty per cent of the men in this group had at least one relationship with a member of their intimate zone which they felt made it easier for them to cope with epilepsy.

\section{General support}

Emotional and material assistance. The men in this group were considerably more likely to report having received assistance from members of their network for non-epilepsy related problems. Seventy-one per cent of the men had received assistance from some member of their intimate zone in securing employment, ranging from encouragement and advice to actually finding them a job. only thirteen per cent had received no material assistance from anyone in their network and only two men had received no emotional support.

Satisfaction. Satisfaction with relationships was skewed in a positive direction. The men were dissatisfied with only three per cent of their relationships with intimate zone members and said they were very satisfied with almost 75 per cent of these relationships.

Mutuality. The exchanges were about equal in over sixty per cent of the relationships, that is, the men judged that they gave about as much as they received. The unequal relationships were more often in the direction of receiving more than giving which is interesting in the 
light of the observation of Hurd et al. (n.d.) that people are more likely to say that they give more than they receive. Perhaps this indicates that this group is, or at least sees itself as, more dependent on others.

Relationships Among Content Variables

The relationships among the content variables are presented in Table III. Objective and subjective indicators of help related to epilepsy were quite highly correlated. Material assistance and emotional support were the most strongly correlated of the four types of support. Specific, epilepsy-related support was more strongly correlated with helping to cope with epilepsy than general emotional support was. Emotional support was also most strongly correlated, of the types of support, with satisfaction with the relationship.

It should also be noted that there was a significant correlation between the amount epilepsy-related support and epilepsy having had a negative effect on the relationship, indicating that the receipt of support may have strained some relationships. The correlation between negative effects and support was strongest in the case of the subjective measure, having network members who made it easier to cope with epilepsy. It is also interesting to note that the receipt of epilepsy related assistance and emotional support are also correlated with having a higher 
TABLE III

NETWORK CONTENT VARIABLES

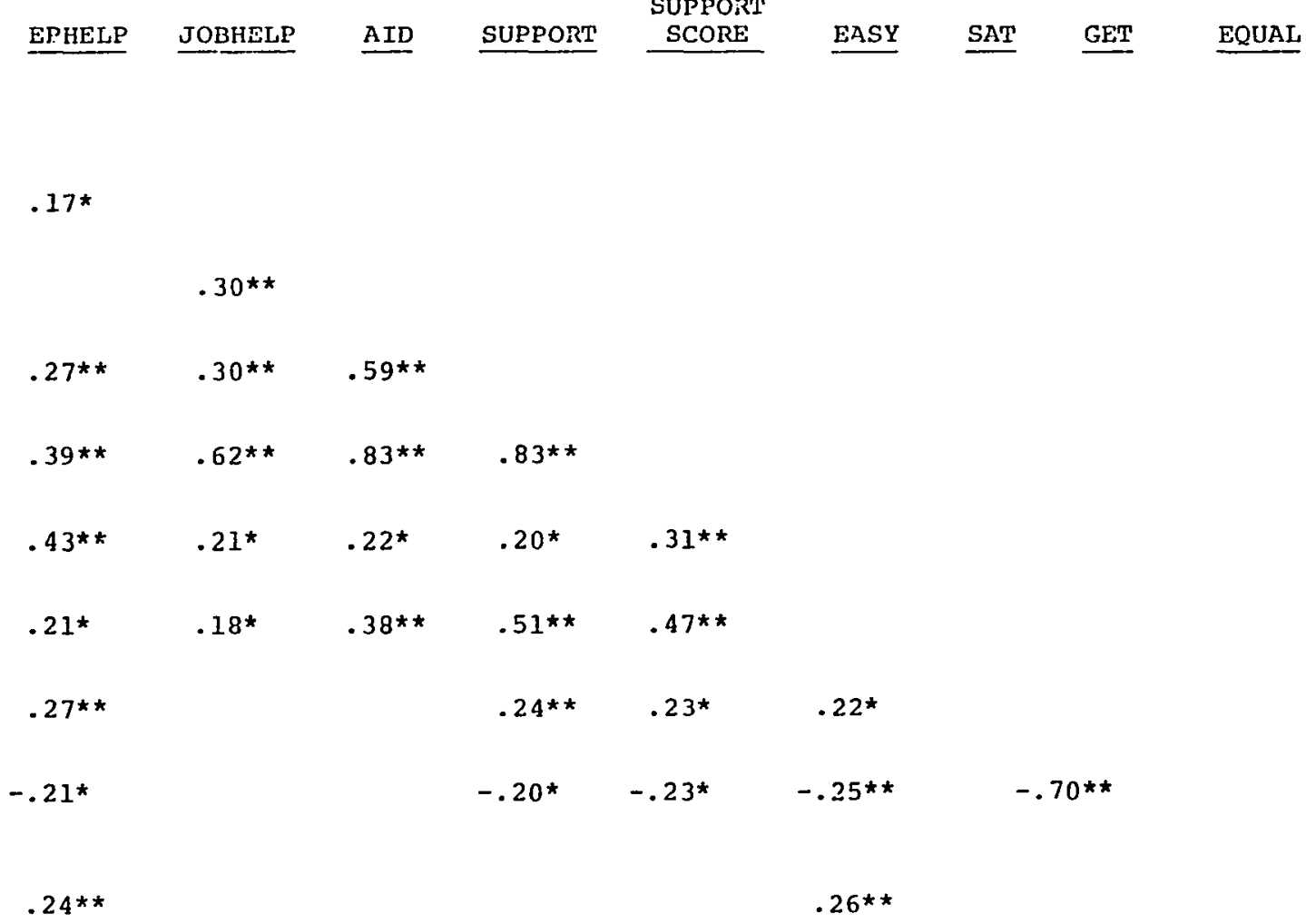

$\star \mathrm{p}<.05$

** $\mathrm{p}<.01$ 
percentage of relationships from which the focal

individual feels he receives more than he gives while that is not the case with job-related or material assistance.

Relationships between structural and Linkage Variables and Content Variables

While there are a number of significant correlations between contextual and content network variables, the correlations are fairly low, leaving a great deal of individual variation in network patterns. Nonetheless, it can be seen from an examination of the correlations in Table IV that the following contextual characteristics are associated with the provision of support: larger size, a higher proportion of kin, greater role diversity, more contact with network members and greater friend-family density. Generally, the same characteristics are associated with the focal individual's subjective assessment that network members have helped him cope with epilepsy and with general satisfaction with these relationships. However, with the exception of contact, these characteristics are also associated with epilepsy having had a negative effect on relationships. We can also see that getting epilepsy-related assistance is correlated with having a network which includes professional helpers. 
TABLE IV

\section{NETWORK VARIABLES}

8 Service

Total No.

Friend/ Family

Size 8 Friends 8 Kin providers Diversity bultiplexity Duration of Contacts Density Density

Help with Epilepsy

$.18 *$

$.17 \star$

$.26 \star \star$

$.23 *$

Help Finding a Job . 32**

$.31 \star \star$

$.17 *$

Haterial Assistance . 31**

Emotional Support $.38 * *$

$.31 * \star$

$.37 * *$

$.17 \star$

General Assistance .44*

$.17 *$

$.44 * \star$

$.24 \star \star$

$.20 \star$

Made it Basier to

$.24 * *$

$.31 * \star$

$.24 * \star$

Made it Easier to

$.21 \star$

$.49 *$ *

$.40 * \star$

$.28 * \star$

Cope With Epilepsy

Satisfied with
Relationships

$.61 * *$

.19 *

$.55^{* \star}$

$.19 *$

$.22 \star$

Get sore Than Give

$-.21 *$

.21 *

.26 *

$.31 \star \star$

Equal Exchange

$-.23 \star$

$.20 *$

.20 *

Epilepsy Affected

Relationships

Negatively

$.19^{\star}$

$.18 *$

* $p<.05$

** p<.01

$N=97$ 
PERSONAL CHARACTERISTICS AND NETWORK VARIABLES

Table $\mathrm{V}$ shows the relationships between network variables and individual characteristics.

Age

Younger men have younger, larger networks containing more friends. Not surprisingly, they have known their friends for a shorter time. In spite of having more friends in them and the relationships being of shorter duration, the younger men's networks tend to be more dense $(r=-.15, p=.07)$. They are more likely to report having received assistance from members of their network but no more likely to be satisfied with these relationships than older men are.

\section{Socioeconomic status}

Education was positively correlated with having a large network as is occupational status (although the latter correlation is not significant). The frequently observed relationship between social status and network size is therefore as true for this special population as it is for more general ones. High socioeconomic status networks are also likely to contain a larger number of friends and a smaller proportion of relatives. They also contain fewer service-giving professionals. In spite of the larger size of the networks of the 
TABLE $\mathrm{V}$

PERSONAL CHARACTERISTICS, NETWORK VARIABLES AND OUTCOMES

\begin{tabular}{|c|c|c|c|c|c|c|c|c|c|c|c|c|}
\hline & $\begin{array}{l}\text { Age } \\
\text { of } \\
\text { Onset } \\
\end{array}$ & $\begin{array}{l}\text { Sev- } \\
\text { erity }\end{array}$ & $\begin{array}{l}\text { General } \\
\text { Impact } \\
\text { of } \\
\text { Epilepsy }\end{array}$ & $\begin{array}{c}\text { Perceived } \\
\text { Limita- } \\
\text { tions } \\
\end{array}$ & Stigma & Age & $\begin{array}{l}\text { Educa- } \\
\text { tion } \\
\end{array}$ & $\begin{array}{l}\text { Positive } \\
\text { Self- } \\
\text { Concept } \\
\end{array}$ & $\begin{array}{l}\text { Deviant } \\
\text { Self- } \\
\text { Concept }\end{array}$ & $\begin{array}{c}\text { Socio- } \\
\text { Economic } \\
\text { Status } \\
\end{array}$ & $\begin{array}{l}\text { Life } \\
\text { Satis- } \\
\text { faction } \\
\end{array}$ & $\begin{array}{l}\text { Employ- } \\
\text { ment }\end{array}$ \\
\hline $\begin{array}{l}\text { Size } \\
8 \text { Friends } \\
8 \text { Kin }\end{array}$ & $-.19 *$ & & & & & $-.34^{\star \star}$ & $.28 * \star$ & & $\begin{array}{l}-.16^{\star} \\
-.22^{\star}\end{array}$ & $.28 * \star$ & & $.19 *$ \\
\hline $\begin{array}{l}\text { Service Providers } \\
\text { Diversity } \\
\text { Multiplexity }\end{array}$ & & & & & $.22 \star$ & & $\begin{array}{l}.21^{\star} \\
.26^{\star} \\
.17^{\star}\end{array}$ & & & $-.20 *$ & $.25^{\star \star}$ & $-.22 \star$ \\
\hline $\begin{array}{l}\text { Duration } \\
\text { Total Number }\end{array}$ & $.21^{\star}$ & & & & $-.21^{\star}$ & $.31^{\star *}$ & & & & & & \\
\hline $\begin{array}{l}\text { of Contacts } \\
\text { Average Number } \\
\text { of Contacts }\end{array}$ & & & $-.18 \star$ & & & $\begin{array}{l}-.31^{\star \star} \\
-.21 \star\end{array}$ & $.17^{\star}$ & $.19 *$ & $-.19 *$ & & $\begin{array}{l}.27 \star \star \\
.27 \star \star\end{array}$ & \\
\hline $\begin{array}{l}\text { Density } \\
\text { Friend/Family }\end{array}$ & & & & & & & & 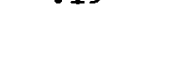 & .28 & $.22 \star$ & & $.22 \star$ \\
\hline $\begin{array}{l}\text { Density } \\
\text { Help With Epilepsy } \\
\text { Help Finding Job }\end{array}$ & & & & $.19 \star$ & & $\begin{array}{l}-.19^{\star} \\
-.21^{\star}\end{array}$ & $.28 * \star$ & & & $.22^{\star}$ & $.1 .9 \star$ & $.24 * *$ \\
\hline Material Assistance & & & & $.25 \star$ & & & $.17^{\star}$ & & & & & $.19 \star$ \\
\hline Emotional Support & & & & $.17 \star$ & & & $.26 \star \star$ & & & & & $.21 *$ \\
\hline $\begin{array}{l}\text { General Assistance } \\
\text { Made It Easier To }\end{array}$ & & & & $.24^{\star \star}$ & & $-.20^{\star}$ & $.25^{\star \star}$ & & & & & $.18 *$ \\
\hline $\begin{array}{l}\text { Cope with Epilepsy } \\
\text { Satisfied With }\end{array}$ & & $.18 *$ & $.30 * \star$ & $.35 * \star$ & & $-.17 *$ & & & & & $-.17^{\star}$ & \\
\hline $\begin{array}{l}\text { Relationships } \\
\text { Get More Than Give }\end{array}$ & & & $-.19 \star$ & & & & $.18 *$ & $.19 *$ & $-.19 \star$ & $-.17 \star$ & $.27 \star \star$ & $\begin{array}{r}.17 \star \\
-.17^{\star}\end{array}$ \\
\hline $\begin{array}{l}\text { Equal Exchange } \\
\text { Epilepsy Affected } \\
\text { Network Negatively }\end{array}$ & $.21 \star$ & & $-.23^{\star}$ & & -.18 & & $.17 \star$ & & $-.23^{\star}$ & $.19^{\star}$ & & $\begin{array}{l}.17 \star \\
.24 \star \star\end{array}$ \\
\hline
\end{tabular}

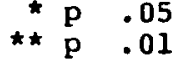


men of higher socio-economic status and the larger number of friends in them, they are more dense than the networks of men of low socio-economic status. This was also true of the networks of younger men. Mathematically, one would expect a negative correlation between size and density, since the number of possible relationships increases greatly with the addition of each new member. While the correlation was negative for this group, it was very small $(r=-.06)$. These observations about the networks of younger men and men of high socioeconomic status indicate that factors other than mathematical probability may be operating. While friends do not necessarily have to know one another, as, presumably, most relatives do, the networks of these men appear to contain clusters of friends while the networks of lower socioeconomic status men contain fewer and more dispersed ties.

The higher status men report receiving a good deal of support from their networks but on the basis of exchanges that are more likely to be equal. They are quite satisfied with these relationships.

\section{Personality}

One of the most frequently made criticisms of the focus on social networks as potential mediators of stress is that the networks are simply the outward manifestation of certain individual traits and characteristics which are 
the "real" predictors of successful coping. We have just seen that, in this group, the possession of certain resources, for which education and socioeconomic status may be taken as indicators, does seem to be associated with having a network which is also rich in resources and actively supportive. The personality measure which was included in this study does not show the same pattern of relationships, however. Men with a good self-concept were no more likely to have larger, denser, or more multiplex networks. They were no more likely to have a large number of friends. The average age of their networks was older but this may be a result of the significant relationships between age, age of the network and self concept. They did not receive more support than men with a low self-concept, but they were more satisfied with their relationships with the members of their networks.

The measure of psychopathology, deviant self concept, was negatively correlated with both size of network and total number of friends. Therefore, it appears that having a good self concept does not ensure a large network or many friends for this group, but having a pronounced degree of personality disturbance makes either very difficult. The men with disturbed personalities also had fewer contacts with network members. Their relationships were unlikely to involve equal exchanges or 
to be satisfactory but there was no relationship between disturbance and the amount of support received.

\section{Epilepsy}

Network size was not related to either of the measures of the severity of epilepsy. The networks of men whose epilepsy was severe were more likely to contain professional service providers but epilepsy did not affect the composition of the network in other ways. Those with more severe symptoms were more likely to have received epilepsy-related assistance from members of their networks and to have had unequal exchanges. While they acknowledged that this assistance helped them cope with their illness, it made the relationships less satisfactory.

On the attitude measures of feelings of stigmatization and perceived limitations or anxiety, several interesting relationships emerged. Those who felt more stigmatized were more likely to have professionals in their networks and to have friendships of shorter duration. Those who perceived themselves as limited received more assistance from members of their network and reported that members of their networks had made it easier for them to cope with epilepsy. Those who feel more stigma and those who are more anxious about their epilepsy are both likely to have more severe symptoms but those who 
feel stigmatized may feel more reluctant to ask for help from non-professionals in their networks while those whose anxiety level is higher may communicate their need for assistance to members of their networks. It may also be true that help from professionals is more stigmatizing and that help from network members is more likely to raise anxiety levels.

There is a strong positive relationship between receiving objective, epilepsy-related assistance and subjectively perceiving that they have a network which helps them cope with epilepsy.

\section{NETWORKS AND OUTCOMES}

We have been able identify a number of network characteristics which are associated with the provision of support. The next question is, how do these supportive characteristics relate to the outcome measures (see Table V)? Of the specific measures of the content of support, while the general measure of support is significantly correlated with employment, it is not help with epilepsy or job-related assistance which appears to be most strongly correlated with employment but material assistance. The successfully employed are also more likely to feel that they participate in equal-exchange relationships. Since equal relationships are also 
correlated with education, high socio-economic status and positive self image, it may be that being successfully employed is part of a general profile of someone who has many resources and exchanges them with network members rather than that receiving general support contributes to employment success. If general support continues to make a difference in employment success when personal resources are controlled for, greater confidence can be placed in the second explanation. The strongest evidence would be if general support was even more predictive of employment when the epileptic symptoms were severe (an interactive effect)

The content measures of support do not seem to affect life satisfaction. Instead, life satisfaction is correlated with positive assessments of network relationships. This may be an example of the confounding of measures of satisfaction. However, having a network which made it easier to cope with epilepsy is negatively correlated with satisfaction.

on the contextual side, size, diversity, frequent contact and higher friend-family density, all of which were seen to be associated with the provision of support, are associated with life satisfaction. With the exception of contact, employment success does not show the same pattern. A higher proportion of friends, rather than 
relatives, is correlated with employment. Again, personal characteristics will have to be controlled for in order to determine whether these network characteristics exert any independent effects.

Once again, the most puzzling correlations between these variables are between the outcomes and the effect of epilepsy on relationships. Having a higher proportion of relationships which have been negatively affected by epilepsy has no relationship to life satisfaction and is positively correlated with employment.

\section{CONCLUSION}

The first general conclusion that can be drawn from the data is that the networks of the men in this study are similar to those described in other studies. The provision of support is associated with a larger, more diverse and more active (that is, more contact) network. Networks with a higher proportion of $\mathrm{kin}$ and more ties between kin and friends also offer more support. There is also empirical validation for the distinction between intimate and effective zones. Effective zones are more heterogeneous and there is less contact with their members. They also contain more neighbors.

The networks of this group differ from those 
reported for normal groups in certain ways that have implications for the support the men receive from them. Half of these networks are smaller than would be expected, and the proportion of $\mathrm{kin}$ is smaller than is usually reported. Some of these networks contain professional service providers, something which is unusual in the general population but might be anticipated in a disabled one. In spite of the smaller proportion of kin, overall density is higher than is usually found.

Professionals provide assistance but those who have professionals in their networks are likely to have more severe symptoms and feel more stigmatized. They are also less likely to be employed in spite of being well-educated.

Assistance from network members does not appear to have strong effects on the outcome measures. Those whose epilepsy is more severe get more support but a price is paid for it in terms of strain on the relationships. One source of strain may be their inability to repay the assistance.

In order to be sure of these conclusions, it will be necessary to control for the severity of the epilepsy and to control for the other personal characteristics which affect the outcomes. Before doing so, we will look at the support received from members of the household. 
CHAPTER VII

\section{FAMILIES AND SOCIAL PARTICIPATION}

The previous chapter focused on the relationships of this group of men with their personal networks. This chapter will describe the supportive elements of their relationships with family members and others in their immediate households and the extent to which they participate in activities in the general community which might offer them support: clubs, churches, general socializing. Both aspects of support are related to personal characteristics and to the outcome variables.

\section{THE FAMILIES OF MEN WITH EPILEPSY}

Many authorities have spoken of the strain that having epilepsy puts on the members of the affected person's family. There is concern that the epileptic child will be over-protected, that dating and marriage will be more difficult for the person with epilepsy, and that the condition will affect the decision about whether or not to have children. In addition to these fundamental effects on basic life decisions, epilepsy can affect the day-to-day aspects of family life in many ways. Family members may be involved in aspects of care and prevention of seizures, helping to make sure the person with epilepsy 
does not take unnecessary risks, deciding whether or not to disclose the condition to others, and dealing with whatever stigma is attached to having epilepsy in the family.

\section{Household types}

Marital status has frequently been used as a support measure and men, in particular, have been found to have better outcomes if they are married. Other studies have found that men with epilepsy are less likely to marry than the general population. In this group, there were basically three household patterns. The majority of the subjects (69 per cent) lived in nuclear families in which they were the head of household. The second largest group (22 per cent) lived alone or with a roommate (those living with a girlfriend were counted as nuclear families). The smallest group ( 9 per cent) lived with their parents. The unequal sizes of the groups makes comparisons difficult but the latter two groups were grouped together in order to create more equally sized groups and some comparisons were made, based on mean differences between the two groups. Differences between the groups are discussed below. All are significant at the .05 level. The two groups were not very different in terms of age, education, socioeconomic status or the severity of 
their symptoms. Those in nuclear families had the best self concepts.

In terms of network characteristics, the men who lived alone or with their parents did not compensate for the lack of a marital relationship by having supportive informal networks. Married men had the largest networks and the most diverse networks, containing a higher percentage of kin. Men who lived in nuclear families were more likely to say that members of their network had helped them cope with epilepsy although they were not more likely to have received specific forms of assistance. Men who lived alone may have been compensating for the lack of informal relationships in another way, since they were more likely to list professionals as network members. Those living in nuclear families had higher life satisfaction scores although they were no more likely to be employed.

Patterns of family support

For a number of these men, members of their households were not heavily involved in helping them cope with epilepsy. Fourteen percent of the men had never had a seizure witnessed by a member of the household. 38 per cent had never received any help with medications. Nevertheless, the majority (60 per cent) of the men who 
did not live alone did have family members who were involved to some degree with helping them deal with epilepsy.

The men were only asked about epilepsy-related help from family members. They were not asked whether members of their families provided general forms of support. The objective and subjective measures were not correlated as they were for the intimate zone. Receiving specific epilepsy-related help did not affect relationships negatively as it did when network menters provided this form of assistance.

Table VI shows the relationships between family support and personal characteristics. Getting help from household members is correlated with the general measure of the impact of epilepsy, more strongly with the emotional aspects, anxiety and stigma, than with the severity of symptoms. The strain that having epilepsy places on family relationships is also shown by the correlations between the measures of severity and the negative effect of epilepsy on these relationships. Those with a low self concept are also more likely to think that epilepsy has affected relationships negatively. It is also interesting to note the negative correlation between strain and socio-economic status. In sum, it appears that epilepsy may have a negative effect on family life when it 
TABLE VI

FAMILY SUPPORT, PERSONAL CHARACTERISTICS AND OUTCOIES

\begin{tabular}{lll} 
Help with & Made It & Epilepsy Affected \\
Epilepsy & To Cope & Relationships \\
\hline
\end{tabular}

Age of Onset

Severity

$-.25 * * \quad .31 * *$

General Impact

of Epilepsy

$.23 *$

$.38 * *$

Perceived

Limitations

$.18 *$

$.27 * *$

Stigma

$.34 * \star$

$.24 * \star$

Age

Education

Positive Self-

Concept

$$
\begin{aligned}
& -.28 * \star \\
& .24 * * \\
& -.21 * \\
& -.31 * *
\end{aligned}
$$

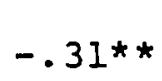

Deviant Self-Concept

Socio-economic

status

Iife Satisfaction

Employment

$* \mathrm{p}<.05$
$\star \star \mathrm{p}<.01$ 
is more severe, when it is felt to be more stigmatizing and when the family has fewer economic resources.

The correlations between family support and network support reinforce the findings of the comparisons of married and single men. Help from household members does not take the place of help from the network but is offered in conjunction with it. Table VII shows that those who are receiving help from their families are also receiving both epilepsy-related and general assistance from the network.

As Table VI shows, neither specific help from the family with medical aspects of managing epilepsy nor the general assessment that family members have helped them cope compensate for whatever problems they have that are keeping them from being employed nor do they contribute to Iife satisfaction. On the other side of the coin, those who said that epilepsy had had a negative effect on these relationships were more likely to be dissatisfied with their lives.

SOCIAL PARTICIPATION

Having epilepsy can also have an impact on a person's ability to participate in more general forms of sociability. Having dinner in a restaurant, participating in clubs or churches, engaging in sports or hobbies may 
TABLE VII

FAMILY SUPPORT AND NETWORK CHARACTERISTICS

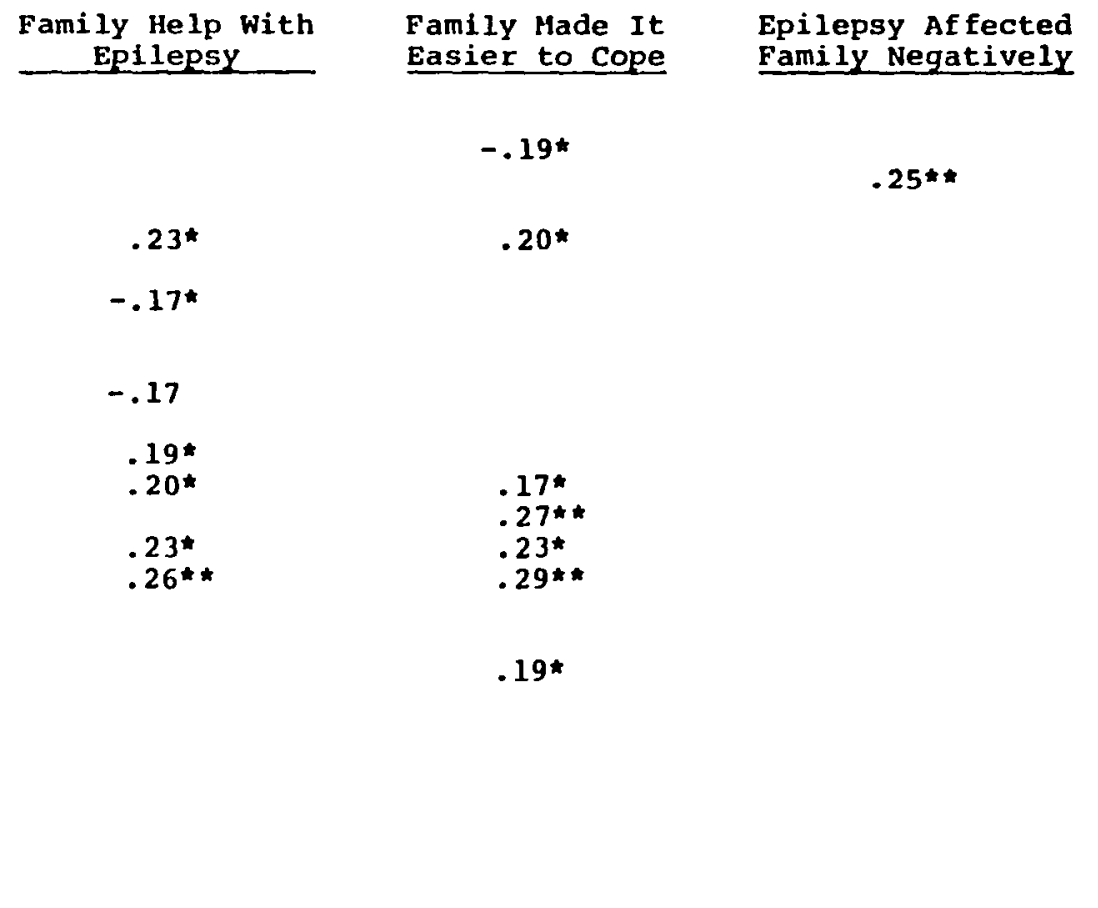


all be curtailed because of seizures or the fear of having seizures in public places. In turn, social isolation prevents the formation of more intimate ties with new friends and probably leads to lower life satisfaction. In this study, we looked at several measures of participation: going out socially with friends, participation in organizations, satisfaction with the amount of social contact and participation in active hobbies or sports. These indicators were also combined in a single measure: general social participation.

As in a general population, social participation is associated with having personal resources (see Table VIII). A high level of participation is correlated with being younger, having more education, a positive self image and a higher occupational status. Epilepsy inhibits social participation. General social participation is associated with having a large, diverse, active and supportive network (Table IX). It is not correlated with receiving help from family members. Social participation is strongly correlated with both life satisfaction and employment (Table VIII).

There is one aspect of social participation which shows a different pattern, however. Participation in religious activities is not correlated with the possession of personal resources, positive personality measures or 


\section{TABLE VIII}

\section{SOCIAL PARTICIPATION, PERSONAL CHARACTERISTICS}

AND OUTCOMES

Church

Membership Social Participation

Age of Onset

Severity

General Impact

of Epilepsy

$-.26 * *$

Perceived Limitations

Stigma

Age

Education

$.28 * *$

Positive Self-concept

$.29 * *$

Deviant Self-concept

$-.29 * *$

Socio-economic status

$.38 * *$

Life Satisfaction

$.29 * \star$

$.36 * \star$

Employment

$.36 * \star$

* $\mathrm{p}<.05$

$\star * \mathrm{p}<.01$

Range of N - 97-100 
TABLE IX

SOCIAL PARTICIPATION AND NETWORK CHARACTERISTICS

\begin{tabular}{ll} 
Church Membership & General Social Pa \\
\hline $31^{\star \star}$ & $.42^{\star \star}$ \\
$.21^{\star}$ & \\
$.51^{\star \star}$ & \\
$.36^{\star \star}$ & $.49 \star \star$ \\
$.24^{\star \star}$ & $.42^{\star \star}$ \\
$.19^{\star}$ & $.26^{\star \star}$ \\
$.38^{\star \star}$ & $.36^{\star \star}$ \\
$.20^{\star}$ & $.27^{\star \star}$ \\
$.38^{\star \star}$ & $.33^{\star \star}$ \\
$.19^{\star}$ & $.41^{\star \star}$ \\
$.29^{\star}$ & $.32^{\star \star}$
\end{tabular}

\section{Size}

8 Friends

8 Kin

\& Service providers

Diversity

Multiplexity

Duration

Total Number of Contacts

Average Number of Contacts

Density

Friend/Family Density

Network Help With Epilepsy

Network Help Finding Job

Network Material Assistance

Network Emotional Support

Network Emotional support

Network Made It Easier To Cope

Satisfied With Relationships

Equal Exchange

$-.26 * \star$

$49 *$

$26 *$

$27 *$

33 t

41 *

$32 \star$

Epilepsy Affected Network Negatively

$\star p<.05$

** p $<.01$

Range of $N=97-100$ 
with the severity of epilepsy. However, a person who participates in religious activities is likely to have a large, diverse, dense and supportive network although not necessarily a supportive family. Church membership is strongly correlated with life satisfaction but not with employment, in spite of the correlation between church membership and job-related assistance. It would appear from these data, that participation in religious activities offers a way for the person who is lacking in personal resources to find meaningful social contact and support. This support pays off in terms in life satisfaction but is not sufficient to overcome all obstacles to successful employment. 


\title{
CHAPTER VIII
}

TESTING THE MODEL

\begin{abstract}
After exploring in some depth the supportive relationships of this sample of men with epilepsy we can now return to the major questions of Chapter I concerning the model of the effects of social support in the coping process. We hypothesized that more severe epileptic symptoms and greater feelings of being handicapped would have negative effects on employment and life satisfaction
\end{abstract} (lines $A 3$ and $A 2$ in Figure 2). Personal resources would have a positive effect (D2). Our major hypothesis was that support would have a direct, positive effect on outcomes (line B3). In addition we speculated that support might have positive interactive effects on the outcomes if high levels of symptom severity or perceived limitations called forth high levels of support (C1 and C2). Since epilepsy is a chronic source of stress, having more severe symptoms or experiencing greater feelings of being handicapped might have either positive or negative effects on the willingness of others to provide support (B1 and B2). B1 is a double-headed arrow because greater support might also decrease stress and make siezures less frequent. B2 is a double-headed arrow because support might also affect 
the individual's reaction to the stressor, in this case, his perception of being handicapped. We have already discussed many of the relationships among the various elements of the model but we will recapitulate them before testing the model by means of multiple regression analysis.

ARE THE ELEMENTS OF THE MODEL RELATED TO EACH OTHER?

The zero-order correlations of all the variables in the model except the measures of social support are presented in Table X. Figure 5 shows the model presented in Chapter I, revised to reflect the empirical relationships in this data set. All of the hypothesized relationships between the predictors and employment exist and are in the predicted direction with the important exception of the relationship between perceived Iimitations and employment which is not significant. This is an indication that the measure either does not adequately measure the subjective responses that affect employment or, more likely, that the severity of the symptoms themselves affect employment rather than their psychological impact, since the severity of symptoms is significantly and negatively related to employment. Realistically, men who are currently experiencing seizures may be less able to conceal the fact that they have 


\section{TABLE $X$}

CORRELATIONS OF ELEMENTS OF MODEI (Excluding Support Variables)

erceived

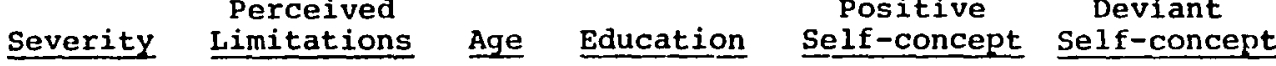

Severity Limitations Age Education Self-concept Self-concept

Age Education

Positive

Deviant

Employment

Severity

Perceived Limitations

$.42 * \star$

Age

Education

--

$-.20^{\star}$

$--$

Positive Self-Concept

$-.34$

$-.18 *$

$-.21 *$

Deviant Self-Concept

$.28 * *$

$-.33^{\star \star}$

Employment

$-.23^{\star}$

$.23 *$

$--\quad-.26$ *

$-.42 * *$

Life Satisfaction

$-.29 * *$

$-.16 \star$

$.24 * *$

$.18 *$

$-.38 * *$

$-$

$.61 \star \star$

$-.29 * \star$

* $P<.05$

$\star * \mathrm{P}<.01$

Range of $\mathrm{N}=97-100$ 

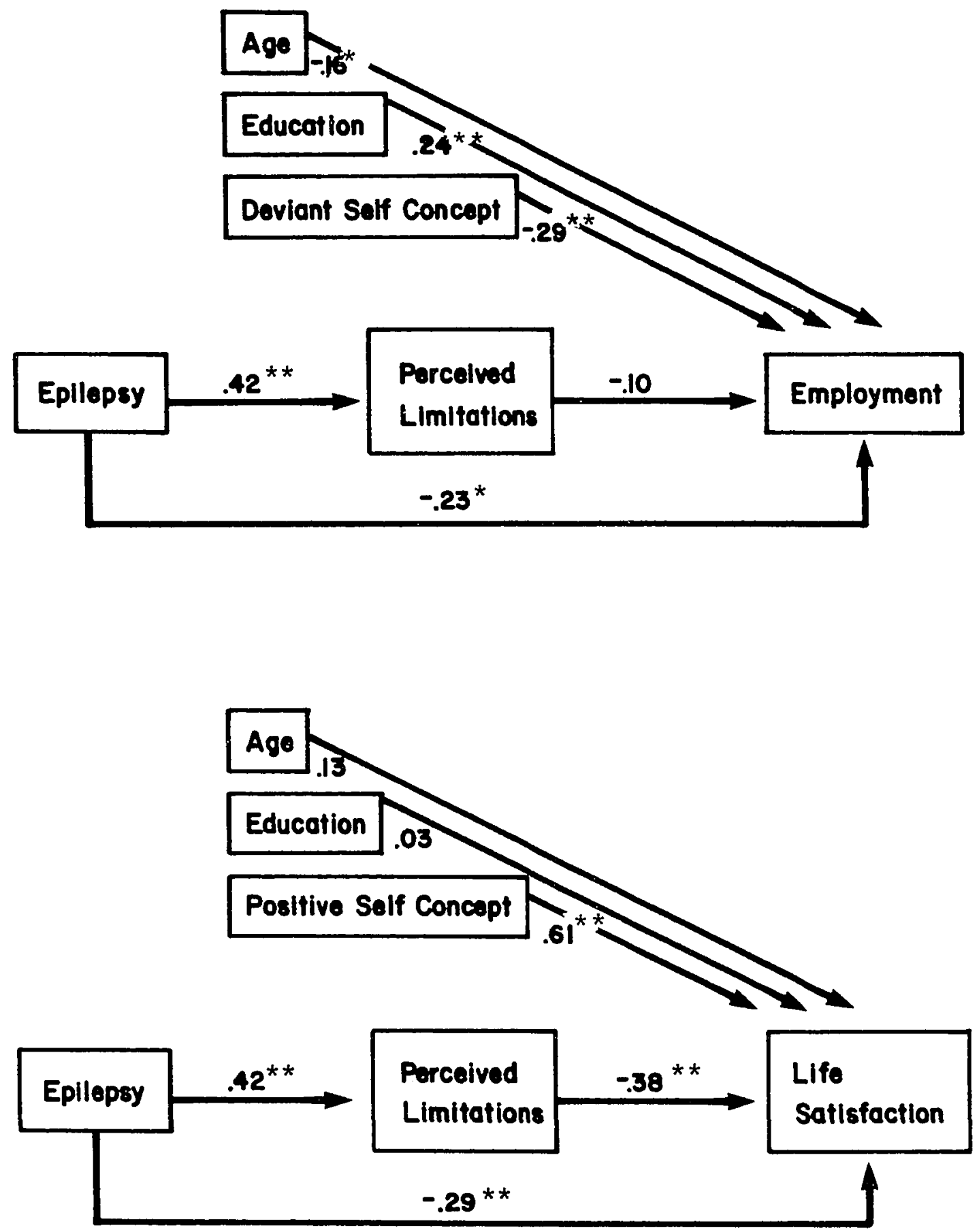

Figure 5. Revised llodel of the Coping Process

$\begin{array}{rl}* & p<.05 \\ * * \quad p<.01\end{array}$

$* * \mathrm{p}<.01$ 
epilepsy. Since employers are sometimes reluctant to hire a person with epilepsy or they may fire him when he has a seizure on the job, severity can also affect the employer's attitudes which, in turn, affect the person's chances of getting or keeping a job.

When life satisfaction is the outcome, perceived Iimitations is a significant predictor. That is, perceiving oneself as handicapped, regardless of the level of symptom severity, is a source of dissatisfaction and unhappiness. Positive self concept is the only personal resource which affects this outcome measure. The correlation matrix in Table $x$ also shows that there are significant relationships between the personal resource variables and the measures of severity and limitations. This indicates that epilepsy could have indirect effects on the outcome measures as well as direct effects. Finally, the matrix shows that the two outcome measures are not highly correlated and that they have different predictors. Since our major concern is to assess the effectiveness of social support, we will not explore the relationships among these elements of the model any further, but, instead, will analyze the relationships among the support variables and these elements. 


\section{ARE THE SUPPORT VARIABLES RELATED TO THE OTHER ELEMENTS OF THE MODEL?}

All of the variables measuring support are shown in Table XI. The introduction of a large number of measures of support increases the possibility of spurious findings due to chance correlations. By attempting to encompass the theoretically relevant indicators of support, however, we can provide a more comprehensive assessment of the utility of the concept. By incorporating all the theoretically relevant variables in the analysis and reporting all the results, significant or not, it is possible to evaluate whether or not the findings could be due to chance. Fifteen support variables were chosen to test in the model: five content variables and ten context variables. The content variables are direct measures of receiving support from members of the household and the intimate zone. Context variables measure various aspects of the structure and links in the network which might be conducive to the provision of support. Certain other aspects of the relationships of the men in this group with members of their networks have been discussed in other parts of this report but they are not considered to be direct measures of support although they may affect whether or not support is provided. They are: 
TABLE XI

SUMMARY OF THE RELATIONSHIPS OF THE SUPPORT VARIABLES

\begin{tabular}{|c|c|c|c|c|c|c|}
\hline \multicolumn{5}{|c|}{ Number of Significant Correlations with: } & \multicolumn{2}{|c|}{ Correlation with: } \\
\hline $\begin{array}{c}\text { Context } \\
\text { variables }\end{array}$ & $\begin{array}{c}\text { Content } \\
\text { Variables }\end{array}$ & $\begin{array}{l}\text { Resource } \\
\text { Variables }\end{array}$ & Severity & $\begin{array}{c}\text { Perceived } \\
\text { Limitations }\end{array}$ & Employment & $\begin{array}{c}\text { Life } \\
\text { Satisfaction }\end{array}$ \\
\hline$N=10$ & $N=5$ & $N=4^{b}$ & & & & \\
\hline $\begin{array}{l}5^{c} \\
6 \\
1\end{array}$ & $\begin{array}{l}2 \\
2(F) \\
2\end{array}$ & $\begin{array}{l}3 \\
0 \\
0\end{array}$ & & & $\begin{array}{l}.22^{\star} \\
.24^{\star \star}\end{array}$ & $.19 \star$ \\
\hline $\begin{array}{l}4 \\
4 \\
2 \\
3 \\
6 \\
3 \\
2\end{array}$ & $\begin{array}{l}1(-) \\
1 \\
1 \\
2 \\
4 \\
0 \\
1(-)\end{array}$ & $\begin{array}{l}1 \\
0 \\
1 \\
2 \\
1 \\
1 \\
1\end{array}$ & & & $\begin{array}{c}.19 \star \\
-.22 \star\end{array}$ & $\begin{array}{l}.27 * \star \\
.25 * \star\end{array}$ \\
\hline 4 & 3 & 1 & & 1 & & \\
\hline $3( \pm)$ & 2 & & 1 & 1 & & \\
\hline 5 & 4 & 2 & & 1 & $.18^{\star}$ & \\
\hline 2 & 2 & 1 & 1 & 1 & & $-.17 \star$ \\
\hline 2 & 1 & 0 & $1(-)$ & & & \\
\hline
\end{tabular}

$a_{\text {These measures are not independent }}$

$b_{\text {Both }}$ self-concept measures were counted

$C_{A 1 l}$ correlations are positive unless indicated

$\star * \mathrm{p}<.05$ 
satisfaction with the relationships; balance of exchange; and the effect of epilepsy on the relationships. They were not included in this analysis and are not listed in Table XI. Since general social participation has been used as a measure of support in many other studies of the relationship between support and coping, such a measure was developed for this group and was included as the sixteenth measure of support.

\section{Relationships Among the Support Variables}

The intercorrelations between the content and context variables summarized in Table XI indicate that there is a relationship between the structure of the network and the support it provides. With the exception of multiplexity and duration of friendships, all of the structural variables are correlated with at least one of the content measures. All of the content measures are correlated with at least two of the contextual measures.

Support and Personal Resources

We had hypothesized that personal resources such as age and personality would affect the amount of support provided. Size and social participation are related to all of the personal resource variables but many of the other support variables are only related to one of the four measures of personal resources and four are related 
to none. This offers fairly weak support for the hypothesis that personal resources affect the amount of support received from others. As was discussed in Chapter $V I$, it is particularly interesting that neither of the personality measures is related to very many support variables, although the personality measures are strongly correlated with the outcome measures.

\section{Support and severity}

The model posited a relationship between the severity of symptoms and the provision of support. In the generai model, higher levels of stressor should elicit greater amounts of support. However, in the case of a chronic stressor, the continuing burden may have "burned out" those who may formerly have been helpful. In this group of men with epilepsy, greater severity of symptoms does appear to elicit more epilepsy-related support but it is not correlated with more general assistance. These findings lend some support to the idea that higher levels of the stressor elicit more support but two of the three correlations only approach significance $(p=.08)$. Evidence that epilepsy may also have a deleterious effect on support is provided in the finding that men were more likely to say that their family made it easier to cope when their symptoms were less severe. 
Support and Perceived Limitations

Those who are receiving more help are more likely to perceive themselves as limited. We had speculated that support might have a direct effect on the reaction to the stressor by lowering the level of perceived threat or limitation or, alternatively that heightened perceptions of limitation might elicit more support from others. The positive correlations between most of the content support variables and perceived limitations would seem to support the latter hypothesis. It is also possible, however, that men perceive themselves as more handicapped by virtue of needing more help from others.

None of the context variables is related to severity or the perception of limitations, nor is social participation. Apparently, the structure and composition of these men's networks and their general participation in community life are not affected by their handicap or their perceptions of the extent to which it limits them. Since epilepsy and perceived limitations do affect education and self concept which, in turn, are related to some of the support variables, it is possible that epilepsy could have indirect effects on support but, since none of these correlations are strong, it is not likely that these effects are large. 
Support and Outcomes

Nine of the sixteen support variables are correlated with at least one of the outcome measures. Two of the five content measures of support are correlated with one of the outcome measures. Six of the context variables are correlated with one of the outcome measures; friend/family density is correlated with both. Social participation is strongly correlated with both outcome measures. Several of these correlations are significant at the .01 level but, even at the .05 level there are more significant correlations than would be expected if the results were solely due to chance.

However, these correlations hardly constitute strong evidence that support can overcome the negative impact of having epilepsy. Only one of the content variables is positively related to either outcome and it is the measure of general support. The subjective perception of support from the intimate zone of the network is negatively correlated with life satisfaction. Having service providers in one's network is also a detriment, in this case to successful employment.

The absence of any significant correlations between the receipt of either objective or subjective assistance specifically directed towards helping the person cope with epilepsy and the outcomes is particularly damaging to our 
initial prediction that support would have a direct and positive impact on the outcomes. We will now proceed to use a multiple regression analysis to see whether the zero-order correlations between the measures of support and the outcomes are affected by the other elements of the model.

RESULTS OF THE MULTIPLE REGRESSION ANALYSIS

The contribution of the support variables to the prediction of outcomes was tested by means of a hierarchical multiple regression analysis. In accordance with the model presented in Chapter I, symptom severity and perceived limitations were entered as the first set of predictors. Entered as a set, the regression procedure selects the variable with the highest correlation with the outcome measure to be entered first in the prediction equation. Since the correlation between severity and employment was much larger than the correlation between perceived limitations and employment, severity was entered first in the prediction equation for employment. The reverse was true for life satisfaction. Personal characteristics (age, education and self-concept) were entered as the second set of predictors. Positive self concept was used as the personality predictor of life satisfaction and deviant self concept for employment 
because there were empirical and theoretical reasons to think that they were the appropriate measures to use with the respective outcome measures. That is, the measure of deviant self concept was more highly correlated with employment than with life satisfaction while the opposite was true for the measure of positive self concept. Theoretically, it was plausible that a positive self concept might contribute more to satisfaction while deviant personality traits might be indicative of factors which would make employment difficult.

Table XII shows the results of the first two stages of analysis, before the support variables were entered. Severity and perceived limitations were not significant predictors of employment when entered together because perceived limitations added nothing to the effect of severity. Severity and perceived limitations were both significant predictors of life satisfaction and together they explained much more of the variance in this outcome measure $\left(R^{2}=.19\right.$ for satisfaction vs. $R^{2}=.06$ for employment).

The second stage in which personal characteristics were entered, accounted for a significant increase in the amount of variance accounted for in both outcome measures. Only the level of personality disturbance is a significant predictor of employment at this stage. We 
TABLE XII

PREDICTORS OF EMPLOYMENT AND SATISFACTION

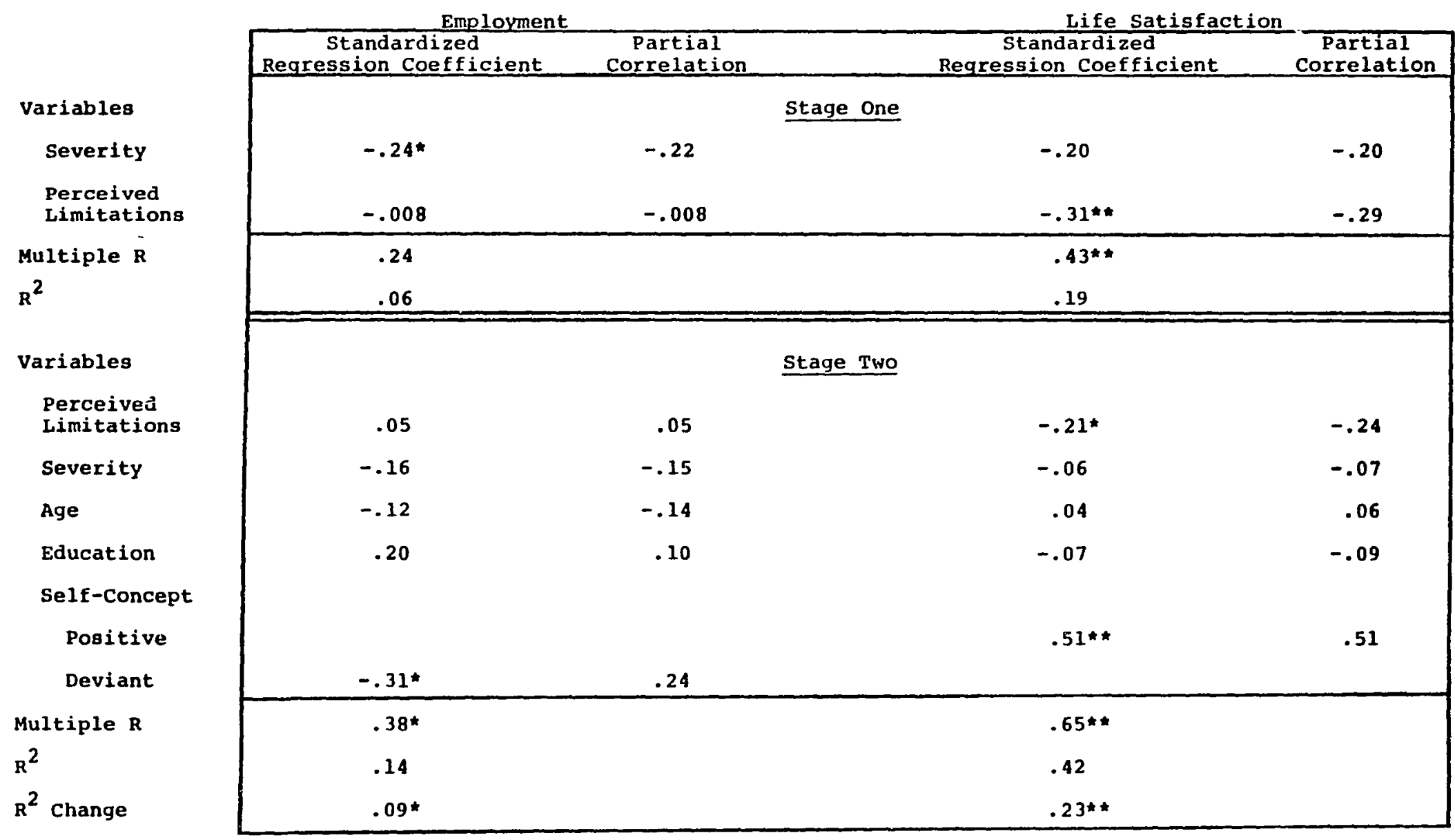

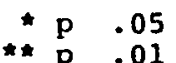

$N=100^{\circ}$ 
have already noted that the severity of physical symptoms was a significant predictor of unemployment while the psychological perception of being handicapped was not. The results of the second stage of analysis indicate that psychological factors are important but it is not the feeling of being handicapped but having generally deviant personality traits which make it difficult to be successfully employed. In fact, these personality characteristics are a more significant impediment to employment than is the severity of the physical handicap. Perceived limitations continues to be a predictor of life satisfaction but it is joined by the measure of positive self concept which makes a more substantial contribution to the equation. This can be taken as further evidence that the more objective indicators of the impact of epilepsy are not nearly as important to the general functioning of the individual as the subjective ones.

Each of the measures of support from Table XI was entered separately as a third stage in the development of the prediction equations for employment and life satisfaction. Since there were sixteen support variables and two outcome measures, thirty-two separate regression equations were tested but the first and second stages for each regression were identical. This procedure permitted 
comparison of the support measures in terms of their relative strength in the prediction equation as well as tests of the significance of each support variable as a predictor of the outcomes. It also kept the number of independent variables (6) in each regression down to a reasonable size, given the size of the sample. Table XIII summarizes the results. The initial criterion of significance was the significance of the change in the $F$ ratio produced by the addition of each support variable. Then the magnitude of the change in explained variance was assessed. The relative importance of each significant support variable was compared by comparing the standardized regression coefficients (betas). Finally, the partial regression coefficent for each significant variable was compared to its zero-order correlation with the outcome variable.

Predicting Employment

Four of the sixteen measures of support analyzed contributed significantly to the prediction of employment success when other factors are taken into consideration. They are: density, friend/family density, percentage of service providers and social participation. In addition, general support approached significance $(p=.08)$. This is more than would be expected by chance at the .05 level but not strong confirmation of the importance of support with 
TABLE XIII

SUPPORT VARIABLES $n$ S PREDICTORS OF OUTCOHES

(Stage Three)

\begin{tabular}{|c|c|c|c|c|c|c|c|c|c|c|c|c|}
\hline \multirow{3}{*}{ Structural } & \multicolumn{4}{|c|}{ Employment } & \multirow[b]{2}{*}{$\begin{array}{l}\text { Standardized } \\
\text { Regression } \\
\text { Coefficient }\end{array}$} & \multirow[b]{2}{*}{$\begin{array}{c}\text { Partial } \\
\text { Correlation } \\
\end{array}$} & \multirow[b]{2}{*}{ Multiple R } & \multicolumn{5}{|c|}{ Life Satisfaction } \\
\hline & Multiple R & $\begin{array}{c}\mathrm{R}^{2} \\
\text { Change }\end{array}$ & $\begin{array}{l}\text { Sign. of } \\
\mathrm{R}^{2} \text { Change } \\
\end{array}$ & $\begin{array}{l}\text { Standard } \\
\text { Erfor }\end{array}$ & & & & $\begin{array}{c}R^{2} \\
\text { Change }\end{array}$ & $\begin{array}{l}\text { Sign. of } \\
\mathrm{R}^{2} \text { Change }\end{array}$ & $\begin{array}{l}\text { Standard } \\
\text { Error }\end{array}$ & $\begin{array}{l}\text { Standardized } \\
\text { Regression } \\
\text { Coefficient }\end{array}$ & $\begin{array}{l}\text { Partial } \\
\text { Correlation }\end{array}$ \\
\hline & & & & & & & & & & & & \\
\hline size & & & & & & & .67 & .03 & .04 & 1.05 & .17 & .21 \\
\hline Density & .46 & .06 & .013 & 3.43 & .24 & .27 & & & & & & \\
\hline $\begin{array}{l}\text { Friend/Family } \\
\text { Density }\end{array}$ & .46 & .05 & .021 & 3.46 & .22 & .24 & .67 & .03 & .04 & 1.05 & .16 & .22 \\
\hline Linkage & & & & & & & & & & & & \\
\hline 8 Friend & & & & & & & .67 & .02 & .05 & 1.05 & -.16 & -.20 \\
\hline $\begin{array}{l}8 \text { Kin } \\
8 \text { Service } \\
\text { Providers }\end{array}$ & .44 & .06 & .025 & 3.47 & -.23 & -.24 & & & & & & \\
\hline Diversity & & & & & & & .70 & .08 & .0005 & 1.01 & .29 & .37 \\
\hline No. of Contacts & & & & & & & .68 & .04 & .008 & 1.03 & .22 & .28 \\
\hline Helping Resources & & & & & & & & & & & & \\
\hline $\begin{array}{l}\text { Help with Epilepsy } \\
\text { From Network }\end{array}$ & & & & & & & & & & & & \\
\hline $\begin{array}{l}\text { Help with Epilepsy } \\
\text { From Family }\end{array}$ & & & & & & & & & & & & \\
\hline $\begin{array}{l}\text { General Assistance } \\
\text { From Network }\end{array}$ & & & & & & & .67 & .03 & .02 & 1.05 & .20 & .24 \\
\hline Subjective Support & & & & & & & & & & & & \\
\hline $\begin{array}{l}\text { Network Made it } \\
\text { Easier to Cope }\end{array}$ & & & & & & & & & & & & \\
\hline $\begin{array}{l}\text { Family Made it } \\
\text { Easier to Cope }\end{array}$ & & & & & & & & & & & & \\
\hline Social Participation & .46 & .08 & .009 & 3.43 & .27 & .27 & .69 & .05 & .005 & 1.03 & .24 & .29 \\
\hline
\end{tabular}


respect to employment. Having a high percentage of friends in the network, which was directly correlated with employment was not a significant predictor when other factors were controlled for. The partial correlations of the other significant support variables with employment were almost identical to their zero-order correlations with employment. In other words the severity of symptoms, the perception of Iimitations and the possession of personal resources make little difference in the importance of network variables as predictors of employment.

Two of the significant contextual variables are mathematically related to each other because a network in which there are more relationships between friends and relatives will also be more dense in general. Since network size and percentage of kin are not significant predictors of employment, nor are they strongly related to density, greater friend/family density appears to be important in its own right as a predictor of employment. Having service providers in the network continues to be a significant predictor of poor employment history, even controlling for severity of epilepsy and personality disturbance. It can be seen by examining Table $V$ that persons with professionals in their networks are not very different in terms of personal characteristics, except in 
their sense of stigmatization. They also have lower socio-economic status. In terms of other network characteristics, they are more likely to have received specific help related to their epilepsy, and to feel that this assistance has helped them cope with epilepsy. But this help does not result in employment success and appears to come at the cost of greater feelings of stigmatization.

Receiving professional assistance is more likely to be an effect of unemployment than a cause, however. It may be that men who were unemployed (whether or not epilepsy was a factor in their unemployment) included more professionals in their networks because they were actively in touch with doctors, employment counselors and rehabilitation workers as they looked for work or sought disability payments or other forms of income maintenance. General social participation continues to be the strongest predictor of employment among the support variables but the increment of variance accounted for by each of the significant support measures in the employment measure is quite similar (from 5 to 8 percent) and considerably less than the variance attributed to the personality measure. In all, the variables in the model, support included, still account for no more than 21 per cent of the variance in employment. The standard error of 
the equation and of the standardized regression coefficients of the support variables are also fairly large, further indications that successful employment is difficult to predict.

The proportion of variance accounted for is at the low end of the range found in other studies of stress, support and coping. However, most studies have used health measures or measures of psychological well being as outcome measures which may be more directly influenced by (or confounded with) support or less subject to a myriad of other factors.

\section{Predicting Life Satisfaction}

The second outcome of interest was the more qualitative one of life satisfaction. The correlation between employment and life satisfaction of this group was 0.19 which while statistically significant, is quite small, indicating that they are distinctly different variables. The regression analysis using life satisfaction as an outcome is also presented in Table XII .

The relationship of support variables to life satisfaction is different in several ways from the relationship of support to employment. More support variables are significant predictors of life satisfaction than of employment and the variables which are significant 
are not identical to those whose zero-order correlations were significant. The significant predictors when other factors are controlled for are: network size, friend/family density, percentage of friends, diversity, number of contacts, general assistance from members of the intimate zone and social participation.

While the total amount of variance accounted for is considerably higher than for employment, the increment contributed by the individual support measures is of the same magnitude, ranging from 3 to 8 per cent. Friend/family density is important for satisfaction as it is for employment although the standardized regression coefficient is quite small. Having a high percentage of friends in the network is negatively related to satisfaction, although, again the standardized coefficient is small. It may be that a network that includes both $\mathrm{kin}$ and friends with a number of connections among the members may be the most satisfactory. Other indicators of gregariousness: network size, diversity, number of contacts and general social participation, are also significant predictors of life satisfaction.

Only one measure of the content of supportive interactions -- general assistance provided by members of the intimate zone -- is a significant predictor of satisfaction. Subjective support from the intimate zone, 
which was negatively correlated with satisfaction was not a significant predictor when severity was controlled for. Since several of the predictors of satisfaction could be related to network size, a separate analysis was done entering size as a control variable before entering each significant support variable. This did not diminish the significance of the effect of the other support variables.

Membership and attendance in religious organizations were included in the general measure of social participation. We have already seen in Chapter VII that the men who belonged to a church were different in many respects from those who did not and that church membership was positively correlated with life satisfaction but not with employment. In order to see whether these relationships would hold up when other factors were controlled for, a dummy variable of church membership was created and used in a separate prediction equation. Church membership was a significant predictor of life satisfaction (beta $=.26$, sign. $t=.001$ ) and accounted for 7 per cent of the variance. It was not a predictor of employment success. 


\section{INTERACTION EFFECTS}

In our initial hypotheses we speculated that support might have interaction effects as well as or instead of main effects. First, support might be effective in reducing the individual's sense of being limited by having epilepsy only when the epileptic symptoms were severe. The second possible interaction effect would be seen if support contributed to favorable outcomes only when the person perceived himself to be quite limited by epilepsy. Since our data show that the severity of the symptoms also has direct effects on the outcome measures, it was also appropriate to test the more general interaction effect that support would only affect outcomes when the level of severity was high.

Interaction effects were analyzeä by multiple regression analysis. Interaction terms were created by multiplying severity and perceived limitations by each content support variable. Only the content variables were used because they were deemed to represent the most direct measures of support. Since interaction effects can be independent of main effects, all five content variables were tested, regardless of their correlations with the outcome measures. In our model, support might have an interaction effect on the reaction to the stressor, 
perceived limitations as well as on the two outcome measures of employment and Iife satisfaction. Each interaction term was entered in a separate prediction equation for each of the three dependent variables (perceived limitations, employment and life satisfaction). Other factors controlled for when predicting perceived limitations were: severity, age, education and self concept. When life satisfaction and employment were the dependent variables, perceived limitations was also entered as a control variable. The interaction term was entered last in each regression. Table XIV summarizes the results.

In all, twenty-five regression equations were analyzed. It can be seen from Table XIV that very few of the interaction terms were significant predictors of the dependent variables. In fact, the results are scarcely different from what would be expected by chance. Nevertheless, there is a consistent pattern to the results which is interesting, particularly in the light of the lack of a main effect of the measures of epilepsy-related support and the absence of a significant relationship between perceived limitations and employment. 
TABLE XIV

PARTIAL CORRELATIONS OF IMTERACTION TERMS

Limitations Employment

Severity x Epilepsy-Related

Help From Networ

Severity $x$ General

Assistance From Network

Severity $x$ Subjective Support From Network

Severity $x$ Epilepsy-Related

Help From Family

Severity $x$ Subjective support From Family

Limitations $x$ Epilepsy-Related Help from Network

Limitations $x$ General

Assistance From Network

Limitations $\times$ Subjective

Support From Networ

Limitations $x$ Epilepsy-Related

Support From Familv

Limitations $x$ Subjective

Support From Family
N.S.
N.S.
N.S.
N.S.
N.S.
N.S.
N.S.
N.S.
N.S.
N.S.
N.S.
$-.19$
$(p=.08)$
$=.23$
$(\mathrm{p}=.04)$
$-.19$
$(\mathrm{p}=.08)$

N.S.

Satisfaction

N.S.

N.S.

N.S.

N.S .

N.S.

$(p=.27$

I.. $S$.

N.S.

N.S. 
Interaction Effects of Severity and Support on Perceived Iimitations

None of the interaction terms were significant, indicating that receiving a great deal of support, either related specifically to coping with epilepsy or of a more general nature, did not help the individual feel either more or less limited by his condition when the symptoms were severe.

Interaction Effects of Severity and Support on Employment and Life Satisfaction

None of the interactions of severity and support were significant. However, two of the interactions of limitations and epilepsy-related support approached significance and one was significant at the $p=.04$ level. In all three cases the relationship was negative. That is, men who saw themselves as more limited by epilepsy and received more epilepsy-related support from others were likely to have a poor employment history. Since the actual severity of the symptoms was controlled for, these findings are an indication that men who rely on family members, kin and close friends for help with managing their condition and who see themselves as relatively helpless fare poorly in employment. It is the pattern of dependency rather than the epilepsy per se which is the barrier to successful employment. This pattern of 
findings may explain why support from others specifically directed toward helping the person deal with epilepsy is not efficacious for this group of men. The same pattern did not hold true for life satisfaction. It is plausible that support from others in dealing with epilepsy would not be as likely to lead to decreased life satisfaction although the zero-order correlation between subjective support from the intimate zone and life satisfaction was negative. Non-epilepsy related support, which was predictive of life satisfaction, was an even more powerful predictor at high levels of symptom severity and perceived limitations.

\section{CONCLUSION}

The general conclusion to be drawn from the findings of the multiple regression analysis of the impact of support on the successful functioning of men with epilepsy is reminiscent of a children's song, "Helping," by shel Silverstein:

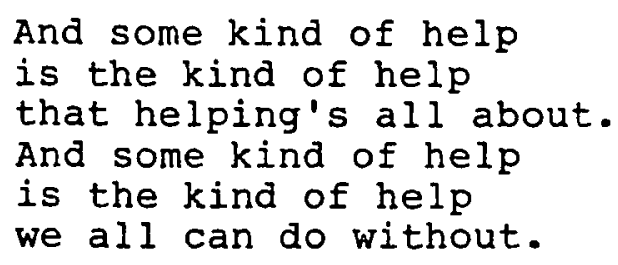

For these men with epilepsy, a generally successful 
lifestyle seems to be associated with having a large, diverse, relatively close-knit network and an active community life. General helping exchanges with network members are important and satisfying. However, help from family or network which is focused on dealing with the epileptic symptoms reinforces feelings of dependence, creates strain in these relationships and helps to sustain personality traits and ways of interpersonal relating that are not conducive to successful employment.

In addition to revealing that some forms of help are more beneficial than others, this study provides justification for looking at a variety of measures of support and for assessing the impact of support on more than one type of outcome measure. A more complex design adds much greater depth to an understanding of the true importance of social support in the lives of individuals. In the final chapter we will discuss the implications of these findings for research and policy. 
CHAPTER IX

\section{IMPLICATIONS FOR RESEARCH AND POLICY}

Many of the initial hypotheses which guided this investigation and which were based on existing models of the process of coping with stressors were confirmed by the data. At the same time, other findings required a number of revisions in the general model. The patterns of support of these men have shown similarities and differences with patterns of support reported in the 1iterature. This chapter will discuss some of these similarities and differences drawing implications for further research.

This research also has implications for policies directed toward the rehabilitation of those with chronic disabilities, in particular, men with epilepsy. While it was not the intent of this study to evaluate the efficacy of various rehabilitative strategies, these results indicate some approaches which are not likely to be effective. Since some of these strategies are currently in effect or under policy consideration, the findings merit some discussion. 
IMPLICATIONS FOR RESEARCH

The chief intent of this research was to see whether social support would be positively associated with successful employment and life satisfaction for a group of men with epilepsy. In order to assess the role of social support, it was necessary to describe a model of the coping process and to control for other factors which might also be associated with employment and satisfaction. In the process of testing this model several interesting things were learned about the relationships among the other elements of the model. These will be discussed followed by the findings related specifically to the role of support.

The General Model of Coping

This research confirmed the findings of other studies that psychological factors are more important in predicting adaptation to epilepsy than the severity of the symptoms. Denner11, Schwartz and Rodin (1968), for example, concluded a study of the employment problems of 177 persons with epilepsy by stating:

...the primary factors in predicting ultimate employment success or failure were neurological functioning or degree of organic brain syndrome present, intellectual and cognitive deficits present, and most particularly the individual's personal adjustment, attitudes and motivation. (p. 45) 
The primacy of psychological factors appears to be true for other disabilities as well. Decker (1982) conducted a study of middle-aged and elderly spinal cord injured perscrs in which she found that the severity of their injury was not highly correlated with subjective well-being. Roessler and Bolton (1978) conducted an extensive survey of the literature on the psychosocial adjustment to disability and concluded that there was no proven relationship between severity of the disability and psychological adjustment.

The data from this study shows that experiencing frequent seizures can be a handicap to employment. There were examples of men in our study group who had been fired from jobs because they had had seizures on the job. Becoming seizure-free with medication or, ideally, "curing" the condition so that medication becomes unnecessary is still the most important goal for these men and must be the most important priority in research and treatment.

However, these findings offer additional confirmation of previous findings that achieving medical control of seizures will not be sufficient, in many cases, to guarantee employment success. There were many examples of men in this study whose seizures had been completely controlled with medication but who were still unable to 
maintain steady employment. On the other hand this study also offers examples of men who are able to be employed successfully and to have satisfying lives in spite of seizures. Self concept seems to be the factor that makes the major difference. Men who have seizures but are successfully employed have personality traits that make them sufficiently valuable employees that their employers are tolerant of their seizures.

Although this study was not able to make distinctions in the types of employment situations of the men, these may also have had some effect. Examination of the cases of men who were successfully employed in spite of a high level of seizure activity shows that some men were able to find jobs in which seizures did not matter because: (a) the seizures never occurred during the hours they worked; (b) they were employed by a rehabilitation program or other government office which had a policy of encouraging handicapped workers; (c) they were self-employed as craftsmen or shop keepers or (d) they were employed by their parents or other family members who expected very little from them. This latter group might be considered somewhat at risk of future unemployment, since their employment depends on the continuing ability of their family to provide it.

Given the importance of psychological factors, it is 
unfortunate that this study did not have better measures of psychological dimensions. There was no measure of neurological impairment. The measure of reaction to the stressor -- perceived limitations -- had low reliability as a scale. Finally, the Tennessee self Concept Scale is not highly regarded as a measure of self concept and is particularly inadequate as a measure of personality disturbance. The fact that these fairly crude measures were significantly associated with the outcome measures points to the utility of including better measures of psychological dimensions in studies of disabled populations. Most of the research on such groups is directed to the medical aspects of the problem and ignores the psychological and social factors. These findings suggest that if rehabilitation is the goal, psychological and social factors are very important.

It is generally assumed in the literature on epilepsy that age of onset will be a major determinant of the extent to which the condition is disabling in adult life. Permanent neurological damage is likely to be cumulative and early onset should have a greater impact on personality formation, patterns of interaction with family and friends and socialization experiences. In the light of this generally accepted "wisdom," it is interesting that age of onset appears to have had little effect on the 
educational level, employment success or life satisfaction of the men in this study. We have argued that having epilepsy may lead to a pattern of dependence and helplessness but, at least from this data, the pattern does not appear to be stronger if the epilepsy developed earlier in life. It may be that changes in public attitudes, improved treatment methods and better education and rehabilitation programs have lessened the impact of epilepsy on younger children and on their families. It is also possible that age of onset is too crude a measure of the impact of the history of having the disability and that other factors, such as the particular developmental phase in which the seizures first occurred, the type and frequency of early symptoms and the way they were handled medically and socially are determining factors of whether or not experiencing epilepsy in childhood has a significant impact on adult functioning.

\section{Social Support and Personal Characteristics}

\section{Demographic characteristics. This study confirmed} the findings of other studies of non-handicapped samples that demographic characteristics are not strongly related to the social networks of individuals (Schaefer et al.., 1981). What relationships there were between demographic characteristics and social network characteristics were similar to those found in other studies. 
older men had smaller networks and had less contact with others. They also got less help from members of their networks. In some cases, this was probably because they needed less help. Examination of the interviews of some of these men indicated that some of them had been stably employed for many years, had raised families and were quite self-sufficient. Younger men, on the other hand, were more likely to need help finding jobs, moving and establishing households, or borrowing tools and other equipment. They were more likely to be involved in mutual exchanges of these forms of assistance with friends and relatives. There may have been some older men in the sample who could have used help and were not getting it, however, since older men were more likely to be unemployed. Schaefer et al. (1981) found that older persons in their study who were unemployed were getting less tangible support. Fischer (1982) also found that older persons in his sample were likely to be at risk of having marginal or inadequate support.

Men with more education and higher socio-economic status had networks that were larger, more diverse and more generally helpful, with help given on the basis of equal exchanges. This pattern is also typical in studies of general populations. Having service providers in the network was positively related to education and negatively 
related to socioeconomic status, possibly indicating that for this group, as for others which have been studied, those men with epilepsy who are better educated are more likely to turn to professionals for help. Personality. One of the most interesting "non-findings" of this study was the lack of relationships between self concept and the support variables. Positive self concept was positively related to general social participation but it had no relationship to the type of network men had or on its helpfulness.

Men with a good self concept were more likely to rate their relationships with their networks and their families positively. These correlations may simply be indicative of a response set which is generally positive as may also be true of the positive correlation of self concept and life satisfaction. However, the men with a good self concept were also more likely to be employed, a condition which is not as directly determined by subjective mood states. Again, this could be because employers prefer workers who are generally optimistic, up beat people. On the other hand, men who say they are satisfied with their relationships may also be indicating that they are getting intangible forms of support, what Gottlieb (1983) has termed "milieu reliability," from these satisfactory relationships which are not indicated 
by the measures of support which were used in this study but which do contribute to employment success and life satisfaction.

Research, such as the present study, which defines support in terms of exchanges of specific forms of help may be failing to capture important dimensions of these relationships. Hammer (1981) notes:

Support may be [only] one function of a
set of social connections... To focus on
'support' rather than on demands, restrictions
or social facilitation reflects a
pathology-oriented approach that assumes the
need for help in coping with problems to be of
primary importance. (p.47)

Epilepsy. In general, the physical manifestations of the disability did not affect the social worlds of these men. They made no effort to conceal the fact that they had epilepsy from members of their networks. Neither age of onset nor current symptoms seemed to be a curb on social participation, nor did it affect the size, general helpfulness or composition of their social networks.

We have seen that psychological adjustment, the reaction to the stressor, was more strongly associated with employment and life satisfaction than were the actual physical limitations of having epilepsy. The way the person reacted to having epilepsy also had a greater effect on the amount of epilepsy-related help he received from others. In other words, family members and members 
of the network offered this form of help, not on the basis of the person's need as demonstrated by the type and frequency of his seizures but instead, were more likely to offer help if the person presented himself as unable to control his seizures and handicapped by his condition. of course, it must be remembered that we do not have measures of the actual amount or type of help offered by members of the network, only the reports of the person with epilepsy as to their helpfulness. It is plausible that greater perceptions of handicap could be part of a set of attitudes that also included a perception of being the recipient of epilepsy-related help. However the method of gathering data separately about each member of the network and the household and asking specific questions about various kinds of assistance should have made these reports somewhat less influenced by the response set of the man being interviewed. It seems more likely that presentation of self is important in eliciting help from others. It is also possible that receiving help from others, if it is focused on the disability, reinforces feelings of helplessness and dependency, creating a circular pattern. Decker (1982) found that more support from others was associated with high levels of perceived control over their lives and favorable social comparisons for her group of persons with spinal cord injuries. However, she asked 
only about general forms of support, not about help specifically directed towards helping them deal with their disability. The findings of the present study indicate that it may be important to distinguish between these two forms of support when studying disabled populations. Although, in the present study, both general assistance and epilepsy-related assistance were associated with greater perceptions of handicap, general assistance was not associated with unemployment while epilepsy-related assistance was.

\section{Social Support and Outcomes}

The model of the coping process outlines a causal chain. An external event occurs which is perceived as stressful by the individual. The individual attempts to deal with the threat to equilibrium posed by the stressor. One of the ways he or she copes is by eliciting the help of others. If these attempts are successful, the individual returns to a "steady state" with no continuing experience of stress. If the attempts are not successful, the individual continues to experience stress which results in negative outcomes such as illness, depression, and lowered self esteem. This model probably describes the process of dealing with an acute stressor or crisis situation better than it does a chronic situation. In the case of a chronic stressor, such as epilepsy, a 
cross-sectional examination of this process is more likely to reveal circular patterns than causal chains. Rather than identifying causal links, it is more accurate to say that the data of this study reveals two circular patterns which distinguish those who are successfully coping with epilepsy from those who are not.

In the successful pattern, men have been able to achieve a lifestyle which includes steady employment, active community participation, a good self image and satisfying personal relationships. Each of these elements helps to sustain the others. In the unsuccessful pattern, just the opposite conditions prevail: unemployment, little community participation, a poor self concept and interpersonal relationships which are too heavily focussed on the person's handicap and are strained.

General social participation. General social participation was a strong predictor of successful outcomes for the men in this study. This might be explained by the circularity of the variables. That is, men who are successfully employed have more economic resources and thus are able to go out more frequently and engage in various active hobbies. They may also be involved in organizational activities that are related to their employment. Higher life satisfaction scores, as we have already mentioned, may be indicative of a person who 
has a generally positive outlook on life and who is gregarious and enjoys being active.

It is also possible that the support derived from general participation is more important for men than that derived from close relationships. Several studies have found that social integration (Henderson, Byrne, Duncan-Jones, Scott \& Adcock, 1980) or the more diffuse support indicated by knowing many people in the neighborhood or at work (Miller \& Ingham, 1976) were associated with positive outcomes for men while close affectional ties or confidantes were important for women. Reviewing these findings, Gottlieb (in press) asks: "Does the male sex role confer a diminished need for emotional intimacy during periods of adversity, while the female role heightens this supportive requirement?" It would be interesting to know whether the women in the larger study, who were not included in this analysis, had different patterns of support.

The significant association between general social participation and life satisfaction is consistent with other studies. Wilson (1967) reviewed studies of happiness and concluded that the most impressive single finding in research on happiness is the correlation of happiness and successful involvement with people. Bradburn and Caplovitz (1965) found that higher scores on 
their positive feelings index among men aged 25-49 were associated with a wide range of social activities such as contact with relatives and friends, organizational membership, going out socially and participating in sports.

Church Membership. A specific form of social participation that seemed particularly satisfying for this group was membership in a church. Men who participated extensively often belonged to churches or sects which offered an all-encompassing lifestyle and afforded, or even required, extensive involvement, such as Jehovah's Witnesses or the Church of Latter Day Saints. Several men mentioned that they found employment through their churches. The relationship with the minister was often an important added benefit of church membership.

It would be interesting to know whether church membership is particularly attractive to persons with epilepsy or is common among disabled persons. Two social workers who have led groups for persons with epilepsy noted that "A large number of them reasoned that their plight was part of God's special plan for them....and the authors wondered if the supernatural quality the patients attached to their seizures facilitated their belief in a supernatural God." (Lessman \& Mollick, 1978, p. 115). The authors also noted that the patients with a strong 
religious belief "experienced a cheerfulness and serenity that made their existence tolerable." (p. 115)

Density. The finding that a close knit network was associated with both Iife satisfaction and employment was confirmation of the hypothesis that has often been stated in the network literature with little empirical evidence that this form of network structure should be helpful in coping with chronic stressors. Although close knit networks were more likely to provide all forms of assistance, we have seen that epilepsy-related assistance was not associated with positive outcomes. So there is some quality in a close knit network, independent of its helpfulness, which seems to be beneficial. Since men could not have a large number of connections between friends and relatives unless they had both friends and relatives in their network, one possible explanation is that balanced networks which include both sorts of members are the most likely to be associated with beneficial outcomes. This might reconcile the findings discussed in Chapter II that kin are more dependable sources of help for chronic conditions but kin-dominated networks are associated with psychopathology. Further research which explored more deeply the nature of the support and the conditions attached to it from various sources would be needed to understand the meaning of this finding. 
Dysfunctional support. In addition to confirming and elaborating on the relationships among the elements of a successful lifestyle for persons with epilepsy, this study also shed greater light on the elements of a dysfunctional lifestyle. In particular, the fact that feelings of being handicapped and actually getting help from others in dealing with epilepsy were associated with unemployment for this group suggests that the negative personality traits which inhibit employment for persons with epilepsy may be maintained by the way that significant others treat them. Unless the problem is conceived of as a problem of a social system rather than of an individual, little change can be expected. Further, the finding that men who were involved in this pattern did not find their lives less satisfying indicates that, if employment is the goal, patterns that may have considerable rewards, both for the person with epilepsy and for the members of his household and personal network, will have to be changed. These findings have implications for treatment and rehabilitation which will be discussed in the next section.

Although family and network members may be deriving some "benefits" from maintaining the dependent behavior of some of these men, there is also ample indication in this data that having epilepsy and perceiving oneself as 
limited by it put significant strains on these relationships. In the case of family members, it appears that it is the impact of the condition itself which is most strongly felt. When the symptoms were more severe and when the men perceived themselves as more limited by their condition they were less likely to feel that their families had made it easier to cope with epilepsy and more likely to feel that epilepsy had affected these relationships negatively. In the case of help from network members, men whose symptoms were more severe were more likely to feel that help from the network, unlike help from family members, had made it easier to cope with epilepsy. However they were also more likely to feel that receiving this sort of help had a negative effect on these relationships. Receiving non-epilepsy related assistance did not affect the relationships negatively. Perhaps this is an indication that the men in this sample did not view their network as an appropriate source of epilepsy-related assistance.

Indications of the impact of epilepsy on these relationships would probably have been even stronger if the significant others had been interviewed. One man said that his wife had left him because she "couldn't take" the strain of his epilepsy. Quite a few of the men had wives or parents present in the interview which may have 
inhibited their responses, particularly to the questions about the effect of epilepsy on these relationships. On the other hand, their dependence was exhibited in the interview situation because, in many of these cases, the wife or parent had to help the person with epilepsy answer the questions. One man is dyslectic as well as epileptic, for instance, and his wife does all his writing for him. It is evident from the findings of this study that studies of the social support networks of the disabled should take a systems approach and should interview significant others as well as the person with the disability.

\section{IMPLICATIONS FOR POLICY}

The findings of this study have implications for policy at two levels. First there are questions about the roles of formal services and informal supports in the maintenance of disabled individuals. The types of formal services available and the way they are delivered may help an individual with epilepsy achieve a satisfying productive life or they may reinforce patterns of dependency and failure. How should services be designed? Reductions in the amount of formal services available because of cutbacks in funds or deliberate policies of encouraging more assistance from the informal sector may 
place more responsibility on family members, personal network members, self-help groups and caring community institutions such as churches. Is there more potential in these sources of assistance than is currently being tapped and in what forms?

There is a second set of questions at the level of individual interventions by professionals. What sorts of interventions are likely to lead to independent functioning and what sorts of interventions are likely to be counter-productive?

The Roles of the Formal and Informal Sectors

Formal services. The evidence of this study is that formal services are not very effective in promoting employment for the men in this group. Having professionals in one's personal network was negatively associated with employment and led to greater feelings of stigmatization which, in turn, could lead to lowered self esteem. Examination of the interviews showed that the professionals in the networks were mostly doctors, employment counselors and rehabilitation workers. The men were highly satisfied with their medical treatment but some of the most dependent men seemed to see their doctors as father figures, important sources of validation and general direction of their lives. There is no way to know from this data whether the doctors realized 
that they were so important in their patients' lives nor whether they encouraged or discouraged such

relationships. However, these relationships might be part of the pattern of dependence and identification with a "sick" role that has been seen to be associated with negative outcomes. If this is a negative and unanticipated consequence of medical treatment, perhaps steps could be taken to prevent this pattern of dependency from developing in the course of bringing the seizures under control.

It would also seem from this data that traditional approaches to rehabilitation and employment were not very successful with this group. Again, examination of the interviews and the employment patterns of the men with poor work histories showed that some of them had been placed on jobs through these services or through an employment program especially aimed at men with epilepsy but they had not been able to hold these jobs for very long. At the same time, the men who were successfully employed in spite of severe symptoms provided no examples of men whose success could be attributed to rehabilitation programs. It would seem that a successful approach to employment would need to concentrate on personality factors and the system of relationships that maintained the dependent pattern of the individual. Job placement 
services are not sufficient.

Dennerll et al. (1968, p. 46) reached the same conclusion:

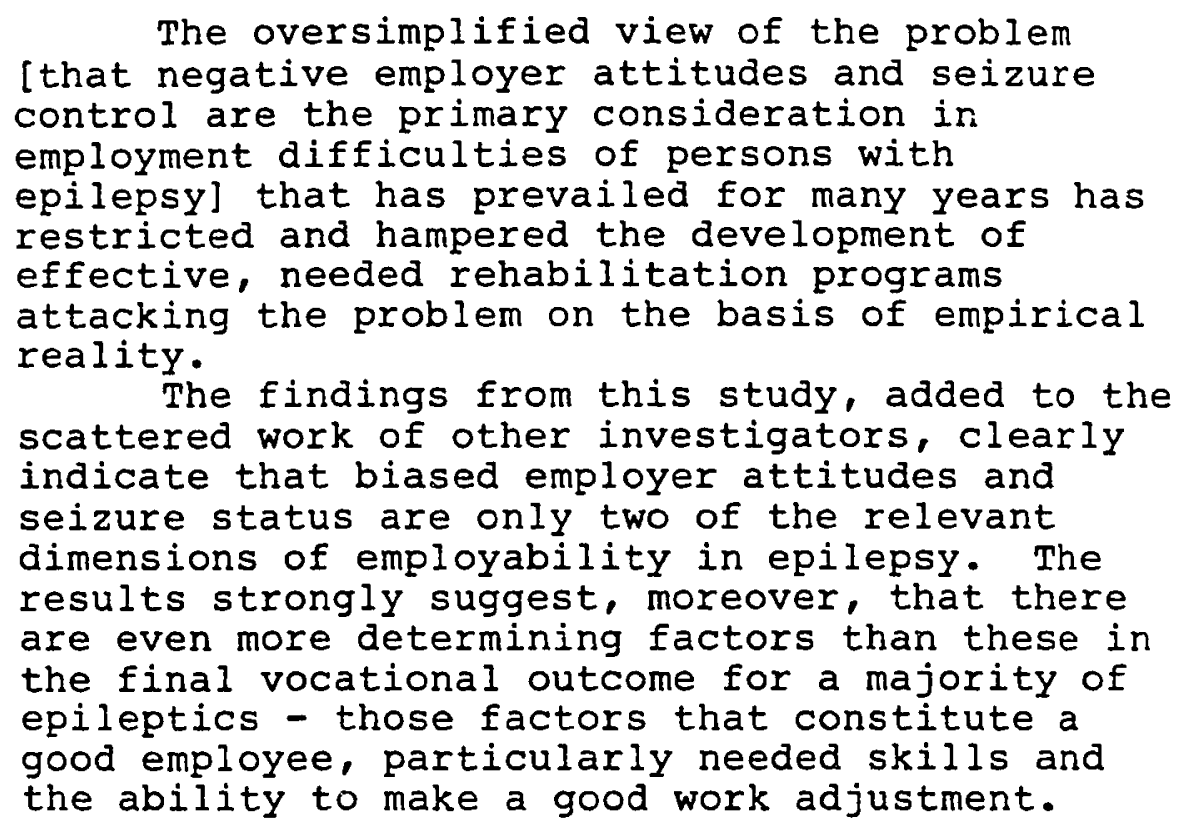

Informal support. We have seen that help from

informal sources produces some of the same negative

effects as formal help. Help which is specifically

focussed on symptoms (e.g. reminding him to take

medication, telling him to eat properly or get enough

rest, taking him to the doctor), when it is associated

with feelings of helplessness, is associated with

unemployment. On the other hand, help that is part of

"normal" informal relationships is positively associated

with life satisfaction. This sort of help is also more

likely to be exchanged on a mutual basis. 
Therefore a policy that demands that the handicapped person seek more epilepsy-related help from family and friends is likely to be unsuccessful; first, because the handicapped person probably will not be able to generate much more assistance from informal sources; secondly, because what additional assistance he manages to obtain will probably lead to greater strain in the relationships, which then becomes a source of additional stress for the handicapped person and finally, because this help is likely to be of the sort which reinforces dependence. Instead, a better policy might be to encourage and enable the disabled person (at least if he is male) to participate in more general forms of community activities which are not focussed on his disability and are more likely to provide more diffuse support. We have seen that churches may be one important source of such support. However, it may also be true that some of the men in this study were looked upon as "special projects" by the congregations to which they belonged, less was expected of them than of other members and more help was offered to them on an unequal basis. When this is the case, church membership may be another way of maintaining helplessness and dependency. It will be remembered that church membership was not correlated with employment while general social participation was. 
An exception to the general conclusion that it might be better for men with epilepsy to avoid relationships which are focused on their handicapped status might be participation in self-help groups. Almost none of the men in this sample included other persons with epilepsy in their networks, few had been involved in activities of the Epilepsy League, although most of them knew of its existence and none of them had been involved in self-help groups. Self-help groups for all sorts of disabilities have become much more common in the six years since these interviews were conducted.

The experience of many others who have participated in self-help groups, particularly when they have a condition which is not well understood or or is even feared by the general public, has been great relief in finally finding a group of people who accept and understand them. Beyond this, a self-help group can serve as a sounding board and a place to ventilate feelings of frustration and disappointment. This might help relieve the strain on members of the person's family and network. An example of this is provided by one man with epilepsy who reported in the Epilepsy Self-Help Newsletter (1981, p. 4) how a self help group helped him after his employer had chastized him for missing work after having a seizure: 


\begin{abstract}
It's much easier for me to go to the group meeting and bitch about that than it is to take it out on my wife and kids.... It was easier then to tell my wife how I felt about it because I had gotten the initial anger out in the groups.
\end{abstract}

If the self help group reinforces the person's identity as a helpless and handicapped person it is likely to do more harm than good. Usually this is not the way such groups develop, however. As the same issue of the Newsletter noted in describing the proceedings of a national conference on self help groups for persons with epilepsy, "It wasn't long before discussion shifted [from personal testimonials about how self help groups had helped them] to issues of policy, legislation, public advocacy, and the 'politics' of epilepsy in the Inited States" (p. 4). It would seem that such discussions and related activities might help persons with epilepsy see themselves as less dependent and helpless and also help to build skills that would be attractive to employers.

Intervention Strategies

An individual rehabilitation worker or employment counselor, attempting to help a person with epilepsy achieve independent living and successful employment will first need to see the person as part of a system of social relationships. The initial assessment and identification of problems needs to be done on the system level, not the 
individual level. The worker must also be prepared to intervene at that level.

A rehabilitation program that operated on this basis was implemented as part of the project which supplied the data for this research (Daggett, Kempner \& Costello, 1982). Beginning with the assumption, which is confirmed by this data, that the best efforts of Eormal and informal helpers to date had not worked and that they might even be counter-productive, this program made a systematic assessment of the benefits that the person with epilepsy and the members of his family and personal network were gaining from maintaining his helpless, dependent behaviors. Then, using a form of therapy called Rapid Problem Resolution (Daggett, 1978), "counter-intuitive" strategies were suggested to break up these patterns. For example, a counselor might suggest to a wife whose urgings of her husband to find work were having no effect, that she discourage him instead and suggest that he stay at home (Daggett et al., 1982).

This approach was successful in rehabilitating a number of men for whom all previous efforts had failed. The findings of this study confirm the need for such an approach. They also suggest that the approach might be even more successful if it was combined with self help groups and opportunities for general social participation 
which could take the place of the gratifications received from the dependent relationships. Members of the individual's network would also have less incentive to perpetuate the dependent relationships if they were encouraged to find other rewarding activities.

\section{CONCLUSION}

Great strides have been made in this century in the treatment of epilepsy and the reduction of the stigma that was formerly attached to it. This study shows that the problems that still remain for persons with epilepsy are social ones and that the solutions are also likely to be social. Instead of spending the vast majority of the research funds that are available to be addressed to the problems of epilepsy on increasingly esoteric research on rare forms of the disease which affect very few people, it would seem appropriate to direct some of this money towards developing solutions to the remaining problems of a significant proportion of those for whom everything that can be done medically has been done.

The social world of the person with epilepsy is one area that definitely merits further study -- as much for what it contributes to the maintenance of his problems as for what it provides in the way of solutions. 


\section{REFERENCES}

American Hospital Association (1971). Report of a Conference on Care of Chronically Ill Adults. Chicago.

Antonovsky, A. (1979) - Health, Stress and Coping. San Francisco, CA: Jossey-Bass.

Arling, G. (1976). The elderly widow and her family, neighbors, and friends. Journal of Marriage and the Family, 38, 757-768.

Barnes, J. A. (1954). Class and committees in a Norwegian island parish. Human Relations. I, 1, 39-58.

Barrera, M.,Jr. (1981). Social support in the adjustment of pregnant adolescents. In B. H. Gottlieb (Ed.), Social networks and social support (pp. 69-96). Beverly Hills, CA: Sage.

Berger, P., \& Neuhaus, R. (1977). To empower people: The role of mediating institutions. Washington, D. C.: American Enterprise Institute for Public Policy Research.

Berkman, I. F., \& Syme, S. I. (1979). Social networks, host resistance, and mortality: A nine-year followup study of Alameda County residents. American Journal of Epidemiology, 109, 186-204.

Boissevain, J. (1974). Friends of friends. New York: st. Martin's Press.

Bradburn, N., \& Caplovitz, D. (1965) - Reports of Happiness. Chicago: Aldine.

Campbel1, A., Converse, P. E., \& Rodgers, W. L. (1973) . The quality of American life. New York: Russell Sage.

Caplan, G. (1974) . Support systems. In G. Caplan (Ed.), Support systems and community mental health. New York: Basic Books.

Caveness, W. F., Merritt, H. H. \& Gallup, G. H. (1974) . A survey of public attitudes toward epilepsy in 1974 with an indication of trends over the past twenty-five years. Epilepsia, 15, 523-536. 
Commission for the Control of Epilepsy and Its Consequences. Plan for Nationwide Action of Epilepsy, Vol.1, DHEW Publication No. (NIH) 78-276, U. S. Government Printing Office, Washington, D.C., 1977, 249 pp.

Croog, S. H., Lipson, A., \& Levine, S. (1972) . Help patterns in severe illness: The roles of $\mathrm{kin}$ network, non-family resources and institutions. Journal of Marriage and the Family, 34, 32-41.

Daggett, S. (1978). Rapid problem resolution: An "uncommonsense" approach to rehabilitation. Journal of Applied Rehabilitation Counseling, $9,2,1 \overline{3-16 .}$

Daggett, S., Kempner, K., \& Costello, J. (1982). The effectiveness of rapid problem resolution with rehabilitation failures. Rehabilitation Counseling Bulletin, 25, 5, 259-267.

Daly, D. D. (1978). Medical education and epilepsy. In J. A. Wada (Ed.) Modern perspectives in epilepsy, Proceedings of the inaugural symposium of the Canadian League Against Epilepsy. Montreal, Canada: Eden Press.

DeAraujo, G., Van Arsdel, P. P., Holmes, T. H., \& Dudley, D. L. (1973). Life change, coping ability and chronic intrinsic asthma. Journal of Psychosomatic Research, 17, 359-363.

Decker, S. D. (1982). Social support and well-being in middle-aged and elderly spinal cord injured persons: a social-psychological analysis. Dissertation Abstracts International, 43, 3407-B. (University Microfilms No. DA8305539)

Dennerll, R. D., Schwartz, M. L. \& Rodin, E. A. (1968). Neurological, psychological and social factors related to employability of persons with epilepsy, Final Report. Detroit, Michigan: Michigan Epilepsy Center.

DiMatteo, M. R. \& Hayes, R. (1981). Social support and serious illness. In B. H. Gottlieb (Ed.), Social networks and social support. (pp. 117-148) - Beverly Hills, CA: Sage.

Durkheim, E. (1951) . Suicide (J. A. Spaulding \& G. Simpson, Trans.). New York: Free Press. 
Eckenrode, J., \& Gore, S. (1981). Stressful events and social supports: The significance of conteit. In $B$. H. Gottlieb (Ed.), Social networks and social support (pp. 43-68) - Beverly Hills, CA: Sage.

Edward. V. E. (1974). Social problems confronting a person with epilepsy in modern society. Proceedings of the Australian Association of Neurologists, 2 , 239-243.

Emlen, A. \& Ryan, R. (1979) . Analyzing unemployment rates among men with epilepsy. Unpublished manuscript, Regional Research Institute for Human Services, Portland State University, Portland, Oregon.

Ervin, F. R. (1975) . Comprehensive Textbook of Psychiatry. Baltimore: Williams \& Wilkins.

Faris, R. E. L., \& Dunham, H. W. (1939). Mental disorder in urban areas. Chicago: University of Chicago Press.

Fischer, C.S. (1982). To dwell among friends: Personal networks in town and city. Chicago: University of Chicago Press.

Fitts, W. H. (1965). Tennessee Self Concept Scale: Manual. Counselor Recordings and Tests, Department of Mental Health, Nashville, Tenn.

Froland, C., Brodsky, G., Olson, M., \& Stewart, L. (1979). Social support and social adjustment: Implications for mental health professionals. Community Mental Health Journal, 15, 82-93.

Froland, C., Pancoast, D. L., Chapman, N., \& Kimboko, P., (1981). Helping networks and human services. Beverly Hills, CA: Sage.

Garrity, T. F. (1973). Vocational adjustment after first myocardial infarction: Comparative assessment of several variables suggested in the literature. Social Science and Medecine, 7, 705-717.

Goodglass H., Morgan M., Folsom A. T., and Quadfasel F. A. (1963). Epileptic seizures, psychological factors, and occupational adjustment. Epilepsia, 4 , 322-341.

Gore, S. (1978). The effect of social support in moderating the health consequences of unemployment. Journal of Health and Social Behavior, 19, 157-165. 
Gore, S. (1981). Stress-buffering functions of social supports: an appraisal and clarification of research models. In Dohrenwend, B. S. \& Dohrenwend, B. P. (Eds.), Stressful life events and their contexts (pp. 202-222). New Brunswick, NJ: Rutgers University Press.

Gottlieb, B. H. (1978). The development and application of a classification scheme of informal helping behaviors. Canadian Journal of Behavioral Science, 10, 105-115.

Gottlieb, B. H. (1981). Social networks and social support in community mental health. In Gottlieb, B. H. (Ed.), Social networks and social support. Beverly Hills, CA: Sage.

Gottlieb, B. H. (1983). Social support strategies: Guidelines for mental health practice. Beverly Hills, CA: Sage.

Gottlieb, B. H. (in press). Theory into practice: issues that surface in planning interventions which mobilize support. To appear in Sarason, I. G. \& Sarason, B. R. (Eds.), Social support: Theory, research and application. The Hague: Martinus Nijhof.

Gouldner, A. (1960). The norm of reciprocity: A preliminary statement. American Sociological Review, 25, 161-178.

Gove, W. R. \& Geerken, M. R. (1977). The effect of children and employment on the mental health of married men and women. Social Forces, 56, 66-71.

Hall, A. H. \& Wellman, B. (1982, September). Support and non-support: a network analytic approach. Paper presented at the annual meeting of the American Sociological Association, San Francisco, CA.

Hammer, M. (1981). Social supports, social networks and schizophrenia. Schizphrenia Bulletin, $7,1,45-57$.

Hammer, M., Makiesky-Barrow, S., \& Gutwirth, L., (1978). Social networks and schizophrenia. Schizophrenia Bulletin, $\underline{4}, 522-545$.

Hatt, P. K. \& North, C. C. (1947). Jobs and occupations: a popular evaluation. Opinion News, September, 3-13. 
Henderson, S., Byrne, D. G., Duncan-Jones, P., Scott, R., \& Adcock, S. (1980). Social relationships, adversity, and neurosis: A study of associations in a general population sample. British Journal of Psychiatry, 136, 574-583.

Hermann, B. P. (1974). MMPI profiles of temporal lobe epileptics and generalized epileptics: The role of age of onset. Unpublished masters thesis, Wichita State University, Kansas.

Hermann, B. P. (1977). Psychological effects of epilepsy: a review. Psychological Documents. 7, 1. (Ms. No. 14301

Hirsch, B. J. (1980). Natural support systems and coping with major life changes. American Journal of Community Psychology, 8, 159-172.

Hirsch, B. J. (1981). Coping and adaptation in high-risk populations: toward an integrative model. Schizphrenia Bulletin, $7,1,164-171$.

Hodge, R.W., Siegel, P.M. \& Rossi, P. (1964) Occupational prestige in the United States, 1925-63. American Journal of Sociology, 70, 286-302.

Holmes, T. H. \& Rahe, R. H. (1967). The social readjustment rating scale. Journal of Psychosomatic Research, 11, 213-218.

House, J. S. (1981). Work stress and social support. Reading, MA: Addison-Wesley.

Hurd,G., Llamas, R. \& Pattison, E. M. (n.d.). The structure and function of normal social networks. Unpublished manuscript, Medical College of Georgia, Augusta, GA.

Killworth, P. D., \& Bernard, H. R. (1979). Informant accuracy in social network data III: a comparison of triadic structure in behavioral and cognitive data. Social Networks. 2 , 19-46.

Klove, H. \& Doehring, D. (1962). MMPI profiles of epileptic groups with different etiology. Journal of Clinical Psychology, 18, 149-153.

Laumann, E. O. (1973) . Bonds of Pluralism. New York: wiley. 
Lazarus, R. S. (1981). The stress and coping paradigm. In Eisdorfer, C., Cohen, D., Kleinman, A. \& Maxim, P. (Eds.), Theoretical bases for psychopathlogy. New York: Spectrum.

Lenrow, P. (1976). Dilemmas of professional helping. In Wispe, L. (Ed.), Sympathy, altruism and helping. Cambridge: Harvard University press.

Lessman, S. E. \& Mollick, L. R. (1978). Group treatment of epileptics. Health and Social Work, 3, 3, 106-121.

Levine, L. S. \& Idler, E. L. (1981). The hidden health care system: Mediating structures and medicine. Cambridge, Mass: Ballinger.

Lewis, C. E. (1966). Factors influencing the return to work of men with congestive heart failure. Journal of Chronic Diseases, 19, 1193-1209.

Liang, J., Dvorkin, L., Kahana, E., \& Mazian, F. (1980). Social integration and morale: A re-examination. Journal of Gerontology, 35, 746-757.

Liem, R., \& Liem, J. (1978). Social class and mental iliness reconsidered: The role of economic stress and social support. Journal of Health and Social Behavior, 19, 139-156.

Lin, N., Simeone,R. S., Ensel, W. M., \& Kuo, W. (1979). Social support, stressful life events, and illness: A model and an empirical test. Journal of Health and Social Behavior, 20, 108-119.

Lindenberg, R. E. (1977). Work with families in rehabilitation. Rehabilitation Counseling Bulletin, September, 1977, 67-76.

MacElveen-Hoehn, P. \& Smith-DiJulio, K. (1978). Social network behavior in long-term illness: preliminary analysis. In Froland, C. \& Pancoast, D. I. (Eds.), Networks for helping: Illustrations from research and practice, proceedings of the conference on Networks, (pp. 68-92). Portland, Oregon.

Matthews, C. G. \& Klove, H. (1968). MMPI classifications in major motor, psychomotor, and mixed seizure classifications of known and unknown etiology. Epilepsia, 9 , 43-53. 
MCCallister (Jones), L., \& Fischer, C. S. (1978). A procedure for surveying persoal networks. Sociological Methods and Research, 7 (November), 131-148.

McFarlane, A. H., Neale, K. A., Norman, G. R., Roy, R. G., \& Streiner, D. L. (1981). Methodological issues in developing a scale to measure social support. Schizphrenia Bulletin, 7, 1, 90-100.

Medalie, J. H. \& Goldbourt, V. (1976). Angina pectoris among 10,000 men. American Journal of Medecine, 60, 910-921.

Milgram, S. (1967). The small world problem. Psychology Today, $1,61-67$.

Miller, P., \& Ingham, J. G. (1976). Friends, confidants, and symptoms. Social Psychiatry, 11, 51-58.

Minor, M. J. (1983). New directions in multiplexity analysis. In Burt, R. S. and Minor, M. J. (Eds.), Appiied network analysis. Beverly Hills, CA: Sage.

Mitchell, J. C. (1969). The concept and use of social networks. In Mitchell, J. C. (Ed.), Social networks in urban situations. Manchester, Eng.: University of Manchester Press.

Mueller, D. P. (1980). Social networks: A promising direction for research. Social Science and Medicine, 14A, 147-161.

Nuckolls, K. B., Cassel, J., \& Kaplan, B. H. (1972). Psychosocial assets, life crisis and the prognosis of pregnancy. American Journal of Epidemiology, 95 , $431-441$.

Pattison, E. M., Llamas, R., \& Hurd, G. (1979), Social network mediation of anxiety. Psychiatric Annals, ‥ 56-67.

Pattison, E. M., \& Pattison, M. L. (1981). Analysis of a Schizophrenic Psychosocial Network. Schizphrenia Bulletin, 7, 1, $135-143$.

Pearlin, L. J., Lieberman, M. A., Menaghan, E. G., and Mullan, J. T. (1981). The Stress Process. Journal of Health and Social Behavior, 22, 337-356. 
Pearlin, L. J., \& Schooler, C. (1978). The structure of coping. Journal of Health and Social Behavior, 19 , 2-21.

Phillips, S. L. (1981). Network characteristics related to the well-being of normals: A comparative base. Schizophrenia Bulletin, $7,1,117-123$,

Phillips, S. L., \& Fischer, C. S. (1981). Measuring social support networks in general populations. In Dohrenwend, B. \& Dohrenwend B. (Eds.), Life stress and illness (pp.223-233). New York: Watson.

Pilisuk, M., \& Froland, C. (1978). Kinship, social networks, social support and health. Social Science and Medicine, 12b, 273-280.

Pool, I. de Sola \& Kochen, M. (1978). Contacts and influence. Social Networks, 1, 5-51.

Roberts. I. (1983). A case against government incentives for home care of dependent adults. New England Journal of Human Services, $3,4,14-\overline{20}$.

Rodin, E., Rennick, P., Dennerl1, R., and Lin, Y. (1972). Vocational and educational problems of epileptic patients. Epilepsia, 13, 149-160.

Roessler, R. \& Bolton, B. (1978). Psychosocial adjustment to disability. Baltimore: University Park Press.

Rosow, I. (1967). Social integration of the aged. New York: Free press.

Ryan, R., Kempner, K., \& Emlen, A. C. (1980). The stigma of epilepsy as a self-concept. Epilepsia, 21, 433-444.

Sandler, I. \& Lakey, B. (1982). Locus of control as a stress moderator: The role of control perceptions and social support. American Journal of Community Psychology, 10, 65-81.

Schaefer, C, Coyne, J.C. \& Lazarus, R.S. (1981). The health-related functions of social support. Journal of Behavioral Medicine, 4, 4, 381-404.

Scott, D. F. (1978). Psychiatric aspects of epilepsy. British Journal of Psychiatry, 132, 431-440.

Schwartz, R.D. (1977). Epilepsy and employment: A historical perspective. In Commission for the Control of Epilepsy and Its Consequences, Plan for Nationwide Action on Epilepsy, 2 , Part 1, pp. 491-546. 
Selye, H. (1976). The stress of life (rev. ed.). New York: McGraw-hill.

Serpico, J. (1981). Dealing with seizures - the mutual aid way. The Epilepsy Self-help Newsletter, $\underline{3}, 1, p$. 3 .

Shumaker, S. A. \& Brownell, A. (1983, September). A taxonomy of social support: disentangling a conceptual morass. Paper presented at the annual meeting of the American Psychological Association, Anaheim, CA.

Smith, I. I. (1978). Social work with epileptic patients. Health and Social Work, $3,2,158-174$.

Sokolovsky, J., Cohen, C., Berger, D. \& Geiger, J. (1978) . Personal networks of ex-mental patients in a Manhatten SRO hotel. Human Organization, 37, 5-15.

Srole, L. (1972). Urbanization and mental health: some reformulations. American Scientist. 20, 576-583.

Stack, C. (1974) All our kin: Strategies for survival in a black community. New York: Harper \& Row.

Sussman, M. (1959). The isolated nuclear family: Fact or fiction? Social Problems, $6,333-340$.

Tolsdorf, C. C., (1976). Social networks, support and coping: An exploratory study. Family process, 15, $407-417$.

Walker, K. N., MacBride, A., \& Vachon, M. H. S. (1977) . Social support networks and the crisis of bereavement. Social Science and Medicine, 2 , 35-41.

Warheit, G. J. (1979). Life events, coping, stress and depressive symptomatology. American Journal of Psychiatry, 136, 502-507.

Wellman, B. (1979). The community question: the intimate networks of East Yorkers. American Journal of Sociology, 84, 1201-1231.

Wellman, B. (1981). Applying network analysis to the study of support. In B. H. Gottlieb (Ed.), Social networks and social support (pp. 171-200). Beverly Hills, CA: Sage. 
Wellman, B. \& Leighton, B. (1979). Networks, neighborhoods and communities. Urban Affairs Quarterly, 15, 363-390.

Wethington, E. (1982, August). Can social support functions be differentiated: a multivariate model. Paper presented at the 90 th annual meeting of the American Psychological Association, Washington, D.C.

Wilcox, B. I. (1981). Social support in adjusting to marital disruption: A network analysis. In B. H. Gottlieb (Ed.), Social networks and social support (pp. 97-116). Beverly Hills, CA: Sage.

Williams, A.W., Ware, J.E., and Donald, C.A. (1981). A model of mental health, life events, and social supports applicable to general populations. Journal of Health and Social Behavior, 22, 324-336.

Wilson, W. (1967) . Correlates of avowed happiness. Psychological Bulletin. 67, 294-304.]

Wylie, R. C. (1974). The self-concept. Rev. Ed. Vol. I. Lincoln, Neb: University of Nebraska Press. 
APPENDIX A

DATA COLLECTION INSTRUMENTS 
EPILEPSY CENTER OF OREGON/EPILEPSY ASSOCIATION OF OREGON cood Semeritan Mospital and Medical Center

\author{
CONSENT TO PARTICIPATE IN A RESEARCH OATA BASE
}

Resesrch Director: Dr. Casper F. Paulson, Jr.. Epilepsy Center of Oregon (503) 838-1220, $\times 404$ Registry Coordinator: Terri Q. Boggs, Epilepsy Center of Oregon $\quad$ (503) 229-7384

Project: The Comprehensive Epllepsy Program in Oregon, funded by the National Institutes of Health, wishes to create a "Comprehensive Data base" of Information on patients treated for seizure-related disorders in Oregon. The data provided will be used for: (1) identification of potential participants in future epilepsy research projects; (2) studies of the characteristics of epileptics as a group (epidemlological studles--does not require identification of patient's names); (3) clinical management of individual patients. The purpose of this research is to discover new and better woys to provide quality heal th care to patients with epilepsy in Oregon. Data identifying patients (e.g. name, address, social security number) will be kept separate from medical data. The only persons who will see the data associated with their name will be the attending physician, the Registry Coordinator, and the patient. This separation will be accomplished by security codes in the computer program that require certain "passwords" or "codewords," known only to authorlzed persons, before ldentifying data will be provided.

Please read the following, and write your signature below if you understand and wish to participate in this project.

1. I understand the risk of accidental disclosure associated with data base and the proceduras that are being employed to safeguard against any such accidental disclosure.

2. I agree and consent to participate by completing a questionnaire describing the history and symptoms of my disease and treatments 1 am receiving for my medical condition.

3. I understand that the information 1 provide on the questionnaire will be maintained as a confidential medical record, and that my name will not be used in studies, reports, or any printed or created documents produced by the project.

4. I have read the second page of the questionnaire and have indicated if I wish to participate in each part of the project. I understand that this may include being contacted in the future, but that 1 am not comitted to continue or participate in any future project. (The Registry Coordinator will contact the participant by phone or by mail.)

5. I understand that there are no medical risks involved by participating in this Data Base project.

6. I understand that 1 am free to particlpate in or to withdraw from participating in this study, or examine my data, at any time, and it will in no way impair my relationship witin or ereatment by cood Samaritan Hospital and Medical Center or any other treasment center or physician.

7. I understand there is no compensation for participation in this project.

8. I understand that my physician ma supply updating information to the Data base.

9. Dr. Paulson and Terri Boggs have offered to answer any quest ions 1 might have.

I have read and understand the foregoing.

$$
\text { Signature } \overline{\text { Date }}
$$

if signed by someone other than the patient, indicate reason and relationship.

\begin{tabular}{llcc}
\hline Patient's Name & Street Address & City & State Code \\
Phone Number & Physicion's Name & Physician's Address
\end{tabular}


PROGRAM PARTICIPATION:

In this section you may indicate your desire for further contacts and how you wish your name to be used, if at all. Please check each program in which you would like to participate.

1. Voluntarf participation in all aspects of the program, as tney have been explained to me. (You will receive all educational and employment mailings and an opportunity to take part in medical and employment research projects.)

\section{OR}

2. Voluntary participation in medical research programs. (You will receive the opportunity to take part in medical research projects.)

$O R$

3. Voluntary participation in employment problems and opportunity research. (You will receive the, opportunity to take part in an employment research project.)

OR

4. To receive educational and employment literature. (You will receive all educational and employment mailings.)

$O R$

5. Other. (If you wish a type of participation not mentioned above, write it here and you will be contacted regarding its possibility.;

To volunteer my information for staistical purfoses only, witn no personal contact or mailings. (The information you provide .vill se used only for compiling statistics to assist us in our studies, ou: ve will not contact you for researcn involvenent or send you an: 0 : the various mailings.) 
Regloasl Research Institute for Human Services

Portland State Unlversity

EPILEPSY, DISCLOSURE, and IOB

PLACEMENT PROJECT

First of all, we would like to know if ary changes have octurred in your emplobment situation siace the last time we were in touch.

hien ycu filled out the yelicw and blue gucstionnaire, you were not workings Thit wiss on

Have you had any jobs since tisen?

EYeS - HOW maרy?

$\square$ No $\longrightarrow$ SKIP AUL DF THE GREEN PAGES ANO GO ON TO THE 
Nivile of Employer

to

inuntht $\overline{\text { year }}$

month 1 year

linb title

: Wh di:tics

S:11arjs.

per

linurs per week worked

1. How did you get the job? (Cr.eck one)

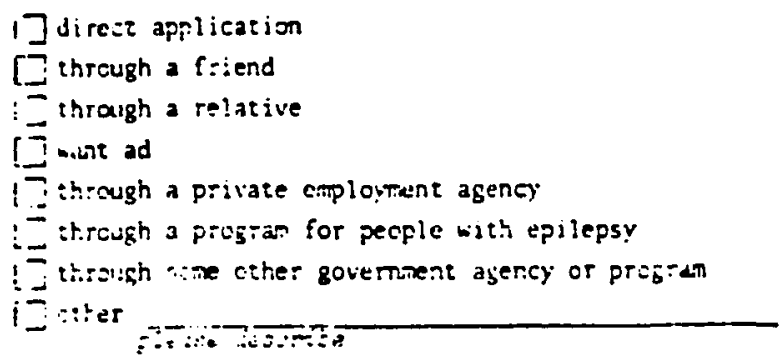

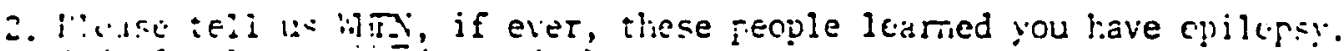

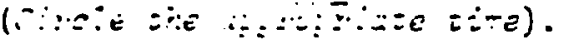

\begin{tabular}{|c|c|c|c|c|c|c|}
\hline \multirow{4}{*}{$\begin{array}{l}\text { chech tere if } \\
\text { s.te ; etcri }\end{array}$} & $\begin{array}{l}\text { Te:-le wro } \\
\text { rire \& Ej:e }\end{array}$ & EA & $\mathrm{BH}$ & Ah & $\boldsymbol{N}$ & $\mathbf{T}$ \\
\hline & $=$ suptervisir & BA & BH & An & $x$ & $\mathrm{NF}$ \\
\hline & $\begin{array}{l}\text { Feilow } \\
\text { ticyees }\end{array}$ & BA & BH & $\lambda k^{\circ}$ & $N$ & $\mathbf{~} \mathbf{P}$ \\
\hline & $\begin{array}{l}\text { So-ple I } \\
\text { Shinidsed }\end{array}$ & 3A & QH & $i H$ & 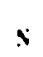 & $\mathbf{S P}$ \\
\hline
\end{tabular}

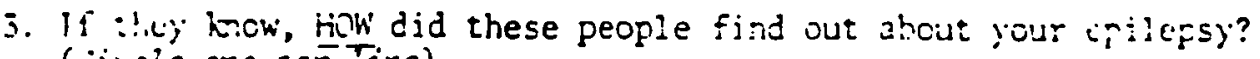

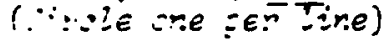

\begin{tabular}{|c|c|c|c|c|c|c|}
\hline \multirow{4}{*}{ 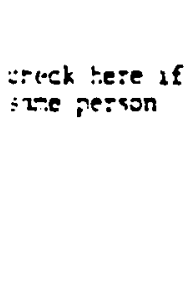 } & $\begin{array}{l}\text { Fecfle who } \\
\text { thre \& f: }\end{array}$ & IT & 5T & SS & $2 x$ & $\mathbb{P}$ \\
\hline & 'Suplenisct & IT & ST & 55 & $5 k$ & TT \\
\hline & $\begin{array}{l}\text { Fellow } \\
\text { exployees }\end{array}$ & IT & ST & SS & $\mathrm{Mk}$ & IT \\
\hline & $\begin{array}{l}\text { Peop!e I } \\
\text { supervised }\end{array}$ & IT & $5 T$ & SS & DK & AP \\
\hline
\end{tabular}


4. If you had it to do over again, would you wart these people to krow abrut your seizures? (Circle yes or no)

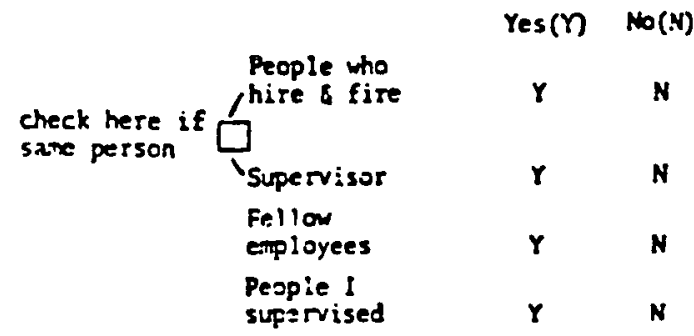

5. In your opinion how dangerous would a seizure on this job be?

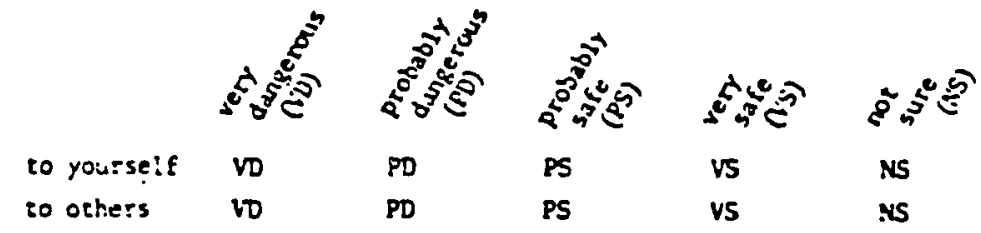

6. Ary seizures on this job?

$\square$ Yes - How mary were grand mal?

How mary were oiter kinds?

№

7. How woild you rate your satisfacticr with this job? (Cirgie one)

\begin{tabular}{|c|c|c|c|c|}
\hline $\begin{array}{l}\text { verv } \\
\text { sal:sfied: }\end{array}$ & $\begin{array}{l}\text { sonewhat } \\
\text { sa::sf:ed }\end{array}$ & $\begin{array}{c}\text { pret:v } \\
\text { neu::al }\end{array}$ & 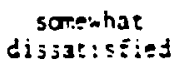 & $\begin{array}{c}\text { very } \\
\text { dissat } 2 \leq: \text { ed }\end{array}$ \\
\hline vs & ss & $P_{i r}$ & so & VD \\
\hline
\end{tabular}

8. If you 'ion't work here anymore, why did you leave?

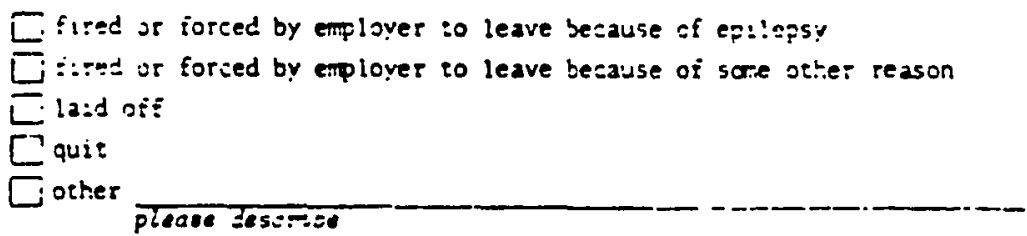

9. Di.i yci leave this job for any of the foilowirg reascns? (Iingie jes or mo)

\begin{tabular}{|c|c|}
\hline fer a betcer job & $Y$ \\
\hline ep:iefsy & $\mathbf{Y}$ \\
\hline other health problems & $\gamma$ \\
\hline poor working condi:ions & $\mathbf{Y}$ \\
\hline to travel & $\mathbf{Y}$ \\
\hline$t=$ yo :o scheol & $\mathbf{Y}$ \\
\hline did not like fellow emplorees & $\mathbf{Y}$ \\
\hline t) care for fasily & $\mathbf{Y}$ \\
\hline haviles at work & $Y$ \\
\hline
\end{tabular}

IF YOU HAVE HELD ANY OTHER JOBS SINZE

STARTING THIS ONE. PLEASE FII.L GUT

ANOTHER GREEN SHEET FOR EACH O:NE.

OTHERWISE. GO ON TO THE PINK SECIION. 
ivile of $E_{m i n}$ ]oyer

rrum iningth year to montht-year

Wb title

. A d d t ics

Silinitys _.... per _... . -

inurs per heek worked .. - _....

1. !'on did you get the job? (cr.eck or.e)

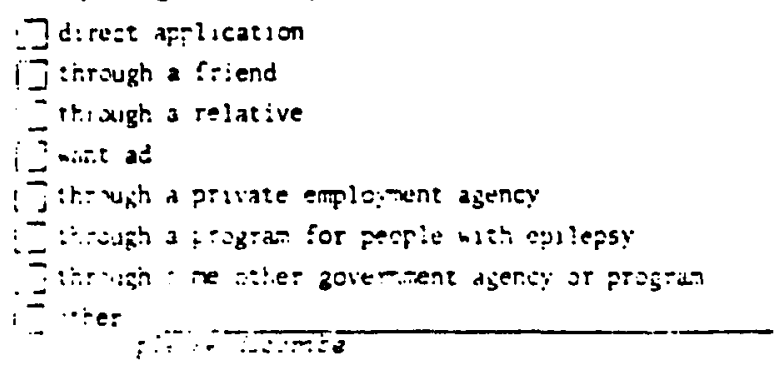

$2 . \because: 0$ :

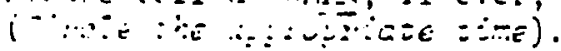

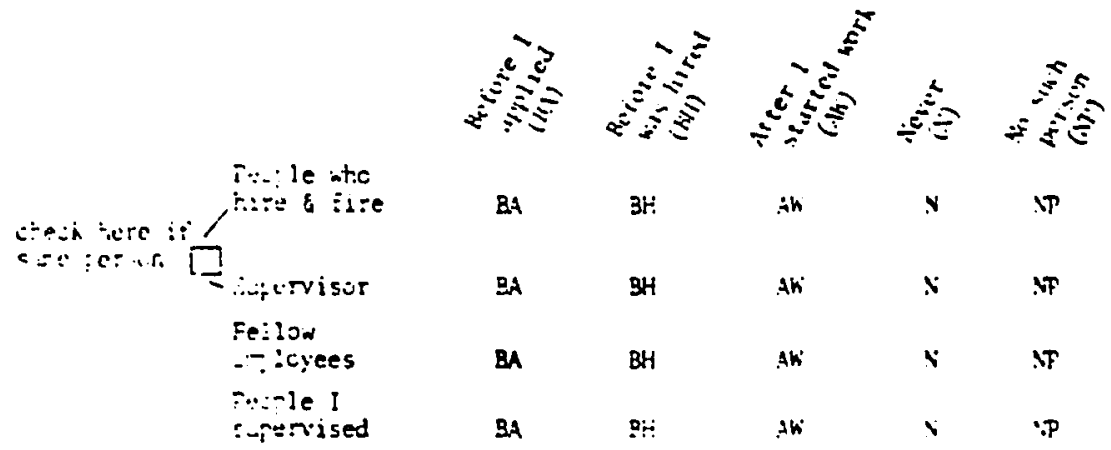

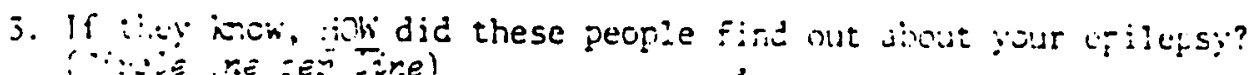

\begin{tabular}{|c|c|c|c|c|c|c|}
\hline \multirow{4}{*}{ 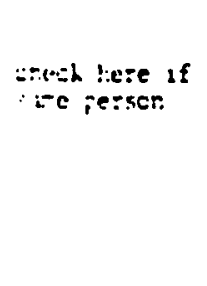 } & $\begin{array}{l}\text { Fecrle who } \\
\text { t:: is fire }\end{array}$ & i: & 5 & ss & $n k$ & $\mathbf{I P}$ \\
\hline & 'Strientisor & IT & 5 & S5 & $x$ & sT \\
\hline & $\begin{array}{l}\text { Fe! low } \\
\text { erf!cyees }\end{array}$ & IT & $S T$ & $5 \Sigma$ & nit & $\mathrm{T} T$ \\
\hline & $\begin{array}{l}\text { Iesple I } \\
\text { supervised }\end{array}$ & IT & $5 i$ & SS & DK & \\
\hline
\end{tabular}


4. If you had it to do over again, would you want these people to know abrut your seizures? (Cirele yes or no)

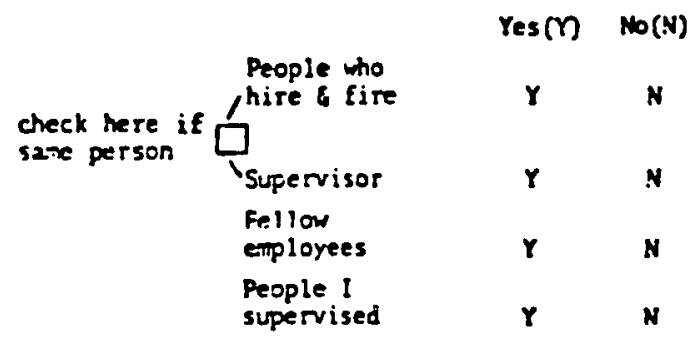

5. In your opinion how dangerous would a seizure on this job be?

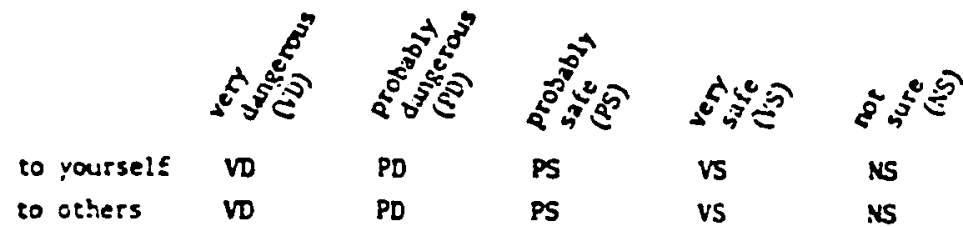

6. Any seizures on this job?

Yes - How many were grand mal? How mary were oiter kinds?

$\square$ No

7. How would you rate your satisfaction with this job? (Circie one)

\begin{tabular}{|c|c|c|c|c|}
\hline $\begin{array}{c}\text { verv } \\
\text { sa:tsfied }\end{array}$ & $\begin{array}{l}\text { sonentits: } \\
\text { sa:25f:ed }\end{array}$ & $\begin{array}{r}\text { pretty } \\
\text { neutral }\end{array}$ & $\begin{array}{l}\text { somewhat } \\
\text { dissatisiied }\end{array}$ & $\begin{array}{l}\text { very } \\
\text { dissatisfied }\end{array}$ \\
\hline vs & SS & PN & SD & VD \\
\hline
\end{tabular}

8. If you don': work here anymore, why did you leave?

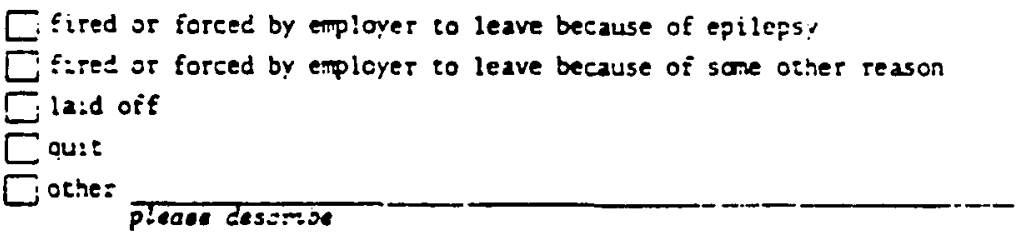

9. Nid you leave this job for any of the following reasons? (Circie jes or ro)

\begin{tabular}{|c|c|}
\hline for a better job & \\
\hline ep: :epsy & \\
\hline other health problems & Y \\
\hline poor wrking conditions & $\mathbf{Y}$ \\
\hline to travel & $Y$ \\
\hline to yo to school & $\gamma$ \\
\hline did tot lite fellow employees & $\mathbf{Y}$ \\
\hline to case for fanalv & \\
\hline hasiles at work & \\
\hline
\end{tabular}

IF YOU HAVE HELD ANY OTHER JOBS SINCE STARTING THIS ONE. PLEASE FIILL OUT ANOTHER GREEN SHEET FOR EACH CINE. DTHERWISE. GD ON TO THE PINK SECIION. 
Nivile of Employer

Prum inuntht $\overline{\text { year }}$ to $\overline{\text { month }}+\overline{y e a r}$

inb title

ish di:ties

S:1]ат: per $-\ldots .$.

iinurs per week worked

1. !inw did you get the job? (F.eck one)

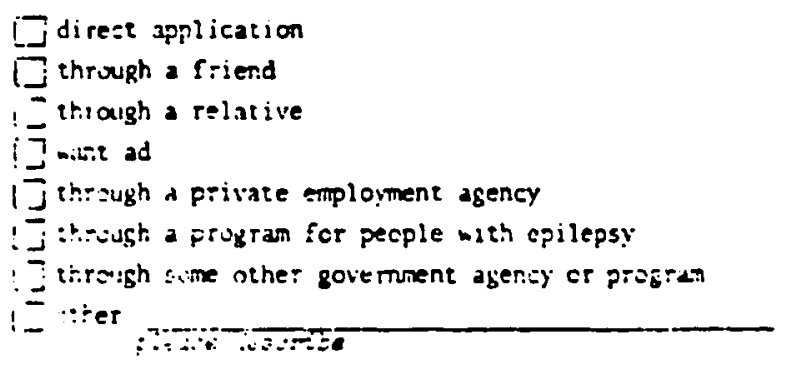

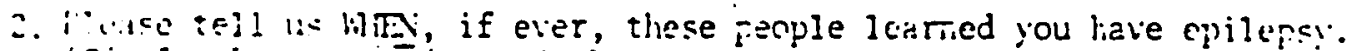

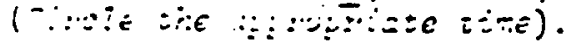
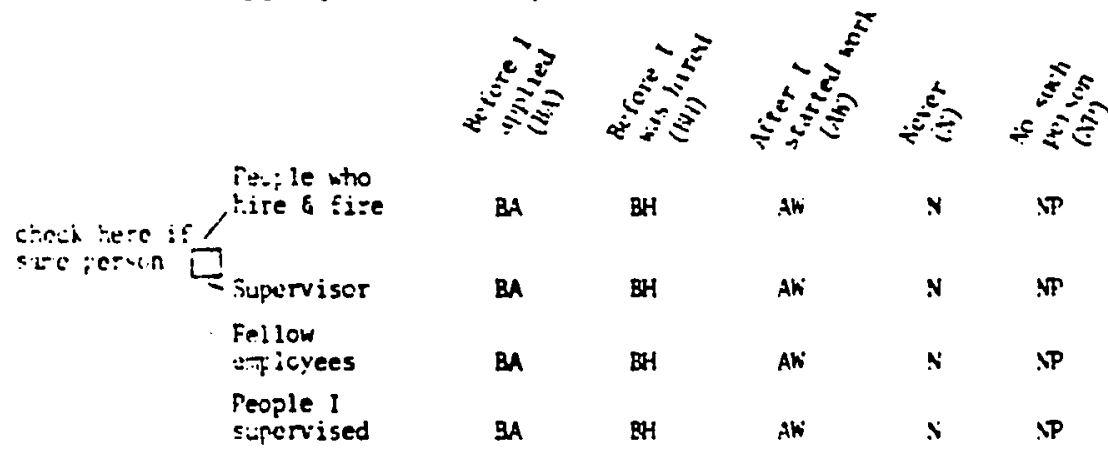

$\begin{array}{lllll}B A & B H & \text { AW } & N & N P \\ B A & B H & A W & N & N P \\ B A & B H & A W & N & N P \\ \text { BA } & \text { BH } & \text { AW } & N & \mathbb{N}\end{array}$

5. 11 :

U. ine zer Tires

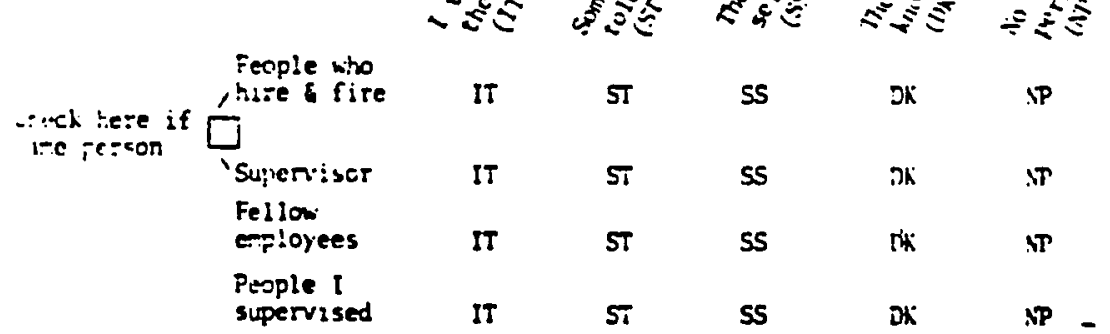


4. If you had it to do over again, would you want these people to krow abiut your seizures? (Circle yes or no)

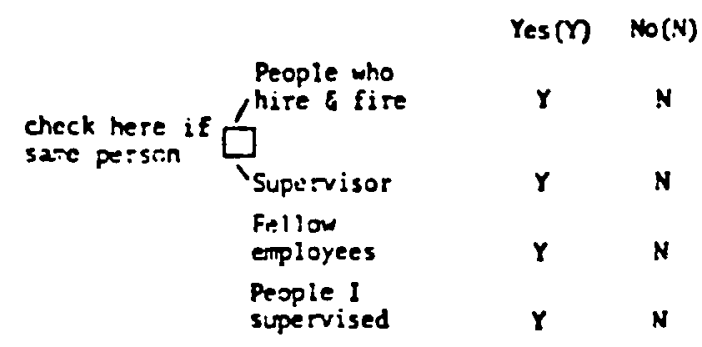

5. In your opinion how dangerous would a seizure on this job be?
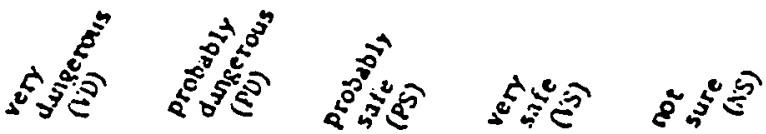

to yourself VD

PD

PS

vs

NS

to others

vD

PD

PS

VS

NS

6. Any seizures on this job?

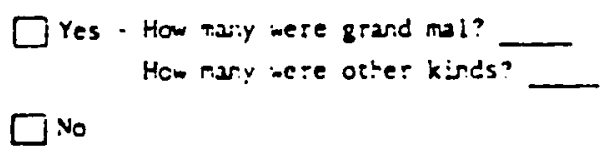

7. How weuld you rate your satisfacticn with tisis job? (Circie one)

\begin{tabular}{|c|c|c|c|c|}
\hline $\begin{array}{c}\text { ver } \\
\text { sat:sti:eri }\end{array}$ & $\begin{array}{l}\text { sorewhiz: } \\
\text { sa: is:i:=d }\end{array}$ & $\begin{array}{r}\text { pre::y } \\
\text { neus:al }\end{array}$ & $\begin{array}{c}\text { surewhat } \\
\text { disjatisîed }\end{array}$ & $\begin{array}{c}\text { very } \\
\text { dissatisised }\end{array}$ \\
\hline vs & ss & PN & SD & $V D$ \\
\hline
\end{tabular}

8. If you don't work here anymore, why did you leave?

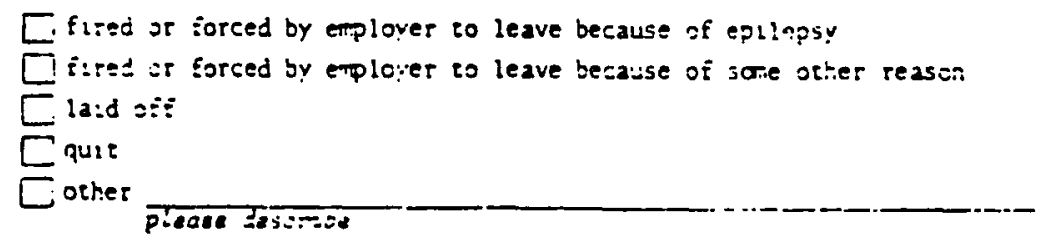

9. Did you leave this job for any of the following reasons? (Gincie jes or ro)

for a better job
epilepsy
other health problens
poor working conditzons
to travel
to go so schcol
d:A not like fe!lou employees
t care for fandlv
has:les at wo:k

$\begin{array}{ll}Y & N \\ Y & N \\ Y & N \\ Y & N \\ Y & N \\ Y & N \\ Y & N \\ Y & N \\ Y & N\end{array}$

IF YOU HAVE HELD ANY DTHER JCBS SINEE STARTING THIS ONE, PLEASE FILL OUT ANOTHER GREEN SHEET FOR EACH ONE. OTHERWISE. GO ON TO THE PINK SECIICN. 
We would like to know something about the people you know well who are not living in your home. Please inake a list of these prople. We will not be contacting them and you may use just their first names if you wish. List as many persons as you like. (It may be more or less than the spaces allowed below).

Then fill in the other squiles for each person.

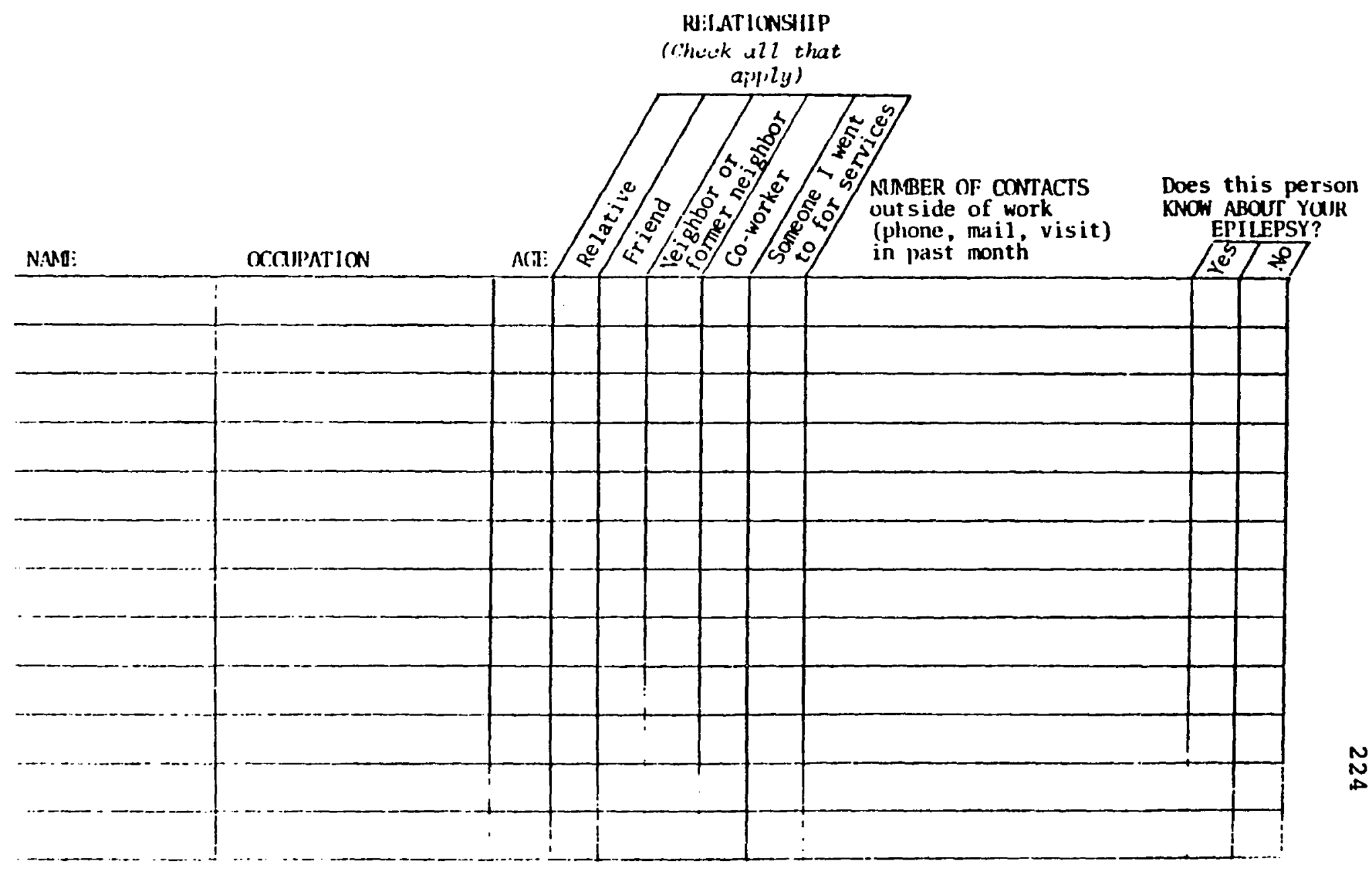


1. Please list any clubs, groups or organjzations you bejong to (such as a howl ing Jeague, church group, social club, etc.)

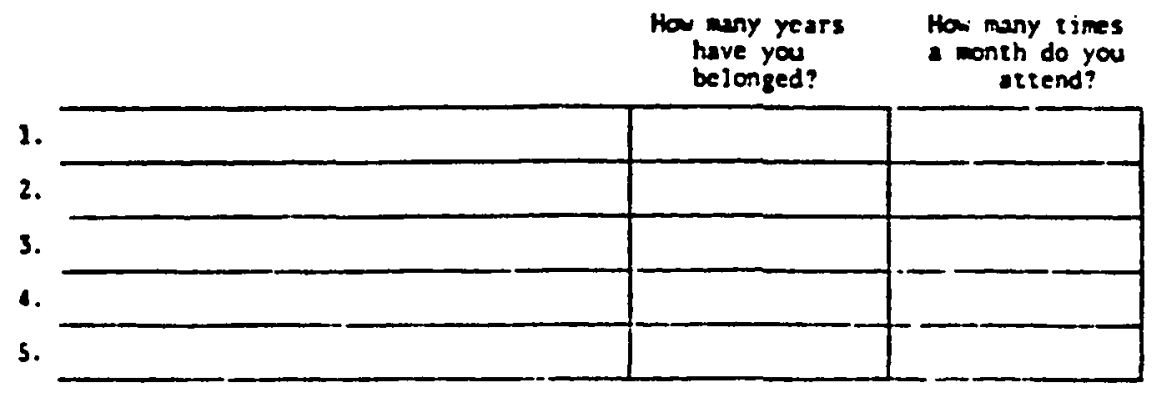

2. Do you have any hobbies or engage in any sports that do not involve ncribership in an organization?

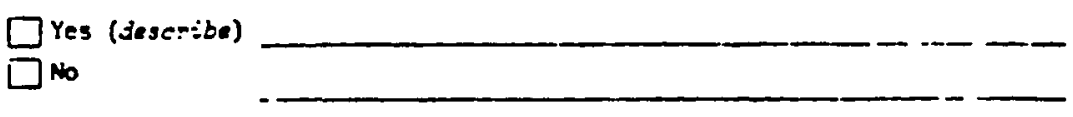

3. On the average, how often do you go out in the evening, for example - to a restaurant, a show, a sports event, or to a friend's house? (FiEaz= sircie ti.e answer that somes closest)

\begin{tabular}{|c|c|c|c|c|c|}
\hline Daily & neeily & Montinly & $\begin{array}{l}\text { Thice } \\
\text { a year }\end{array}$ & Yearly & $\begin{array}{l}\text { Less than } \\
\text { once a ycar }\end{array}$ \\
\hline D & w & $M$ & $T \gamma$ & $\mathbf{Y}$ & LY \\
\hline
\end{tabular}

4. Do you feel like vou are frart of a close group of frichis? yes io

5. How many of your friends know each other? (Cirnie ure)

$\begin{array}{ccccc}\text { Al } & \text { Most } & \text { Some } & \text { A few } & \text { ione } \\ \text { A } & M & S & \text { F } & \text { N }\end{array}$

6. How much contact (Fhone, mail, visit) do you have with:

(ciir:ie one :er ijr.e)

\begin{tabular}{|c|c|c|c|c|}
\hline Yout !amily & $\mathbf{M}$ & هִ & VE & NS \\
\hline Your friends & M & $\sqrt{R}$ & . $\mathrm{E}$ & is \\
\hline Feople you work with & TM & P & VE & NS \\
\hline Neighiors & MI & $\pi$ & NE & NS \\
\hline
\end{tabular}

7. Has there been a change in the last 6 nonths in how much contact yo: have with:

Your friends Feople you work with veightors

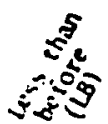

LB

L

18

LB

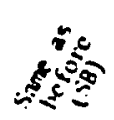

58

$5 B$

SB

58

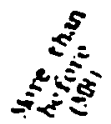

BB

9

4

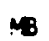

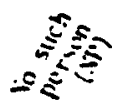

NI'

NF

NP

NP 
This last section asks you to think about how your life is going in ycneral.

8. How satisfied with your life as a whole are you these days? (Circle one)

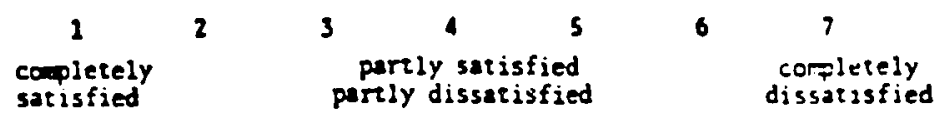

D. In general how are things going compared to when you filled out the yellow and blue questionnaire? (Circle one)

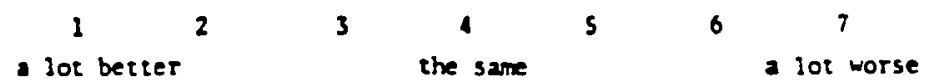

10. Hicre are some words and phrases which we would like you to use to describe how you feel about your present life. For example, if you thisk your present life is very boring, put an $X$ in the box right next to the word 'boring'. If you think it is very interesting, put an $X$ in the box right next to the word 'interesting'. If you think it is somewhere in be:ween, put an $X$ where you think it belongs. (Zut an $X$ in one bcs or eash i ive.)

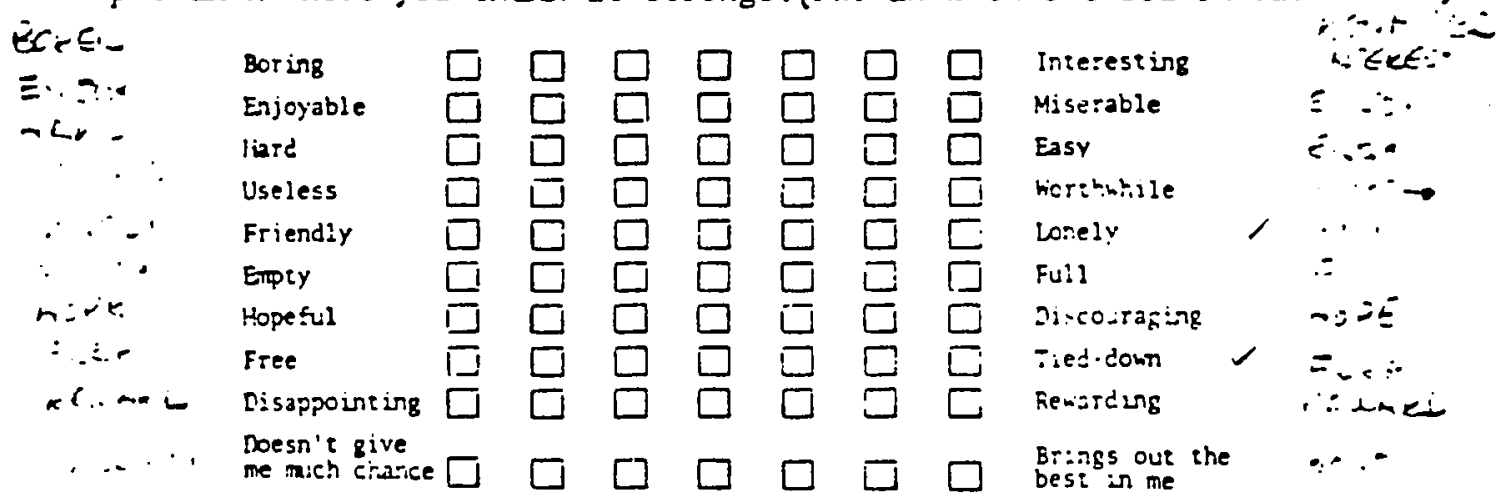

11. How impcrtant has epilepsy been in inf:uencing the way you feel about yiidr ilfe? (Circle one)

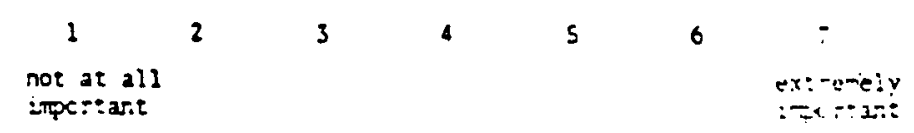

THANKS AGAIN FOR DOING THIS QUESTIONNAIPE. THE IATERVIENER WILL PICK IT UP WHEN SHE COMES TO SEE YOU. - 
The first thing we want to do is clieck on our inforration about your seizires.

1. Kirat kind of seizures do you have?

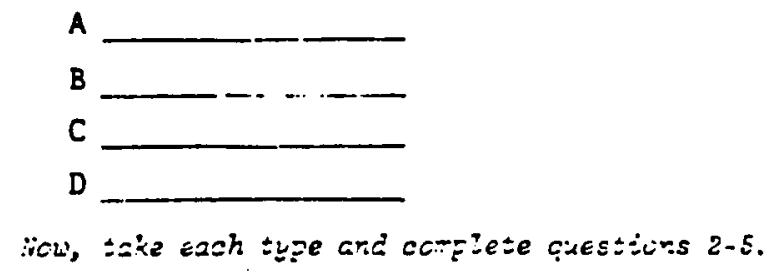

2. What do the seizures lock like?

A

B

C

D

If since

last questionraire

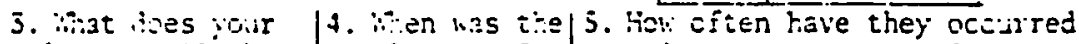
\begin{tabular}{l|l|l|l|}
\hline & \\
\hline & & \\
\hline & & \\
\hline
\end{tabular}

Seizure frequency codes

2 - Iess than one per year
3 - one per year
4 - $2-4$ per year
5 - $5-12$ per year
6 - more than once/7onth
7 - rore itan once/heek
8 - icre than once'day
9 - respondent can't say

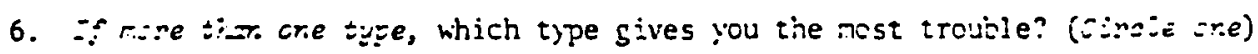

A

B

C
D $\quad \mathrm{At}$
(only one type or none is problematic)

7. Besides the seizures themselves, do feople tell you about things you do, which you think are caused by the epilepsy?

Q ies - cescribe

W 
8. What medications are you taling? (rake each type of redication ard complete 228 questions 9-22).

Same

9. How long have you taken? (yTs)

10. !low pills/ ofter/
day?

12. Change in medication*
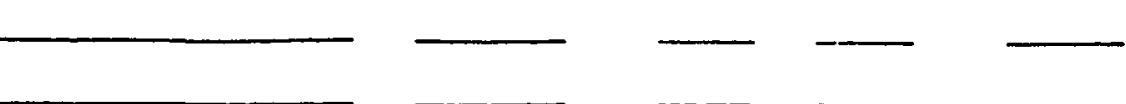<smiles>C=CCCC</smiles>
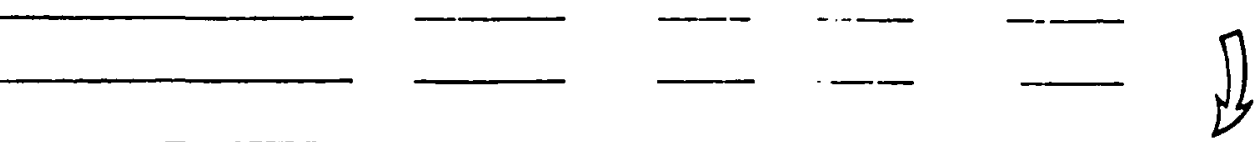

12. * Five you made any changes on your own in the emount of this recication prescribed for you?

$$
\begin{aligned}
& 1 \text { - no change } \\
& 2 \text { - more } \\
& 3 \text { - less } \\
& 4 \text { - stopped taking }
\end{aligned}
$$

13. Do you do anything else to avoid seizures?

$$
\begin{aligned}
& \square \text { Iies }-~ \square \text { avoid alcohol } \\
& \square \text { avoid drugs } \\
& \square \text { avoid stress } \\
& \square \text { proper rest } \\
& \square \text { exercise } \\
& \square \text { diet - cescribe } \\
& \square \text { other - iescribe }
\end{aligned}
$$

14. How often do you forget to take your medication as scheduled?

$$
\begin{aligned}
& \text { Eabout every day } \\
& \square \text { about once a week } \\
& \square \text { about once a month } \\
& \square \text { almost never } \\
& \text { E never }
\end{aligned}
$$

15. How satisfied are you that your epilepsy is being treated as well as it can be?
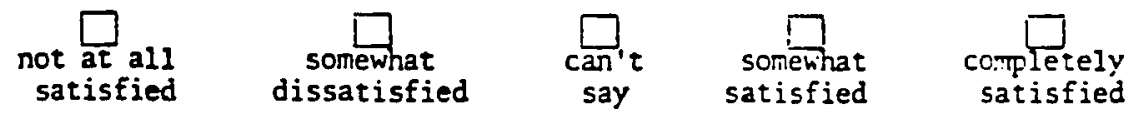

16. I want to ask you about how your seizure control is now compared to some times in the past. Flease look at the orange card and tell me how such better or worse it is now compared to:

\begin{tabular}{l|c|c|c|c|c|c|c} 
& $\begin{array}{c}\text { much } \\
\text { better } \\
\text { now }\end{array}$ & $\begin{array}{c}\text { better } \\
\text { now }\end{array}$ & same & $\begin{array}{c}\text { worse } \\
\text { now }\end{array}$ & $\begin{array}{c}\text { much } \\
\text { worse } \\
\text { now }\end{array}$ & $\begin{array}{c}\text { didn't have } \\
\text { epilepsy } \\
\text { then }\end{array}$ & $\begin{array}{c}\text { can't } \\
\text { remember }\end{array}$ \\
\hline I y'ear ago & & & & & & & \\
\hline $\begin{array}{l}\text { syears ago } \\
\text { when you were } \\
\text { around 15 or 16 }\end{array}$ & & & & & & & \\
\hline $\begin{array}{l}\text { when you were } \\
\text { in grade school }\end{array}$ & & & & & & & \\
\hline
\end{tabular}


17. Sow I would like to ask you about hito on your (current job hrowis) about your epilepsy. Please look at the cream card and tell me:

18. Who you told personally about your epilepsy?

\begin{tabular}{|c|c|c|c|c|}
\hline \multirow{5}{*}{$\begin{array}{l}\text { Froo } \\
\text { check here if } \\
\text { sarie person }\end{array}$} & for $(a c h)$ & $\begin{array}{l}\text { les } \\
(y)\end{array}$ & (N) & $\begin{array}{l}\text { Not applicable } \\
(\mathrm{NA})\end{array}$ \\
\hline & $\begin{array}{l}\text { People who } \\
\text { /hire \& fire }\end{array}$ & $Y$ &. $\mathrm{~V}$ & VA \\
\hline & 'Supervisor & $Y$ & $\mathrm{~N}$ & $\mathrm{iA}$ \\
\hline & $\begin{array}{l}\text { Fellow } \\
\text { employ'ees }\end{array}$ & $Y$ & $\therefore$ & iH \\
\hline & $\begin{array}{l}\text { Feople I } \\
\text { supervised }\end{array}$ & $Y$ & $\mathbf{N}$ & NA \\
\hline
\end{tabular}

19. Who now knows (or knew) that you have epilepsy?

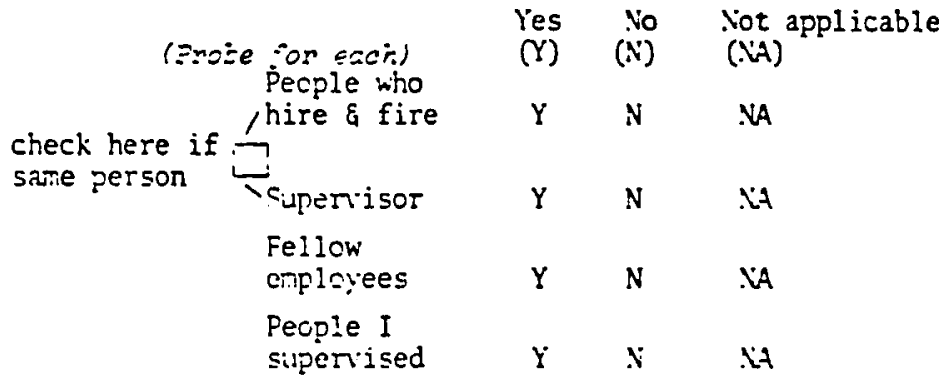

20. Did you tell aryene at work what to do or what not to do in case you had a sei=ure?

\begin{tabular}{|c|c|}
\hline 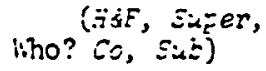 & What instructions? \\
\hline & \\
\hline
\end{tabular}

21. (Is arijene knows)

Iid any of these people become more friendly or less friendly after they found out you had epilepsy?

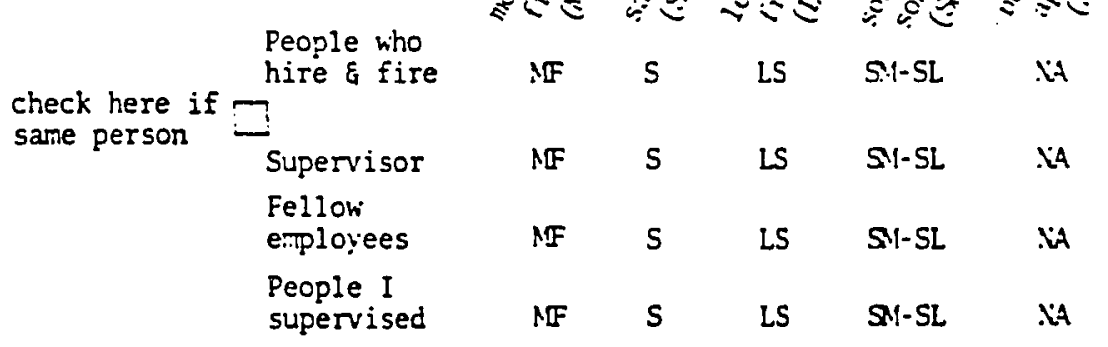

22. Did you have a seizure on this job? I tio - (oo to gestion 2s, bctto- c? pase 4).

Yes - (sontirue) 
I would like to ask you a few questions about the first seizure you had on this job.

23. Did anyone try to help you during the seizure?

24.

(Ask questions $23 \& 24$ about each jes'sen liko ine:-ed) Did you feel that (bis, Super,

Who? Co, sub) ( What did they do? they did the

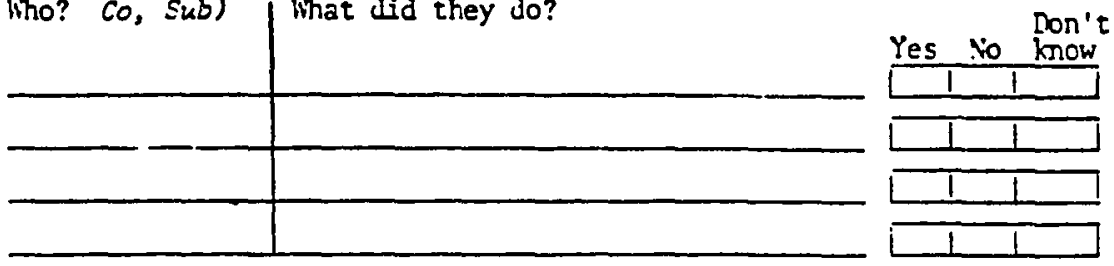

25. Afterwards, did you give anyone any instructions or information about epilepsy?

\begin{tabular}{l|l} 
Who? $\begin{array}{l}\text { (asF, Super, } \\
\text { co, sut) }\end{array}$ & What did you tell them? \\
\hline & \\
\hline
\end{tabular}

26. Did any of these people become more friendly or less friendly after you had a seizure at nork?

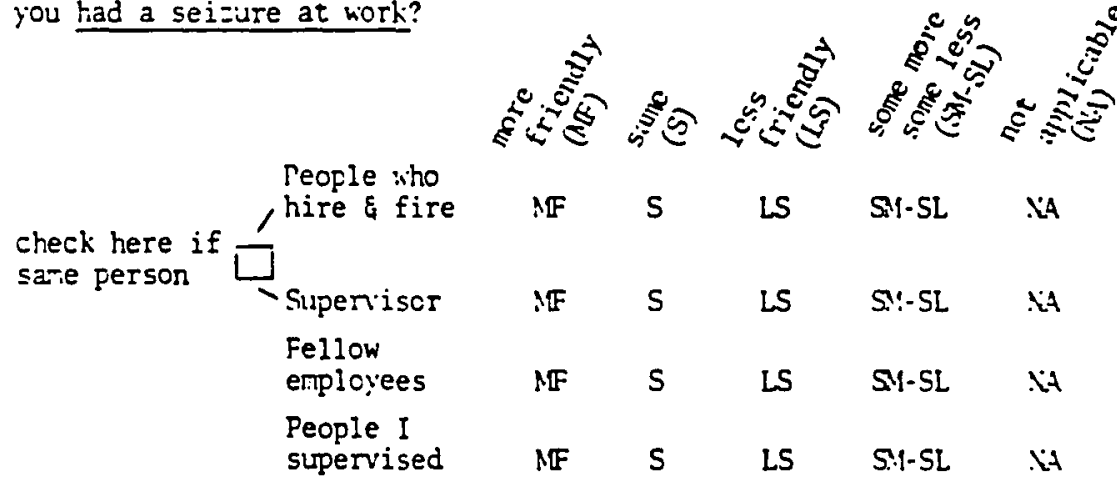

27. Did anything shange in your work assignment as a result of the seizure?s;?

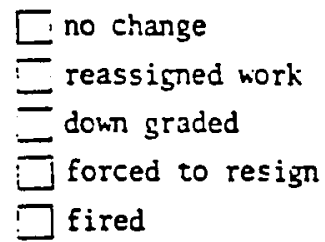

28. lie are interested in knowing what seriices people are using, and what otiner services people need. I'm going tu read a list of prograns or services and ask you if you have ever heard of or participated in any of them.

\begin{tabular}{|c|c|c|c|c|c|}
\hline & $\begin{array}{c}\text { never } \\
\text { heard of }\end{array}$ & $\begin{array}{l}\text { know about } \\
\text { but never used }\end{array}$ & 1 or $\frac{\cos t a c t}{2}$ & $\begin{array}{l}\text { former } \\
\text { client }\end{array}$ & $\begin{array}{l}\text { current } \\
\text { client }\end{array}$ \\
\hline \multicolumn{6}{|l|}{ V.A. Hospital } \\
\hline \multicolumn{6}{|l|}{$\begin{array}{l}\text { Seizure Clinic at } \\
\text { Medical School }\end{array}$} \\
\hline \multicolumn{6}{|l|}{$\begin{array}{l}\text { Oocational } \\
\text { Rerabilitation }\end{array}$} \\
\hline \multicolumn{6}{|l|}{ Emplosment Service } \\
\hline \multicolumn{6}{|l|}{ lielfare } \\
\hline IAPS & & & & & \\
\hline
\end{tabular}




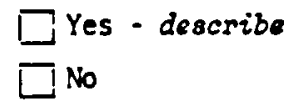

30. How about the Epilepsy League (Bette Stokes)?

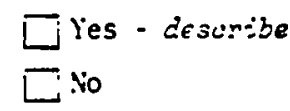

31. Are there anj sen-ices you use that I have not mentioned?

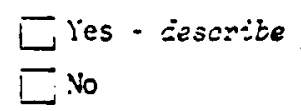

32. Are there senices you have tried to get and could not?

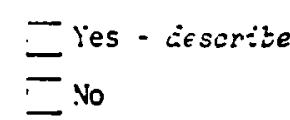

:ich I'd Iihe to ask you some questions about how epilepsy affects your life outside of work - like in the things you do for fun, or like going shopping activities that take you out in public.

53. Are there things you would like to do which you don't do because of epilepsy?

$$
\begin{aligned}
& \text { ZYes - cessrije } \\
& \text { Z io }
\end{aligned}
$$

54. Are there any special things you do before going out or while you are out that seem to reduce the chance of having a seizure?

$$
\begin{aligned}
& \text { - Yes - cescribe } \\
& \text { — No }
\end{aligned}
$$

35. When you are out, do you ever tell people what to do in case you have a seizure?

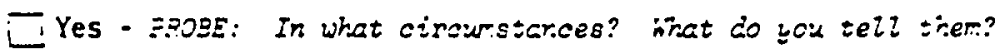

$$
\begin{aligned}
& \text { - io }
\end{aligned}
$$

36. liave you had any really bad experiences with people as a result of having a seizure while you vere out in public?

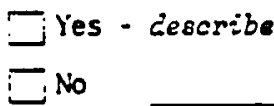




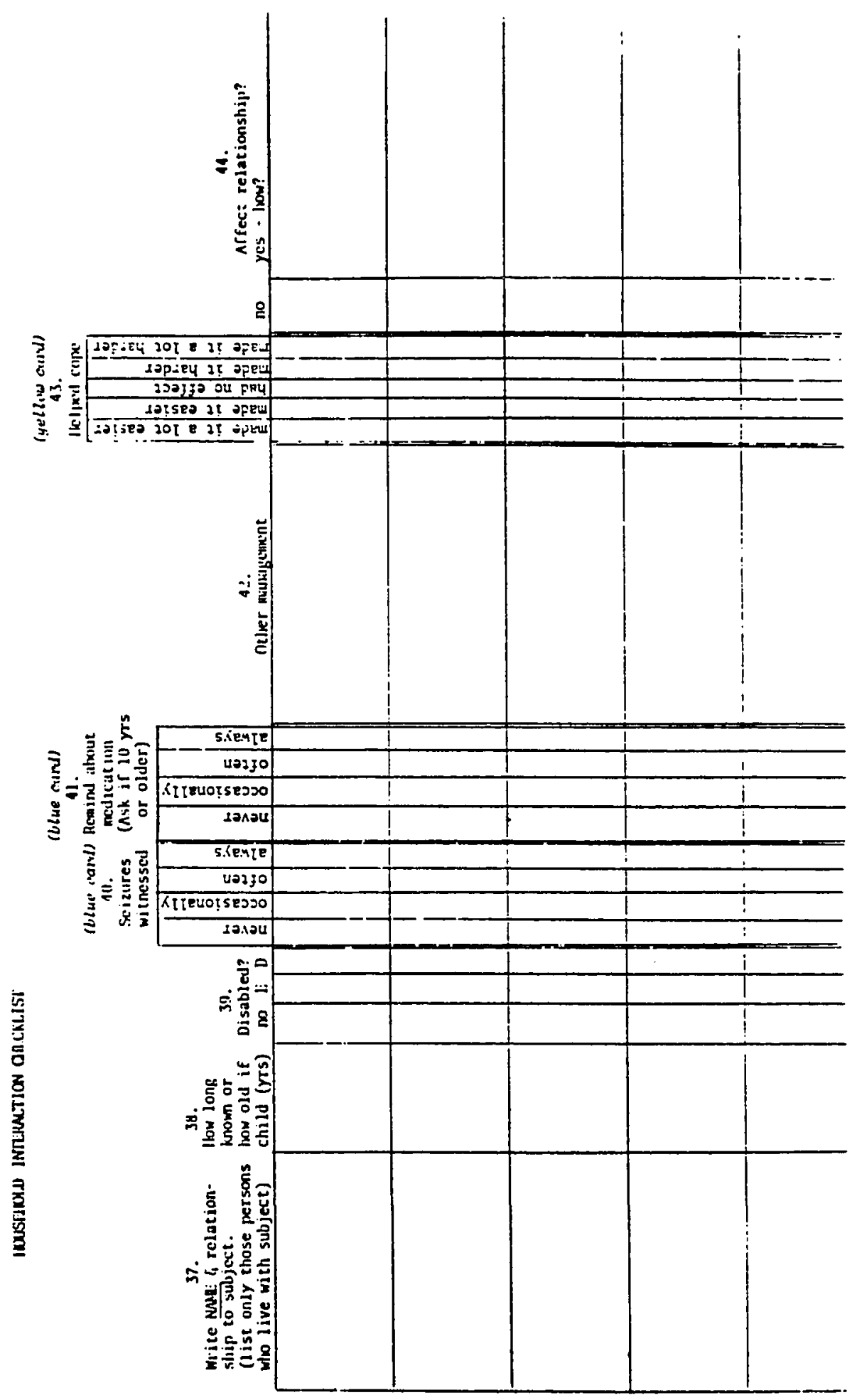




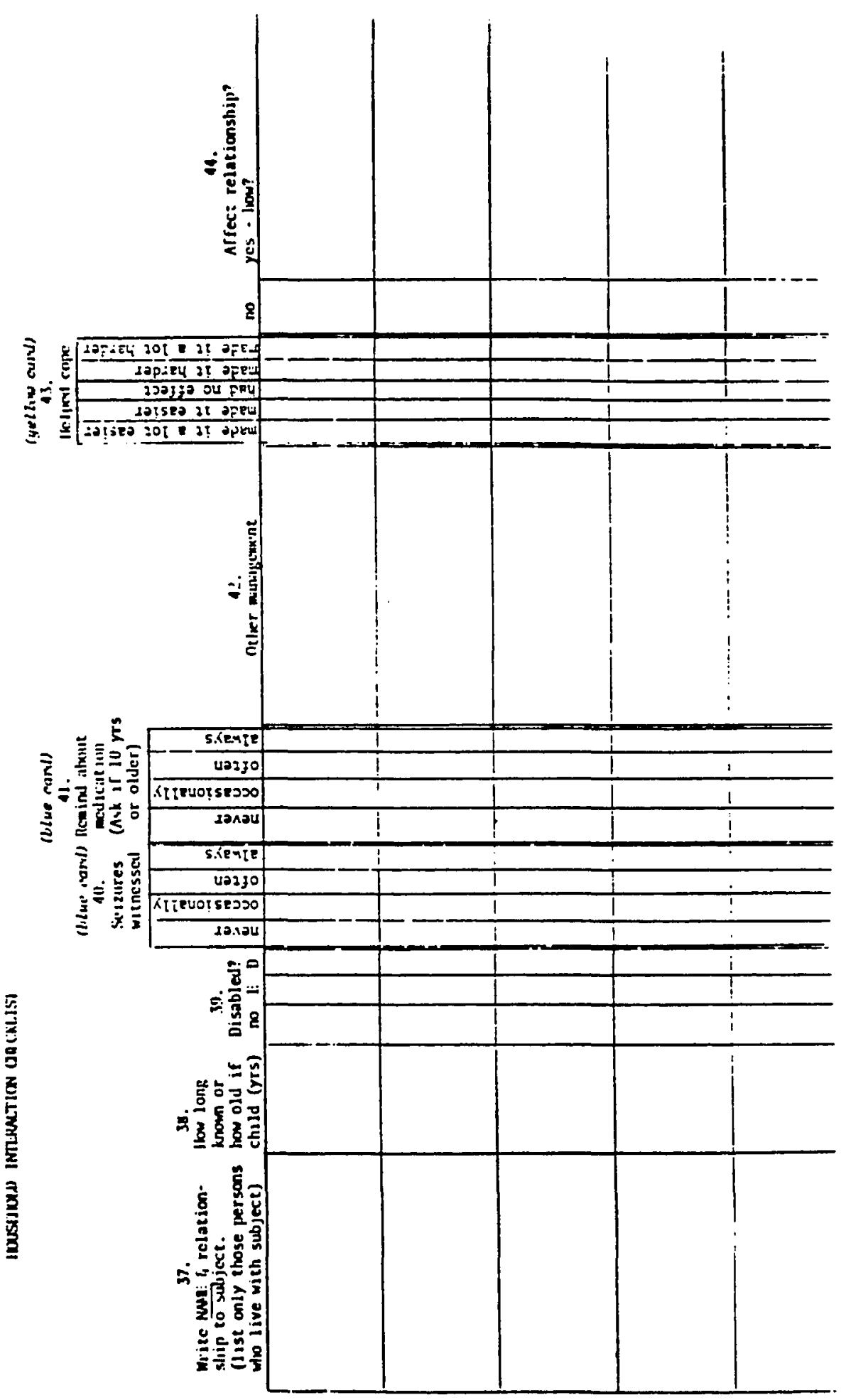




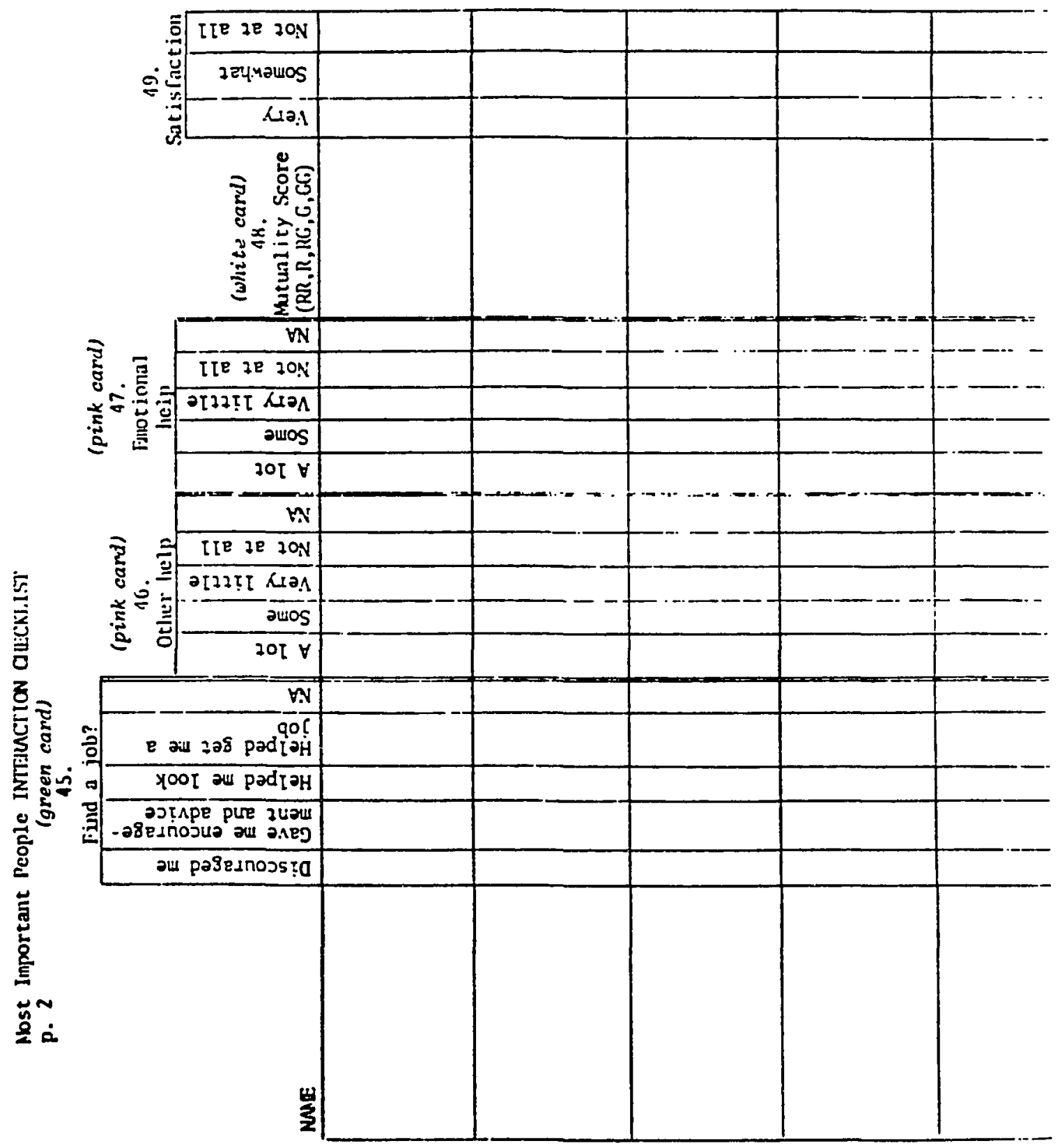


50. In the questionnaire you filled out, we asked you what your job(s) paid. besides salaries and kages, we hould like to $\mathrm{kncw}$ generally wiat other incone YOU personally had in the past ycar. Please put a check in the linx 235 which describes how riluch jou have received from what sources during the past year.

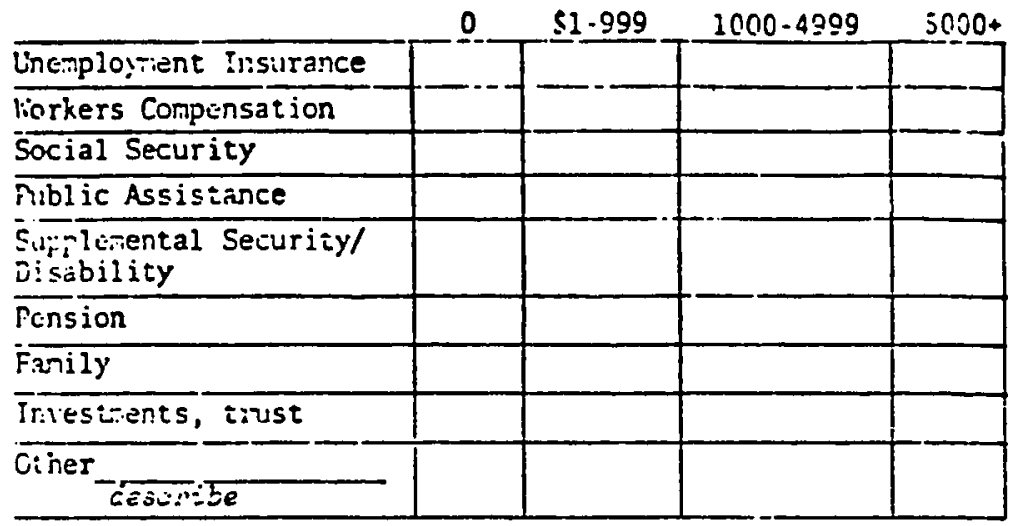

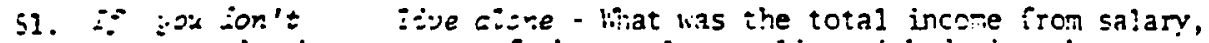
aiges, aid citier sourtes of tie people you live with ciuring the past year?

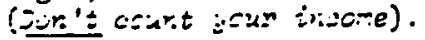

$$
\begin{aligned}
& \square-4,999 \\
& 5,000-9,999 \\
& \square 10,000-14,999 \\
& 15,000-19,099
\end{aligned}
$$

52. Ices anyone depend on you for financial support?

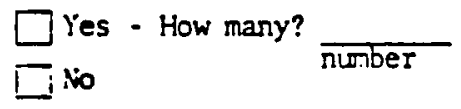

55. What did (does) your father do for a living?

54. Hok rany years of school did he have?

55. What did (does) your mother do?

56. How many years of school did she have? nisher

If sintiect is not tire main breacininer and not living with zarer.ts - ils: is trie main jreativirner's occupation and relatisrsitip to su'ileat?

57. lihat does do?

59. How many years of school did he/she have? number

\section{BE SURE TO COLLECT:}

- CARDS

- hIAILED QUESTIONNAIRE

- TENNESSEE SELF-CONCEPT FORM

IS THE ID ON THE QUESTIOHNALRE? 
DFISITn M4TRIX for "Feople you Ninow Best List"

Nimber the people identified on the "People you Know Best List". Take the first person and read down column 1 in the matrix below putting an $X$ in the appropriate box for each individual known to person 1 . Do the sare for each person listed.

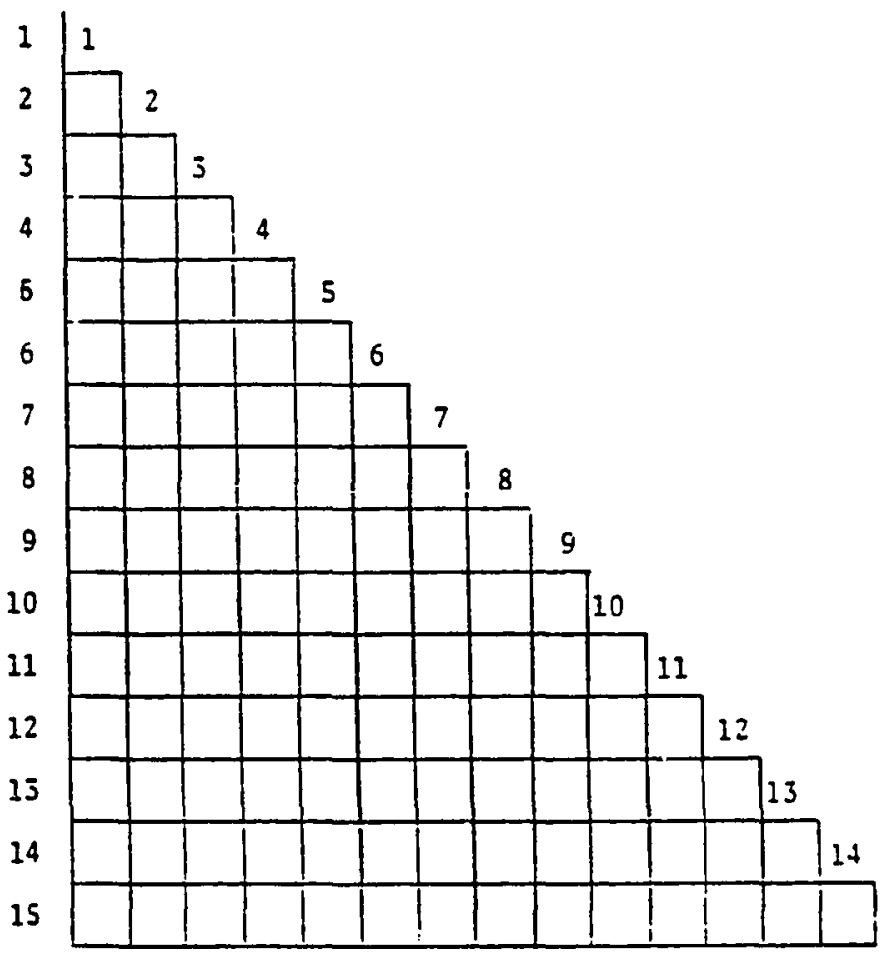


Hite the names of those persons living with subject on the Household Interaction Checklist. Then ask questions 37-44 below for each person listed.

After you have completed the Household Interaction Checklist - go back to the list of "People you know best" from the mailed portion.

Ask subject to:

A. Draw lines connecting the people who know each other, and

B. Put an $X$ by the names of the 5 people who are most important to you.

Enter the 5 rames on the Nost Important People Interaction Checklist and ask questions $37-49$ about each one, recording answers on the chart.

37. What is 's relationship to you?

38. How long have you known $?$

39. Does have epilepsy or any other disability?

40. Looking at the blue card, how often has a seizure? seen you have

41. (If person is 20 years of age or older) How often does remind you to take your medication?

42. Does do anything else to help you control your epilepsy?

43. Looking at the yellow card, how much has cope with epilepsy? helped you

44. Does epilepsy affect your relationship with this person?

Now I would like to ask you some questions about other aspects of your relationship with

45. Turning to the green card, has you find a job? ever tried to help

46. Now looking at the pirk card, how much help has given you with such things as finding a house, moving, caring for you when you were sick, lending you money?

47. Still on the pirk card, how much do you count on for encouragement, advice, understanding?

48. Loking at the white card, where would you place your relationship with on this line?

49. ISow satisfied are you with your relationship with 
DENSITY MATRIX for "People you Know Best List"

Number the people identified on the "People you Know Best List". Take the first person and read down colum 1 in the matrix below putting an $X$ in the appropriate box for each individual known to person 1. Do the same for each person listed.

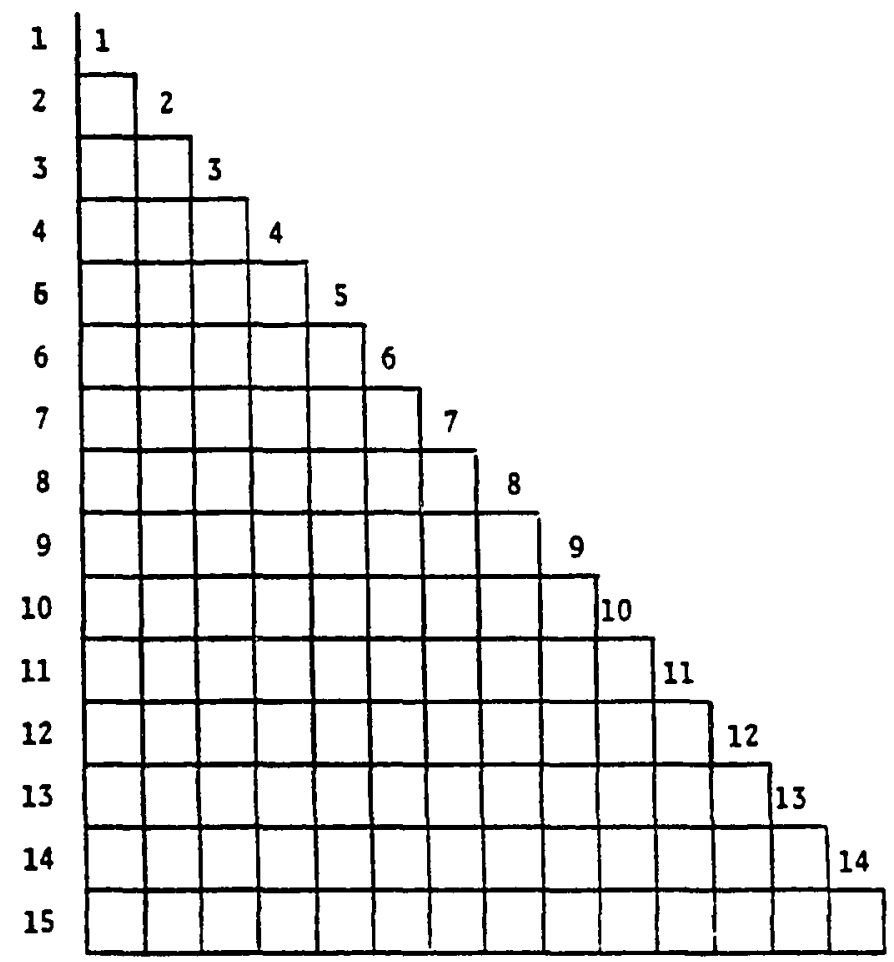


APPENDIX B

SCALE CONSTRUCTION 
APPENDIX B

SCALE CONSTRUCTION

I. Personal Characteristics

AGE Subject's age in years.

EDUCATION Years of schooling.

SELF CONCEPT Two scales from the Tennessee Self Concept Scale were used:

TOTPOS - (positive self concept) Total score of all items (1-90) on the scale yielding a measure of self concept. High scores usually indicate that individuals tend to like themselves and feel that they are persons of value and worth, have confidence in themselves and act accordingly.

DEVSIGN - (deviant self concept) Summarizes the deviant features in the self concept; scores exceeding the normal limits and deviant fluctuations in the profile, across all the scores. Best single index of psychopathology. High scores indicate deviant self concepts.

II. Epilepsy variables

SEVERI TY

Combination of type of seizure and frequency in the following order (from low to high):

$1=$ less than 1 grand mal seizure per year, 0-4 minor seizures per year, or less than 1 psychomotor seizure per year; 
2 = 1-4 psychomotor seizures per year;

3 = five or more minor seizures per year;

4 =five or more psychomotor seizures per year;

5 =one or more grand mal seizures per year.

ANXIETY

(perceived limitations) Standardized attitude scale score developed by this project which measures perceived

limitations, seizure awareness and the extent to which people feel vulnerable to the physical risks of seizures. It is based on the following five items:

- my epilepsy is pretty obvious to people

- because of epilepsy there is a limit to the things I can do

- there is a good chance I could hurt myself during a seizure

- if I get really nervous or tense it can bring on a seizure

- as long as I take care of myself, I can control my seizures.

STIGMA

Standardized attitude scale score developed by this project which measures perception of stigma due to epilepsy. It is based on the following six items:

- employers I've dealt with have treated me fairly

- people put unreasonable limits on what I do

- people who know I have epilepsy treat me differently

- most people I know are willing to be educated about epilepsy

- it really doesn't matter what you say to 
people, they usually have their minds made up

- I always feel I have to prove myself.

EPSCORE

(general impact of epilepsy) Combined scale score of the degree of impairment caused by epilepsy consisting of the following measures which were recoded on a 10 point scale, added together and averaged: SEVERITY, ANXIETY,STIGMA, present and past use of health and welfare services (e.g. Veterans Administration Hospital, Seizure Clinic at the University of Oregon Health Sciences Center, Vocational Rehabilitation, Employment Servicel, satisfaction with medical treatment, self-assessed importance of epilepsy, number of things epilepsy prevents them from doing and whether or not they have had any bad experiences due to epilepsy.

II. Support Variables

A. Intimate Zone

IAGEPHSC (epilepsy-related help) specific help with epilepsy-related problems from members of the intimate zone. The number of things each member of the retwork had done to help with epilepsy (e.g. remind to take medication, help during a seizure, help relax and stay calm, give emotional support or advice, set out medications or take to doctor, insure proper rest or nutrition or help with household chores) were counted and the individual scores of network members were added together to make a score for the zone.

IAGEASY

(made it easier co cope) Responses to the question "Has this person helped you cope with epilepsy?" were aggregated as the percentage of the zone which had made it "easier" or "a lot easier" to cope. 
I AGNEGEF

IAGJOBSC

(epilepsy affected relationship negatively) Percentage of relationships which were affected negatively by the subject's epilepsy.

(helped finding job) Assistance directed to finding or maintaining employment from members of the intimate zone. Each member of the zone was given a score based on the following values:

$0=$ no assistance

1 = gave me encouragement and advice

2 = helped me look

3 = helped me get a job.

These individual scores were added together for a score for the zone.

IAGAID

(material assistance) Responses to the question "Has this person helped you in other ways such as loaned you money, helped you move, etc?" coded:

$0=$ no assistance

1 = very little

2 = some

$3=a 10 t$

These responses were added together.

IAGSUP

(emotional support) Responses to the question "Has this person given you emotional support, encouragement or advice?" The values were the same as for IAGAID and were aggregated in the same way.

B. Household

HAGEPHSC

(epilepsy-related help) The measures of support from household members were derived in the same way as the intimate zone support measures from the same questions, asked about household members.

HAGEASY (made it easier to cope) Same measure as 
IAGEASY for household.

HAGNEGEF (epilepsy affected relationship negatively) Same measure as IAGNEGEF for household.

C. General Social Participation

SOCSCORE (general social participation) A general measure of social participation was derived from the following items:

- number of organizations belonged to

- number of meetings attended per month

- how often goes out socially

- number of active hobbies

- satisfaction with the amount of contact with friends, relatives and neighbors

Each item was recoded on a scale of $1-6$ and they were added together.

IV. Outcomes

EMPSCORE (employment)A combined measure of employment was derived from three sources:

WORKIN - A dummy variable indicating whether or not the subject was working at the time of the interview.

STABIL - Percent of reported work history (past four jobs) subject has worked.

WANTJB - Combined measure of employment status and satisfaction two years prior to the interview.

1 = unemployed, not interested, not looking

2 = unemployed, interested, has not applied in past month

3 = unemployed, interested, has applied in last month 
4 = employed, not satisfied with job

5 = employed, partially satisfied with job

6 = employed, satisfied with job

STABIL and WORKIN were recoded on a 6 point scale and the three items were added together.

SATSCORE

(life satisfaction) The measure of life satisfaction was derived from two items:

The response to the question "How satisfied with your life in general are you these days?" $(1$ = very dissatisfied, 7 = very dissatisfied)

Responses on a scale of 1 to 7 (very dissatisfied to very satisfied) to the followed items as a sematic differential:

- Boring/Interesting

- Miserable/Enjoyable

- Hard/Easy

- Useless/Worthwhile

- Lonely/Friendly

- Empty/Full

- Discouraging/Hopeful

- Tied down/Free

- Disappointing/Rewarding

- Doesn't give me much of a chance/Brings out the best in me

The "hard/easy" and "tied down/free" items were dropped because they lowered the reliability of the scale. The remaining items were added together and averaged. 
APPENDIX C

ADDITIONAL TABLES 
TABLE XV

DEMOGRAPHIC CHARACTERISTICS OF THE STUDY GROUP $(\mathrm{N}=100)$

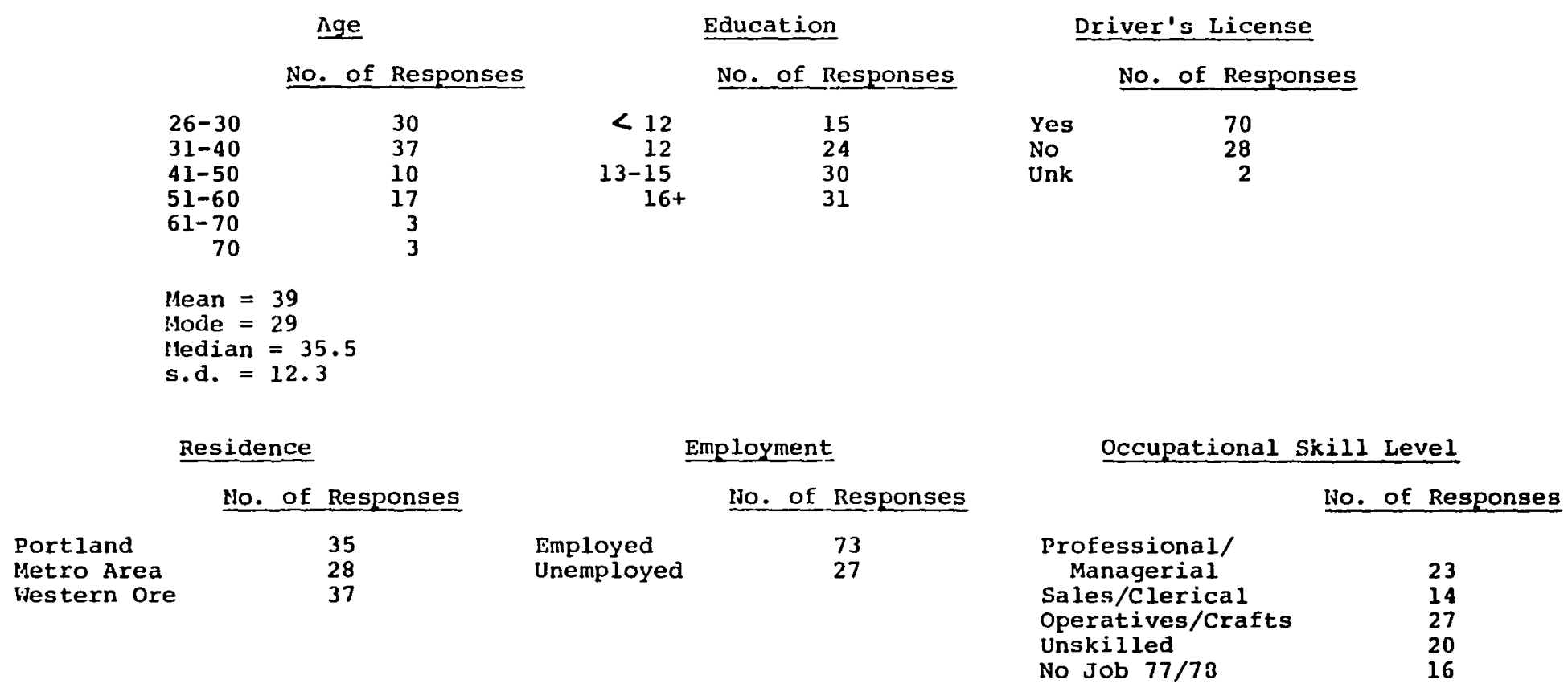

\section{Family status}

No. of Responses

$\begin{array}{lr}\text { Lives with Parents } & 9 \\ \text { Lives Alone } & 19 \\ \text { Lives with Roommate } & 3 \\ \text { Lives with Spouse } & 24 \\ \text { lives with Dependent } & \\ \quad \text { Children } & 3 \\ \text { Lives with Spouse } & \\ \quad \text { and Children } & 42\end{array}$


TABLE XVI

EPILEPSY-RELATED CHARACTERISTICS OF THE STUDY GROUP

Seizure Type

Current

No. of Responses

$\begin{array}{rr}39 & 39 \\ 14 & 22 \\ 12 & 18 \\ 20 & 12 \\ 9 & 5 \\ 4 & 2 \\ 0 & 2 \\ 2 & 0\end{array}$

\section{Seizure Frequency}

No. of Responses

None in $5+$ years None $1-5$ years

$1 /$ year

$<12$ year

$\leq 1 /$ day

Can't say

23
16
10
20
20
10
1

16

10

Age at Onset

No. of Responses

$1-10$

$11-20$

$21-30$

$31+$ years

35

18

Mean $=9$

Median $=17$
Forget to Take Medication

\section{No. of Responses}

$\begin{array}{lr}\text { About every day } & 33 \\ \text { l/week } & 31 \\ \text { l/month } & 16 \\ \text { Almost never } & 13 \\ \text { Never } & 5 \\ \text { Not taking med. } & 2\end{array}$

Not taking med.

Importance of Epilepsy

No. of Responses

$\begin{array}{lrr}\text { Not Important } & 1 & 22 \\ & 2 & 11 \\ & 3 & 5 \\ & 4 & 9 \\ & 5 & 15 \\ \text { Extremely Important } & 6 & 10 \\ & 7 & 28\end{array}$

$\mathrm{N}=100$ 
TABLE XVII

VARIABLES

Effective Zone $\mathrm{N}=316$

INDIVIDUAL NETWORK MEMBERS

\section{Age}

Relationship with client

Contacts

knows about epilepsy

Relationships (Multiplexity)

Considered a friend?

Duration of relationships

Disabled?

Witnessed seizures

Reminds about medications

other epilepsy-related assistance

Made it easier to cope with epilepsy

Epilepsy affected relationship negatively

Material assistance

Emotional assistance

Equal exchange

lore getting than giving

Satisfaction with relationshio

Epilepsy assistance score

\section{AGGREGATED NETHORK CHARACTERIST ICS}

\section{Density}

FR/FAil density

Age homogeneity (SD)

Age homogeneity (Friends) (SD)

Percent and number of friends

8 , No. Relatives

8 , No. Coworkers

8 , No. Professionals

\&. Ho. Honprofessional Service Providers
Intimate zone $\mathrm{N}=437$

Household Zone

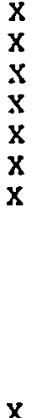


TAELE XVII (Continued)

No. roles

No. friends

8 , No. multiplex relationships

No. Contacts

Average No. contacts

\& Know about epilepsy

Average duration of relationships

Longest duration of relationship

8 Never witnessed seizure

\& Never remind about medication

Total score of zone on remind/med

Average score of zone on remind/med

8 Help manage epilepsy

Total score on "helped cope"

Average score on "helped cope"

\& Made it easier to cope

\& had no effect on coping

\& Made it harder to cope

Made it harder to cope

8 Relationships positively affected by EP

Total score on "helped find job"

Total Score on "material assistance"

Average material assistance score

Total "emotional support" score

Average "emotional support" score

$z$ Relationshios with more get than give

8 Relationships with Even exchange

8 Relationships with more give than get

Total satisfaction with relationship score

Average satisfaction with relationship score

Total help with epilepsy score

Average help with epilepsy score

Total general assistance score

Average general assistance score

\section{Effective zone}

$\mathrm{N}=316$

$\mathrm{x}$

$x$
$x$
$x$

$\mathrm{X}$

$\mathrm{X}$
$\mathrm{X}$
$\mathrm{X}$

* Children < 5 omitted 
TABLE XVIII

\section{MAJOR VARIABLES}

Ranges Mean Median Skew \&zero SD Missing

AGE

EDUCATION

TOTPOS

DEVSIGN

EPSCORE

SEVERITY

AGEON

ST IGMA

ANXIETY

FORGET

SOCSCORE

SIZE

PCT FRIEND

PCT KIN

PCT SERVICE PRO.

DENSITY

DENIRFA

DURATION

MULTIPLEXITY

MUTUALITY

DIVERSITY

TOTCONTACT

ITSUPPORT

ITEPHELP

ITEASY

ITSAT

FAMEP HELP

FAMCOPE

LIVSIT

EIAPSCORE

SATSCORE
26-75

39.3

35.5

1.0

$13.9-.076$

$4.8 \quad .33$

$4.9 \quad .33$

.181

10-49

27.6

26.4

4.4

.375

$0-53$

5.0

16.8

.911

1-10

4.75

4.5

.32

1- 10

5.4

$5.5-.10$

4.4

4.0

.64

1-19

10.2

$0-15$

7.5

10.17

.16

$7.5-.04$

$0-100$

.47

.4

$0-100$

.25

.17

$0-100$

.055

$.05-1.00$

.49

$0-1$

.27

.46

.001

4.127

.88

$.001 \quad .97$

13.0

10.0

.97

$0-100(8)$

.17

.00

1.7

$0-100$

62.85

61.20

1.67

2.1

$1-5$

45.0

34.5

1.365

$19.1 \quad 18.3$

.38

1.2

.3

2.26

59

$43.2 \quad 0$

9.773

$0-9$

$1-10$

1.1

$.85 \quad 3.19$

40

1.345

$13.65 \quad 0$

I. 80

$2.134 \quad 0$

2.46

.360

.390

.33

.25

.14

.305

.35

10.35

.280

30.923

2.143

$\begin{array}{lrrrrr}4-17 & 11.7 & 12.2 & -.47 & 3.72 & 0 \\ 1-7 & 4.91 & 4.95 & -.41 & 1.35 & 0\end{array}$

